\title{
JUN 111998
}

0.91

\section{Development of Advanced Hot-Gas Desulfurization Sorbents}

\author{
Final Report \\ October 1997
}

\author{
By \\ K. Jothimurugesan \\ A.A. Adeyiga \\ S.K. Gangwal
}

Work Performed Under Contract No.: DE-FG21-94MC31393

For

U.S. Department of Energy

Office of Fossil Energy

Federal Energy Technology Center

P.O. Box 880

Morgantown, West Virginia 26507-0880

By

Department of Chemical Engineering

School of Engineering \& Technology

Hampton University

Hampton, Virginia 23668 


\section{Disclaimer}

This report was prepared as an account of work sponsored by an agency of the United States Government. Neither the United States. Government nor any agency thereof, nor any of their employees, makes any warranty, express or implied, or assumes any legal liability: or responsibility for the accuracy, completeness, or usefulness of any information, apparatus, product, or process disclosed, or represents that its use would not infringe privately owned rights. Reference herein to any specific commercial product, process, or service by trade name, trademark, manufacturer, or otherwise does not necessarily constitute or imply its endorsement, recommendation, or favoring by the United States Government or any agency thereof. The views and opinions of authors expressed herein do not necessarily state or reflect those of the United States Government or any agency thereof. 


\section{DISCLAIMER}

Portions of this document may be illegible in electronic image products. Images are produced from the best available original document. 


\section{EXECUTIVE SUMMARY}

This report describes the project, " Development of Advanced Hot-Gas Desulfurization Sorbents" sponsored by U.S. Department of Energy, Federal Energy Technology Center under Grant No. DE-FG-22-94MC31393. The work was performed by Hampton University (prime contractor) with support by Research Triangle Institute as subcontractor.

Hot-Gas Desufurization (HGD) of fuel gas in integrated gasification combined cycle (IGCC) power systems has received a great deal of attention over the past two decades due to the potential for high thermal efficiency (up to $47 \%$ ) and low environmental impact of these advanced power systems using HGD. In an IGCC system coal is gasified at elevated pressures, typically 20 to $30 \mathrm{~atm}$, to produce a low-volume fuel gas which is desulfurized prior to burning in a combustion turbine to produce electricity. Higher efficiency and lower cost are achieved by efficient integration of modular designs of the gasification, hot-gas cleanup, and turbine subsystems. Gas cleaning primarily involves removal of particulates and sulfur compounds -mostly $\mathrm{H}_{2} \mathrm{~S}$ and some carbonyl sulfide (COS). Sorbents based on zinc oxide, currently the leading candidates, can effectively reduce the $\mathrm{H}_{2} \mathrm{~S}$ in coal gas to around $10 \mathrm{ppm}$ levels and can be regenerated for multicycle operation. However, all current first-generation leading sorbents undergo significant loss of sulfidation reactivity and capacity with cycling, as much as $50 \%$ or greater loss in only $25-50$ cycles. Stability of the hot-gas desulfurization sorbents over one hundred cycles is essential for improved IGCC economics over conventional power plants.

The objective of this study was to develop advanced attrition-resistant hot-gas desufurization sorbents would maintain stability and high sulfidation reactivity and capacity at $343^{\circ} \mathrm{C}\left(650^{\circ} \mathrm{F}\right)$ to $538^{\circ} \mathrm{C}\left(1000^{\circ} \mathrm{F}\right)$. Further, the sorbents would also regenerable at lower 
temperatures than leading first generation sorbents.

Fifty sorbents were synthesized using a coprecipitation technique. The preparation technique and the formulations are proprietary and pending a patent application. Thus no details regarding the technique are divulged in this report. Sulfidations were conducted with a simulated gas containing (vol \%) $10 \mathrm{H}_{2}, 15 \mathrm{CO}, 5 \mathrm{CO}_{2}, 1 \mathrm{H}_{2} \mathrm{~S}, 15 \mathrm{H}_{2} \mathrm{O}$, and balance $\mathrm{N}_{2}$ in the temperature range of $343-538^{\circ} \mathrm{C}$. Regenerations were conducted at temperatures in the range of $400-600^{\circ} \mathrm{C}$ with air- $\mathrm{N}_{2}$ mixtures. To prevent sulfation, catalyst additives were investigated, which promote a lower regeneration temperature. Characterization were performed for fresh, sulfided and regenerated sorbents.

A superior zinc-based sorbent (designated MCRH-25) was tested for 100 cycles in a laboratory -scale reactor. The 100-cycle test clearly demonstrated that the MCRH-25 sorbent does not chemically deactivate. In fact, the capacity at breakthrough increased between cycles 1 to 25 from 22.5 to $27.7 \mathrm{gS} / 100 \mathrm{~g}$ sorbent and remained stable thereafter. TGA and physical property data confirmed the breakthrough data. This is in contrast to existing leading sorbents such as Z-sorb and ZT-4 that deactivated significantly, as much as $50 \%$ in 50 to 100 cycles. Furthermore, the MCRH-25 sorbent regenerated at temperatures as low as $475^{\circ} \mathrm{C}$, in contrast to current zinc-based sorbents that require $600^{\circ} \mathrm{C}$ or higher.

Following the successful preparation of MCRH-25, attention was shifted to preparing the MCRH-25 recipe with binders to provide attrition-resistance suitable for a transport reactor. An attrition-resistant form of MCRH-25, namely MCRH-61 was tested for 50 cycles of sulfidation in the lab-scale reactor at $482^{\circ} \mathrm{C}$. Regeneration between cycles was conducted with 2 volume percent $\mathrm{O}_{2}$ in $\mathrm{N}_{2}$ at $550^{\circ} \mathrm{C}$. The gas hourly space velocity for the 50 -cycle test was about 
$2500 \mathrm{~h}^{-1}$ during both sulfidation and regeneration. MCRH-61 sorbent showed excellent sulfidation behavior. The pre-breakthrough $\mathrm{H}_{2} \mathrm{~S}$ level was less than $100 \mathrm{ppm}$ and the breakthrough conversion was $100 \%$. There was no deactivation in 50 cycles in this fixed bed study. This promising test results indicates that an optimized MCRH- 61 should be a good candidate sorbent for Sierra-Pacific clean coal project or similar project involving transport reactor. 


\section{ACKNOWLEDGMENTS}

This study was sponsored by the U.S. Department of Energy (DOE) under Grant No: DE-FG-2194MC31393. The authors would like to acknowledge with gratitude the guidance provided by the DOE Contracting Officers's Representative, Dr. Kamalendu Das, of the Federal Energy Technology Center. Mr. Daniel C. Cicero of FETC provided a number of important suggestion on the research. United Catalysts, Inc assisted with preparations of sorbents. 


\section{CONTENTS}

Section

Page

Executive Summary $\ldots \ldots \ldots \ldots \ldots \ldots \ldots \ldots \ldots \ldots \ldots$ iii

Acknowledgment $\ldots \ldots \ldots \ldots \ldots \ldots \ldots \ldots \ldots \ldots \ldots \ldots$ vi

Contents . . . . . . . . . . . . . . . . . . . . . . . . vii

List of Tables $\ldots \ldots \ldots \ldots \ldots \ldots \ldots \ldots \ldots \ldots \ldots \ldots \ldots \ldots$ viii

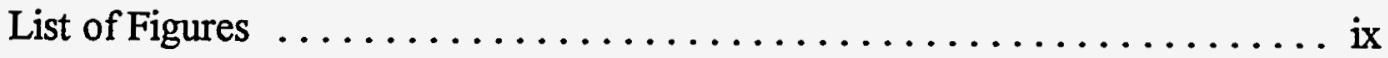

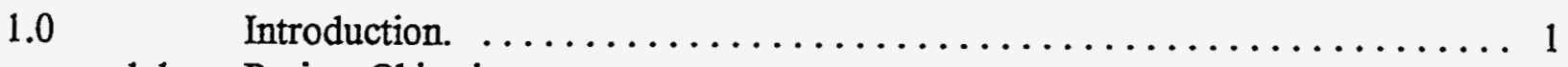

$1.1 \quad$ Project Objectives. ........................ 7

Description of Project Tasks $\ldots \ldots \ldots \ldots \ldots \ldots \ldots \ldots \ldots \ldots \ldots$

Experimental Approach $\ldots \ldots \ldots \ldots \ldots \ldots \ldots \ldots \ldots \ldots \ldots \ldots \ldots$

3.1 Sorbent Preparation and Characterization $\ldots \ldots \ldots \ldots \ldots \ldots \ldots \ldots \ldots$

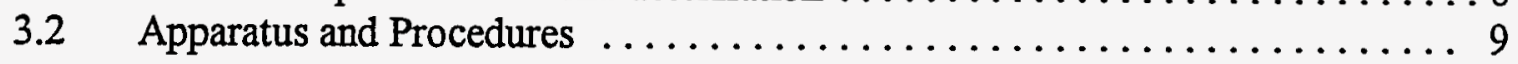

Results and Discussions $\ldots \ldots \ldots \ldots \ldots \ldots \ldots \ldots \ldots \ldots \ldots \ldots \ldots$

Conclusions $\ldots \ldots \ldots \ldots \ldots \ldots \ldots \ldots \ldots \ldots \ldots \ldots \ldots \ldots \ldots \ldots$

Recommendations $\ldots .0 \ldots \ldots \ldots \ldots \ldots \ldots \ldots \ldots \ldots \ldots \ldots \ldots$

References $\ldots \ldots \ldots \ldots \ldots \ldots \ldots \ldots \ldots \ldots \ldots \ldots \ldots \ldots \ldots \ldots$ 


\section{LIST OF TABLES}

Number

Page

1 Summary of Sulfidation Tests with MCRH Sorbents $\ldots \ldots \ldots \ldots \ldots \ldots \ldots$

2 Regeneration Light-Off Temperature for MCRH Sorbents. . . . . . . . . . . 45

3 BET Surface Area of the Attrition-Resistant MCRH Sorbents $\ldots \ldots \ldots \ldots \ldots$

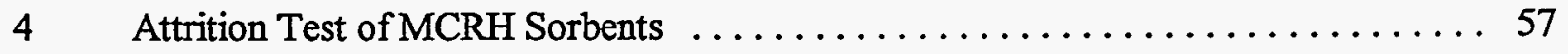


Number

\section{LIST OF FIGURES}

1. HGD Laboratory -Scale Fixed-Bed Reactor System $\ldots \ldots \ldots \ldots \ldots \ldots \ldots \ldots \ldots \ldots \ldots$

2. SEM Micrographs of MCRH-1 Fresh Sorbents. ...................... 14

3. $\mathrm{H}_{2} \mathrm{~S}$ Breakthrough Curves in Successive Sulfidation Cycles of MCRH-1 Sorbent ......... 15

4. $\mathrm{H}_{2} \mathrm{~S}$ Breakthrough Curves in Successive Sulfidation Cycles of MCRH-1 Sorbent ......... 16

5. TGA Reactivities of MCRH-1 Sorbents $\ldots \ldots \ldots \ldots \ldots \ldots \ldots \ldots \ldots \ldots \ldots \ldots \ldots \ldots \ldots \ldots \ldots \ldots \ldots$

6. $\mathrm{H}_{2} \mathrm{~S}$ Breakthrough Curves in Successive Sulfidation Cycles of MCRH-2 Sorbent ......... 19

7. $\mathrm{H}_{2} \mathrm{~S}$ Breakthrough Curves in Successive Sulfidation Cycles of MCRH-4 Sorbent ......... 21

8. $\mathrm{H}_{2} \mathrm{~S}$ Breakthrough Curves in Successive Sulfidation Cycles of MCRH-7 Sorbent $\ldots \ldots \ldots \ldots 22$

9. $\mathrm{H}_{2} \mathrm{~S}$ Breakthrough Curves in Successive Sulfidation Cycles of MCRH-8 Sorbent ......... 23

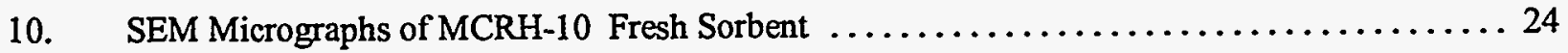

11. $\mathrm{H}_{2} \mathrm{~S}$ Breakthrough Curves in Successive Sulfidation Cycles of MCRH-10 Sorbent ........ 26

12. $\mathrm{H}_{2} \mathrm{~S}$ Breakthrough Curves in Successive Sulfidation Cycles of MCRH-24 Sorbent .........27

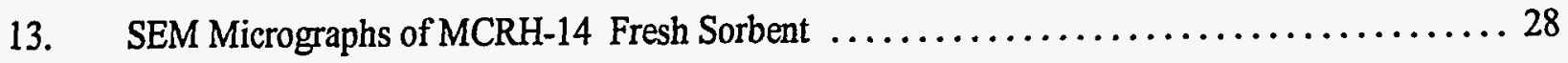

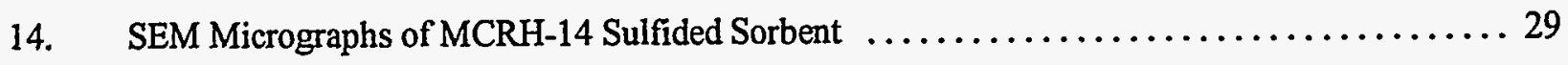

15. $\mathrm{H}_{2} \mathrm{~S}$ Breakthrough Curves in Successive Sulfidation Cycles of MCRH-14 Sorbent ........ 30

16. SEM Micrographs of MCRH-18 Fresh Sorbent $\ldots \ldots \ldots \ldots \ldots \ldots \ldots \ldots \ldots \ldots \ldots \ldots \ldots \ldots \ldots \ldots \ldots \ldots$

17. SEM Micrographs of MCRH-18 Sulfided Sorbent $\ldots \ldots \ldots \ldots \ldots \ldots \ldots \ldots \ldots \ldots \ldots \ldots \ldots$

18. $\mathrm{H}_{2} \mathrm{~S}$ Breakthrough Curves in Successive Sulfidation Cycles of MCRH-18 Sorbent ......... 34

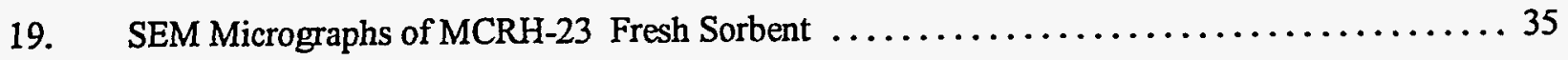

20. $\mathrm{H}_{2} \mathrm{~S}$ Breakthrough Curves in Successive Sulfidation Cycles of MCRH-23 Sorbent ........ 36

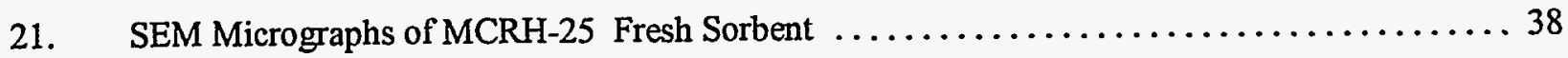

22. SEM Micrographs of MCRH-26 Fresh Sorbent $\ldots \ldots \ldots \ldots \ldots \ldots \ldots \ldots \ldots \ldots \ldots \ldots \ldots \ldots \ldots \ldots \ldots$ 
23. $\mathrm{H}_{2} \mathrm{~S}$ Breakthrough Curves in Successive Sulfidation Cycles of MCRH-26 Sorbent ........ 40

24. SEM Micrographs of MCRH-27 Fresh Sorbent $\ldots \ldots \ldots \ldots \ldots \ldots \ldots \ldots \ldots \ldots \ldots \ldots \ldots$

25. $\mathrm{H}_{2} \mathrm{~S}$ Breakthrough Curves in Successive Sulfidation Cycles of MCRH-27 Sorbent ........42

26. $\mathrm{H}_{2} \mathrm{~S}$ Breakthrough Curves in Successive Sulfidation Cycles of MCRH-31 Sorbent ........44

27. Regeneration Light-Off Temperature for $\mathrm{MCRH}$ Sorbents $\ldots \ldots \ldots \ldots \ldots \ldots \ldots \ldots$

28. Regeneration Light-Off Temperature for $\mathrm{MCRH}$ Sorbents $\ldots \ldots \ldots \ldots \ldots \ldots \ldots \ldots \ldots$

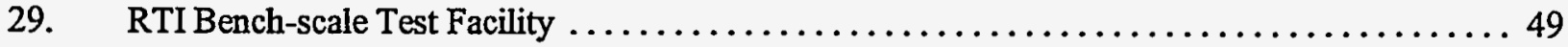

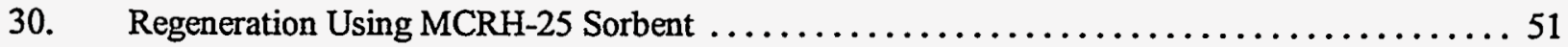

31. $\mathrm{H}_{2} \mathrm{~S}$ Breakthrough Curves in Successive Sulfidation Cycles of MCRH-39 Sorbent ......... 54

32. $\mathrm{H}_{2} \mathrm{~S}$ Breakthrough Curves in Successive Sulfidation Cycles of MCRH-51 Sorbent ........ 56

33. $\mathrm{H}_{2} \mathrm{~S}$ Breakthrough Curves in Successive Sulfidation Cycles of MCRH-53 Sorbent ........ 58

34. $\mathrm{H}_{2} \mathrm{~S}$ Breakthrough Curves in Successive Sulfidation Cycles of MCRH-54 Sorbent ......... 60

35. $\mathrm{H}_{2} \mathrm{~S}$ Breakthrough Curves in Successive Sulfidation Cycles of MCRH-55 Sorbent ........ 62

36. $\mathrm{H}_{2} \mathrm{~S}$ Breakthrough Curves in Successive Sulfidation Cycles of MCRH-56 Sorbent .........6 64

37. $\mathrm{H}_{2} \mathrm{~S}$ Breakthrough Curves in Successive Sulfidation Cycles of MCRH-25 Sorbent ........66 66

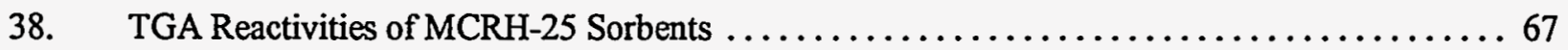

39. $\mathrm{H}_{2} \mathrm{~S}$ Breakthrough Curves in Successive Sulfidation Cycles of MCRH-60 Sorbent $\ldots \ldots \ldots \ldots 68$

40. $\mathrm{H}_{2} \mathrm{~S}$ Breakthrough Curves in Successive Sulfidation Cycles of MCRH-61 Sorbent ........ 70 


\subsection{INTRODUCTION}

Advanced integrated gasification combined cycle (IGCC) power plants are being developed to produce electricity from coal due to their potential for superior environmental performance, economics, and efficiency in comparison to conventional coal-based power plants. The U.S. Department of Energy (DOE), Federal Energy Technology Center (FETC) Clean Coal Technology program has led to the successful construction of two such advanced plants--Sierra Pacific and Tampa Electric Company (TECO), with shakedown and commissioning currently in progress. A key component of these advanced IGCC plants is a hot-gas desulfurization (HGD) process that employs efficient regenerable zinc-based mixed-metal oxide sorbents. These sorbents can remove the hydrogen sulfide $\left(\mathrm{H}_{2} \mathrm{~S}\right)$ in coal gas to $<20 \mathrm{ppmv}$ and that can be regenerated with air for multi-cycle operation as shown below for zinc oxide:

$$
\begin{array}{lll}
\mathrm{ZnO}+\mathrm{H}_{2} \mathrm{~S} & -\mathrm{ZnS}+\mathrm{H}_{2} \mathrm{O} & \text { (Sulfidation) } \\
\mathrm{ZnS}+(3 / 2) \mathrm{O}_{2}-\mathrm{ZnO}+\mathrm{SO}_{2} & \text { (Regeneration) }
\end{array}
$$

For economic reasons, the sorbent must be able to maintain an acceptable level of reactivity over one hundred absorption (sulfidation)-regeneration cycles.

High temperature sulfur removal techniques are based on the reaction of $\mathrm{H}_{2} \mathrm{~S}$ with solid sorbents to form solid sulfur compounds. Metal oxide sorbents can be classified as disposable or regenerable. Disposable sorbents are typically calcium based and are generally employed in situ, but they can also be employed externally in a once-through process. Fundamental studies on calcium-based sorbents by Michel et al. (1996) and Heesink and VanSwaaij (1996) provide an excellent review of the research on the $\mathrm{CaO}-\mathrm{H}_{2} \mathrm{~S}$ reaction at 700 to $1,000^{\circ} \mathrm{C}$. The problem with these sorbents is disposal following sulfidation. When employed in situ, the intent is to convert 
$\mathrm{CaS}$ to stable $\mathrm{CaSO}_{4}$; however, pore plugging limits this phenomenon. Also, these sorbents cannot typically achieve more than $80 \%$ sulfur removal. Finally disposable in landfills is becoming more and more difficult due to scarcity of land in many parts of the world. Past studies have attempted to regenerate calcium sulfide back to calcium oxide but with very limited success (Curran et al., 1977; O'Brien et al., 1976). Calcium-based sorbents are presently employed in situ in two gasifiers-U-gas and KRW (Kellogg). IGCC systems employing these gasifiers require an external regenerable sulfur polishing sorbent to achieve a high degree of sulfur removal.

Regenerable sorbents can be employed in the polishing mode to remove essentially all of the $\mathrm{H}_{2} \mathrm{~S}$ and COS for IGCC systems such as Shell, Destec, or Texaco gasifiers that do not use inbed desulfurization. The principle requirement during air regeneration is that the sorbent should predominantly revert back to its oxide ( $\mathrm{MS}+3 / 2 \mathrm{O}_{2} \rightarrow \mathrm{MO}+\mathrm{SO}_{2}$ ) rather than to sulfate ( $\mathrm{MO}+$ $\mathrm{SO}_{2}+1 / 2 \mathrm{O}_{2}-\mathrm{MSO}_{4}$ ). Air regeneration is highly exothermic and requires tight temperature control using large quantities of diluent $\left(\mathrm{N}_{2}\right)$ or other means to prevent sorbent sintering and sulfate formation.

A number of metal oxides have been and/or are currently being evaluated as regenerable sorbents (Gangwal et al., 1995). These include oxides of copper, cerium, manganese, cobalt, tin, iron, and zinc, both individually and in combinations. The chemistry associated with the use of these sorbents is generally similar with a few exceptions. These metal oxide or mixed-metal oxide sorbents have been investigated with and without a secondary oxide such as silica, alumina, titania, and chromia. These secondary oxide act as supports for strengthening mechanical structure, stabilizers against reduction of the metal oxide to metal in a reducing environment, and modifiers of thermodynamic properties of the metallic oxide (by forming a perovskite type 
structure) to enhance elemental sulfur formation during regeneration.

The bulk of research on regenerable sorbents has been on zinc-based sorbents because sorbents based on zinc oxide appear to have the fewest technical problems among all sorbents. Zinc oxide has highly attractive thermodynamics for $\mathrm{H}_{2} \mathrm{~S}$ adsorption and can reduce the $\mathrm{H}_{2} \mathrm{~S}$ to parts-per-million levels over a very wide temperature range. Iron oxide appears to be the next most popular sorbent; however, the thermodynamics for iron is not very attractive. Also iron oxide can readily undergo reduction $\left(\mathrm{Fe}_{2} \mathrm{O}_{3} \rightarrow \mathrm{Fe}_{3} \mathrm{O}_{4} \rightarrow \mathrm{FeO} \rightarrow \mathrm{Fe}\right)$ depending on the reducing power of coal gas. This can consume valuable fuel gas and cause sorbent deterioration. Iron oxide can also catalyze carbon formation if sufficient steam is not present in the fuel gas.

In contrast to calcium-based sorbents, which can operate up to 900 to $1,000^{\circ} \mathrm{C}$, zinc and iron sorbents operate at lower temperatures. A temperature of $480^{\circ} \mathrm{C}$ appears to be the limit of iron-based sorbents due to iron's reduction potential. A combined zinc oxide ( $\mathrm{ZnO}$ )-iron oxide $\left(\mathrm{Fe}_{2} \mathrm{O}_{3}\right)$ sorbent, namely, zinc ferrite $\left(\mathrm{ZnFe}_{2} \mathrm{O}_{4}\right)$, was developed by Grindley and Steinfeld (1981) to combine the advantages of $\mathrm{ZnO}$ and $\mathrm{Fe}_{2} \mathrm{O}_{3}$ and to extend the upper temperature limit to around $600^{\circ} \mathrm{C}$. A temperature range of 550 to $750^{\circ} \mathrm{C}$ received the major research emphasis in the United States during the 1980 s and early 1990 s. Because of zinc oxide's potential for reduction (ZnO + $\mathrm{H}_{2} \rightarrow \mathrm{Zn}+\mathrm{H}_{2} \mathrm{O}$ ) at $>600^{\circ} \mathrm{C}$ followed by evaporation, a zinc oxide-titanium oxide sorbent, namely zinc titanate sorbent, was developed and tested at high temperature and high pressure (Gangwal et al., 1988; Jothimurugesan and Harrison, 1990; Stephanpoulos and Jothimurugesan, 1990; Woods et al., 1990;1991). Zinc titanate is currently one of the leading sorbents. However, all current first-regeneration leading sorbents undergo significant loss of reactivity with cycling, as much as $50 \%$ or greater loss in only $25-50$ cycles. Stability of the hot-gas desulfurization sorbent 
over one hundred cycles is essential for improved IGCC economics over conventional power plants.

Air regeneration, a highly exothermic process, leads to a dilute $\mathrm{SO}_{2}$ tail gas that must be disposed. In this context, Kellogg's transport reactor technology for HGD that is to be used at Sierra-Pacific represents one of the most significant recent developments in HGD because it allows the use of neat air for regeneration by using fast sorbent circulation to soak up the heat generated. This results in a relatively small volume $\mathrm{SO}_{2}$ tail gas containing around $14 \mathrm{vol} \% \mathrm{SO}_{2}$. Converting to a salable product-sulfuric acid or elemental sulfur is an attractive option as opposed to lime absorption leading to a waste. Elemental sulfur is particularly attractive because it is the smallest volume sulfur product and because it can be stored easily, transported over long distances, readily disposed, or sold. A promising process called Direct Sulfur Recovery Process (DSRP) (Portzer et al., 1996) is currently in an advanced development stage to treat the $\mathrm{SO}_{2}$ tail gas. In this process the $\mathrm{SO}_{2}$ is catalytically reduced to elemental sulfur at the pressure and temperature condition of the tail gas using a slipstream of the fuel gas:

$$
\left.\mathrm{SO}_{2}+2 \mathrm{H}_{2} \text { (or } \mathrm{CO}\right)-1 / 2 \mathrm{~S}_{2}+2 \mathrm{H}_{2} \mathrm{O}\left(\text { or } 2 \mathrm{CO}_{2}\right. \text { ) }
$$

The process is undergoing testing with actual coal gas from a gasifier and is being scaled up to a small pilot-scale stage. As seen above, the problematic $\mathrm{SO}_{2}$ tail gas produced by air regeneration not only needs disposal but also consumes 2 mol of valuable reducing components in fuel gas for every mole of sulfur dioxide treated if elemental sulfur is to be produced. Novel regeneration processes that could lead to elemental sulfur without use of fuel gas or with limited use of fuel gas are being developed (Harrison et al. 1996; Gangwal et al., 1996). RTl (Gangwal, 1996) has been testing a novel zinc-iron sorbent that could be regenerated using $\mathrm{SO}_{2}$ to directly produce 
elemental sulfur.

During recent years, research emphasis has shifted toward lower temperatures (350 to $550^{\circ} \mathrm{C}$ ) based on a study in the Netherlands (NOVEM, 1991). According to this study, the thermal efficiency of a 800 MWe IGCC plant increased from $42.75 \%$ using cold-gas cleanup to $45.14 \%$ using $\mathrm{HGD}$ at $350^{\circ} \mathrm{C}$ and to $45.46 \%$ using $\mathrm{HGD}$ at $600^{\circ} \mathrm{C}$. The small efficiency increase from 350 to $600^{\circ} \mathrm{C}$ suggested that the temperature severity of the hot-gas cleanup devices can be somewhat reduced without significant loss of thermal efficiency. An important reason for development of sorbents in the temperature range suggested above is the reduction of the operating temperature of the upstream ceramic candle filter which have not provided reliable long-term operation at high temperatures. Reduction in the hot-gas cleanup temperature would also result in reduction in semi-volatile contaminants (e.g. alkali vapors), which may be particularly damaging to ceramic filters. Another important reason to reduce hot-gas cleanup severity is to reduce the operating temperatures and temperature swings of on-off valves and vessels for cyclic fixed-bed desulfurization/regeneration systems, lock-hopper valves for movingbed applications, and the turbine load control valves. Finally, the current plans in Europe (for example, slip-stream tests at the Buggenum IGCC plant) call for hot-gas desulfurization system operation at $350-600^{\circ} \mathrm{C}$. Also iron-oxide process development studies in Japan have concentrated on a temperature range of $400-600^{\circ} \mathrm{C}$. Thus development of suitable advanced sorbents in the U.S. for this temperature range is necessary for U.S. manufactures and sorbent vendors to license their products overseas.

Reduction in severity of temperature would lead to greater reliability of long-term operation of hot-gas cleanup devices and lesser stress on piping and vessels. The challenge, 
however, is to develop suitable sorbents that are sufficiently reactive and regenerable at the relatively lower temperatures of interest in this work. The rate of the sulfidation reaction of metal oxide sorbents drops exponentially as temperature is reduced. Thus in order to maintain sufficient reactivity that results in reasonable reactor size to remove $\mathrm{H}_{2} \mathrm{~S}$ down to low ppm level in large scale systems, it will be necessary to prepare highly dispersed porous mixed-metal oxide sorbents with sufficiently small and accessible metal oxide crystallites. During regeneration, unless temperature is raised sufficiently, sulfation of the metal may occur leading to incomplete regeneration and sorbent deterioration. On the other hand, if the temperature is increased to prevent sulfation, sintering of crystallites may occur leading to reduced reactivity for the subsequent cycle.

A two-reactor configuration is necessary for hot-gas desulfurization due to its cyclic nature. Early developments emphasized fixed beds. The highly exothermic regeneration led to a move away from fixed beds toward moving beds (Ayala et al., 1995; Cook et al., 1992) and fluidized beds (Gupta and Gangwal, 1992). Pelletized sorbents were developed using appropriate binders in the size range of 3 to $6 \mathrm{~mm}$ for fixed and moving beds. However, the binders could not hold the sorbents together over several cycles due to chemical reactions leading to expansion and - /or contraction followed by spalling and cracking. Durable zinc titanate sorbent development for fluidized beds is on-going (Gupta et al., 1996). Recently a zinc oxide -nickel oxide sorbent (Zsorb) produced by Phillips Petroleum Company for $\mathrm{H}_{2} \mathrm{~S}$ removal from Claus plant tail gas has been extensively tested for HGD (Khare et al., 1996). Several advanced version of this sorbent have been developed to incorporate special features such as resistance to sintering in hightemperature steam, low light-off temperature, and high attrition resistance. 


\subsection{PROJECT OBJECTIVES}

The objective of this project was to develop hot-gas desulfurization sorbent formulations for relatively lower temperature application, with emphasis on the temperature range from 343$538^{\circ} \mathrm{C}$. The candidate sorbents include highly dispersed mixed metal oxides of zinc, iron, copper, cobalt, nickel and molybdenum. The specific objective was to develop suitable sorbents, that would have high and stable surface area and are sufficiently reactive and regenerable at the relatively lower temperatures of interest in this work. Stability of surface area during regeneration was achieved by adding stabilizers. To prevent sulfation, catalyst additives that promote the lightoff of the regeneration reaction at lower temperature was considered.

Another objective of this study was to develop attrition-resistant advanced hot-gas desufurization sorbents which show stable and high sulfidation reactivity at 343 to $538^{\circ} \mathrm{C}$ and regenerabilty at lower temperatures than leading first generation sorbents.

\subsection{DESCRIPTION OF PROJECT TASKS}

\section{TASK 1: Sorbent Preparation and Characterization}

The objectives of this task were to prepare and characterize various sorbents. A detailed description of sorbent preparation is given in section 3.1 of the report. Several parameters were varied in the sorbent preparation to study their effects on the physical properties and chemical phases of the sorbents. Section 3.1 also describes the various analytical techniques employed for sorbent characterization. 
TASK 2: $\quad$ Experimental Testing and Sorbent Evaluation

The objective of this task was to evaluate the performance of various sorbents under similar conditions in a fixed-bed microreactor. Section 3.2 describe the experimental apparatus and procedures employed throughout the project. Sorbent comparisons were to be carried out at the following operating conditions:

$\mathrm{P}=1 \mathrm{~atm}, \mathrm{~T}=343-538^{\circ} \mathrm{C}, \mathrm{S} . \mathrm{V} .=2500 \mathrm{~h}^{-1}$

Sulfidation Gas (vol \%): $10 \mathrm{H}_{2}, 15 \mathrm{CO}, 5 \mathrm{CO}_{2}, 1 \mathrm{H}_{2} \mathrm{~S}, 15 \mathrm{H}_{2} \mathrm{O}$, balance $\mathrm{N}_{2}$. Regeneration gas (vol \%): 10 air-90 $\mathrm{N}_{2}$ At least four to five cycles of sulfidation/regeneration were run with each sorbent until stabilized performance was attained. Following these tests, the most promising sorbent was further tested over multicyles.

TASK 3: $\quad$ Cyclic Testing

The objectives of this task was to determine how well the sulfidation performance of the sorbents was retained in many cycles of consecutive sulfidation/regeneration.

\subsection{EXPERIMENTAL APPROACH}

\section{TASK 1: 3.1 SORBRNT PREPARATION AND CHARACTERIZATION}

Sorbents were prepared by precipitation of soluble salts of appropriate metals with a basic solution. The principal novelty of the method involves incorporation of surface area stabilizers. Zinc nitrate, iron nitrate, cobalt nitrate hexahydrate, nickel nitrate hexahydrate, copper nitrate and ammonium molybdate hexahydrate (all the chemicals were obtained from Aldrich) were used as the metal salts. The precipitation was carried out by adding the raw salt solution and the basic 
solution simultaneously under vigorous mixing at room temperature. The product of the precipitation was washed, separated by filtration, dried at $150^{\circ} \mathrm{C}$ for $12 \mathrm{~h}$, and then calcined in an air stream in the range of $600-800^{\circ} \mathrm{C}$. The product thus obtained was crushed and sieved to $32+60$ mesh.

A detailed physical and chemical characterization of the fresh, sulfided and regenerated sorbent materials was carried out using the following analytical techniques.

1. X-ray powder diffraction patterns were obtained using a Phillips PW $1800 \mathrm{X}$-ray unit using $\mathrm{CuK} \alpha$ radiation. Analyses were conducted using a continuous scan mode at a scan rates of $0.05^{\circ} 2 \theta$ per second.

2. The BET Surface area of the sorbents were determined by $\mathrm{N}_{2}$ physisorption using a Micromeritics Gemini 2360 system. The samples were degassed in a Micromeritics Flow Prep 060 at $120^{\circ} \mathrm{C}$ for $1 \mathrm{~h}$ prior to each measurement.

3. Hg-porosimetry was used for pore volume, bulk density, average pore diameter and pore size distribution determination.

4. Atomic Absorption (AA) Spectrometry for elemental composition analysis.

5. The SEM (Scanning Electron Microscopy) micrograph was taken using a Cambridge Stereoscan 100.

\section{TASK 2: 3.2 APPARATUS AND PROCEDURES}

The sorbent materials prepared were tested in a laboratory scale high-temperature and high- pressure (HTHP) fixed bed reactor which is shown in Figure 1. Briefly, the experimental setup consisted of a gas delivery system, a fixed bed reactor, and a gas analysis system. In the gas delivery system, a simulated fuel gas of any desired composition could be generated using the 


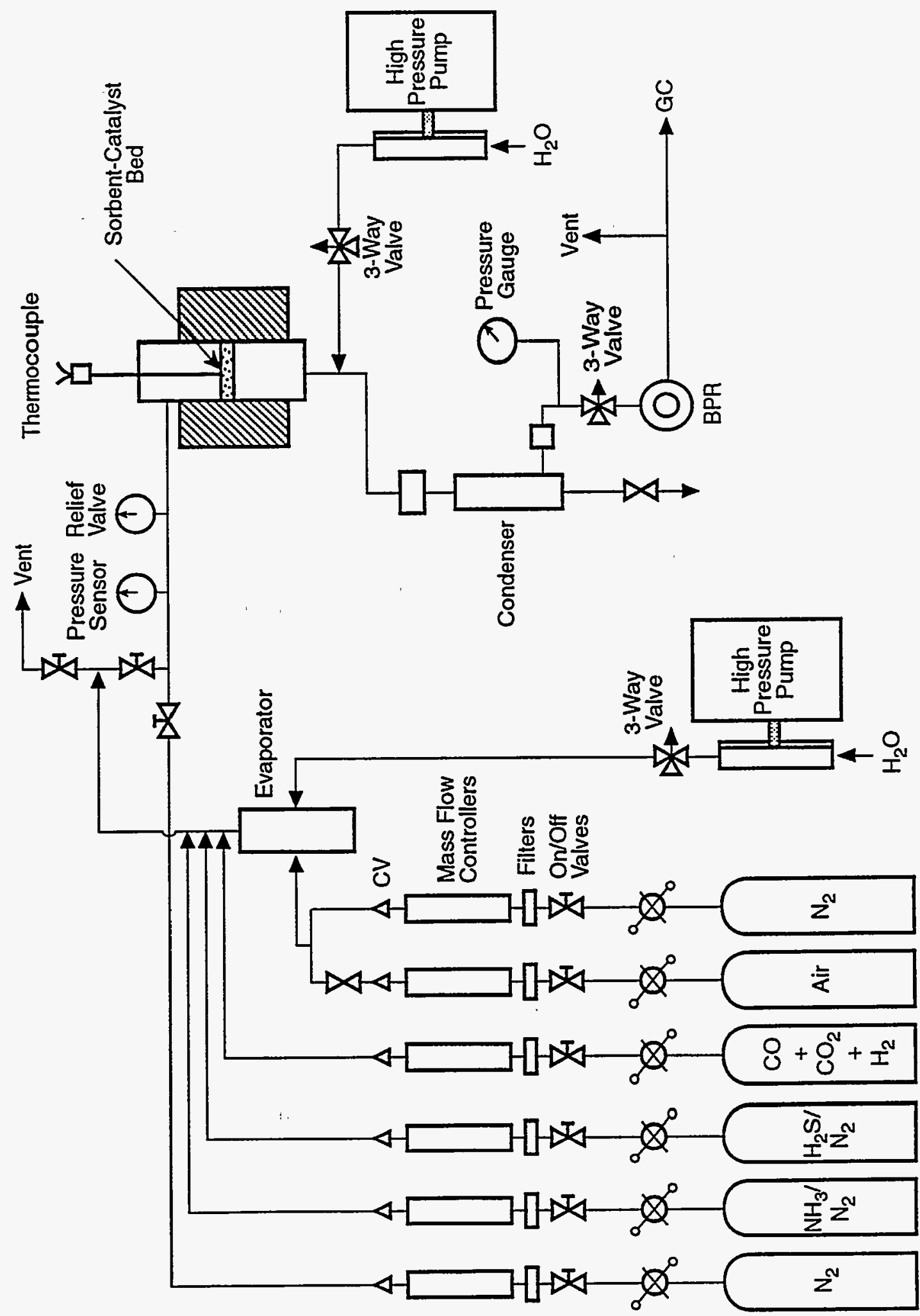


bottled gases, a set of mass flow controllers, and high-pressure syringe pumps. Steam was added to the mixed dry gas by vaporizing liquid water injected it into the gas stream at a controlled rate by a high pressure syringe pump. The reactor was made from a 3/4-inch stainless steel tube. Inside the 3/4-inch there was a removable 316 stainless steel $1.0 \mathrm{~cm}$ I.D insert with a porous alumina plate in the bottom that acted as a gas distributor. The insert was Alon-processed to prevent corrosion of stainless steel by sulfurous gases in the presence of steam. The pressure in the reactor was controlled by a back pressure regulator and measured by an electronic pressure sensor. Thermocouples were positioned to measure the temperatures of the preheated feed gas, the sorbent bed, and the product gas. The tests were conducted with a simulated gas nominally containing (vol \%) $10 \mathrm{H}_{2}, 15 \mathrm{CO}, 5 \mathrm{CO}_{2}, 1 \mathrm{H}_{2} \mathrm{~S}, 15 \mathrm{H}_{2} \mathrm{O}$, and balance $\mathrm{N}_{2}$. The outlet $\mathrm{H}_{2} \mathrm{~S}$ and $\mathrm{SO}_{2}$ concentrations were monitored using a gas chromatograph.

A typical run consists of loading the sorbent having a particle size range of $-32+64$ mesh and heating the reactor to a desired temperature of $350-500^{\circ} \mathrm{C}$ with continuous flow of nitrogen. Once the desired temperature was attained, the flow of fuel gas to the reactor was started and the concentration of $\mathrm{H}_{2} \mathrm{~S}$ was measured continuously in the effluent gas. When the $\mathrm{H}_{2} \mathrm{~S}$ concentration reached $500 \mathrm{ppmv}$, the run was stopped and the system was prepared for regeneration. The regeneration of sulfided material was carried out at the desired temperature ranging between 400 $550^{\circ} \mathrm{C}$ with 2 to 4 volume $\%$ oxygen in nitrogen. In all the runs, space velocity used was in the range of 2000-3000 $\mathrm{h}^{-1}$. The regeneration of the sulfided material was carried out until the $\mathrm{SO}_{2}$ concentration in the reactor effluent dropped below $50 \mathrm{ppm}$. These sulfidation-regeneration cycles were repeated as many times as desired. Typically each material was tested for 4 to 5 cycles to obtain meaningful data on material durability. At the end of the 4 to 5 cycle run, the 
material was removed from the reactor and all physical and chemical characterizations, as listed above, were carried out on the reacted material to determine changes due to reaction.

\subsection{RESULTS AND DISCUSSIONS}

The summary of the experimental data for sulfidation are presented in Table 1, with $t$ denoting real time and $t^{*}$ a calculated time corresponding to 100 percent metal oxide conversion. Sulfidation tests were carried out with a sulfidation gas containing (vol\%) $10 \mathrm{H}_{2}, 15 \mathrm{CO}, 5 \mathrm{CO}_{2}$, $1 \mathrm{H}_{2} \mathrm{~S}, 15 \mathrm{H}_{2} \mathrm{O}$, balance $\mathrm{N}_{2}$ for all the sorbents shown in Table 1. The temperature was chosen in the range $350-500^{\circ} \mathrm{C}$ and was held fixed for the duration of the sulfidation. Sulfided sorbents were regenerated using a nitrogen-air at temperatures of $400-600^{\circ} \mathrm{C}$.

Table 1. Summary of Sulfidation Tests with MCRH Sorbents

\begin{tabular}{|c|c|c|c|c|}
\hline Sorbent & $\begin{array}{l}\mathrm{T}_{3} \\
\left({ }^{\circ} \mathrm{C}\right)\end{array}$ & $\begin{array}{l}\text { Pre-Break- } \\
\text { Through } \\
\mathrm{H}_{2} \mathrm{~S} \text { (ppm) }\end{array}$ & $\begin{array}{l}\text { Breakthrough } \\
\text { Sorbent } \\
\text { Conversion, } \\
\left(\mathrm{t} / \mathrm{t}^{*}\right) \text { at cycle-4 }\end{array}$ & $\begin{array}{l}\text { Sulfur Loading } \\
\text { (gS/100g sorbent) } \\
\text { at cycle } 4\end{array}$ \\
\hline MCRH-1 & 427 & $4-6$ & 0.82 & 19.49 \\
\hline MCRH-2 & 427 & $8-10$ & 0.72 & 28.66 \\
\hline MCRH-10 & 427 & $50-60$ & 0.88 & 21.06 \\
\hline MCRH-14 & 427 & $50-60$ & 0.69 & 17.31 \\
\hline MCRH-23 & 427 & $50-60$ & 0.31 & 7.81 \\
\hline MCRH-24 & 427 & $80-90$ & 1.0 & 23.77 \\
\hline MCRH-25 & 427 & $60-70$ & 0.94 & 24.12 \\
\hline MCRH-26 & 427 & $60-70$ & 0.43 & 11.89 \\
\hline MCRH-27 & 427 & $65-75$ & 0.97 & 23.73 \\
\hline
\end{tabular}


MCRH-1 : A mixed oxide sorbent (designated MCRH-1) was prepared by coprecipitation. For the coprecipitation, the salt solutions were mixed in the proportions needed to obtain the desired molar ratio in the final sorbent and then precipitated using a basic solution. The resulting precipitate was filtered off, and washed with deionized water twice. The filtered precipitates were then dried for $16 \mathrm{~h}$ at $150^{\circ} \mathrm{C}$. Finally it was calcined in a muffle furnace at $700^{\circ} \mathrm{C}$ for $2 \mathrm{~h}$ under a stream of air to produce the final mixed-oxide phase. The SEM morphology of the fresh MCRH1 sorbent is depicted in Figure 2.

This material was tested for sulfidation in a laboratory scale reactor. Regeneration between cycles was conducted with 10 vol $\%$ air- 90 vol $\% \mathrm{~N}_{2}$ at $600^{\circ} \mathrm{C}$. The gas hourly space velocity was about $2500 \mathrm{~h}^{-1}$ (STP) both in sulfidation and in regeneration. In tests with MCRH-1 sorbent conducted at $427^{\circ} \mathrm{C}$, with a sulfidation gas containing (vol \%) $10 \mathrm{H}_{2}, 15 \mathrm{CO}, 5 \mathrm{CO}_{2}, 1$ $\mathrm{H}_{2} \mathrm{~S}, 15 \mathrm{H}_{2} \mathrm{O}$, balance $\mathrm{N}_{2}$, the sorbent conversion at breakthrough was 80 percent as shown in Figure 3. In fact, the $\mathrm{H}_{2} \mathrm{~S}$ level remained at $0 \mathrm{ppm}$ until 17 percent conversion and then gradually increased to $\sim 5 \mathrm{ppm}$ when conversion reached 80 percent. There was no decline in activity for 6 cycles. The sulfidation summery is summarized in Table 1.

The sulfidation performance of the MCRH-1 sorbent was examined as a function of temperature up to $538^{\circ} \mathrm{C}$. The results are shown in Figure 4. As expected, sulfidation efficiency increased at higher temperatures. The sorbent conversions at 343 and $538^{\circ} \mathrm{C}$ were 60 and 100 percent, respectively. Apparently this is due to faster kinetics at higher temperature and to the absence of diffusional limitations. The sulfur capacities of the MCRH-1 sorbent during cycles 1 and 6 were 19.49 and $19.49 \mathrm{gS} / 100 \mathrm{~g}$ of sorbent, respectively, indicating a 100 percent capacity utilization even after 6 cycles. Sulfur capacity is calculated using the concentration of $\mathrm{H}_{2} \mathrm{~S}$ in 


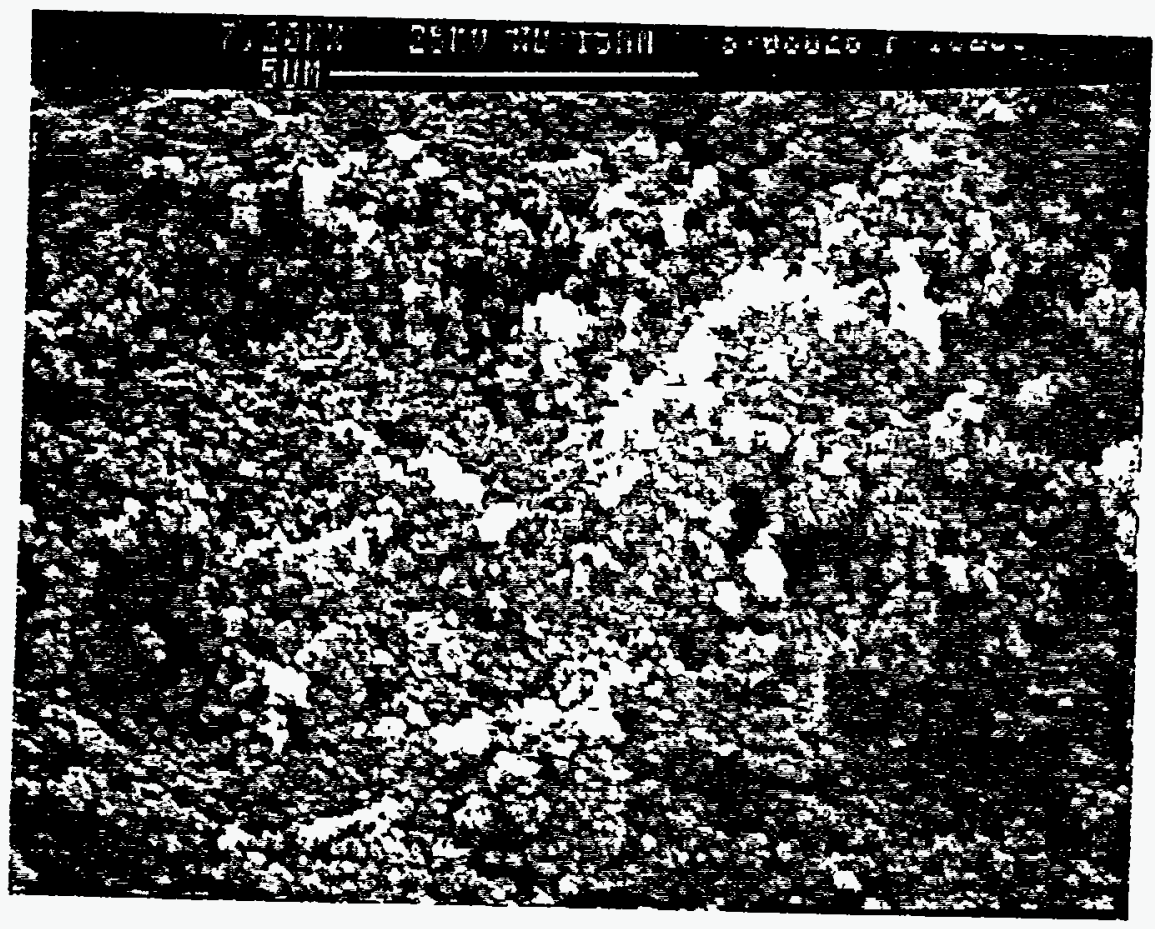

Figure 2. SEM Micrographs of MCRH-1 Fresh Sorbents 


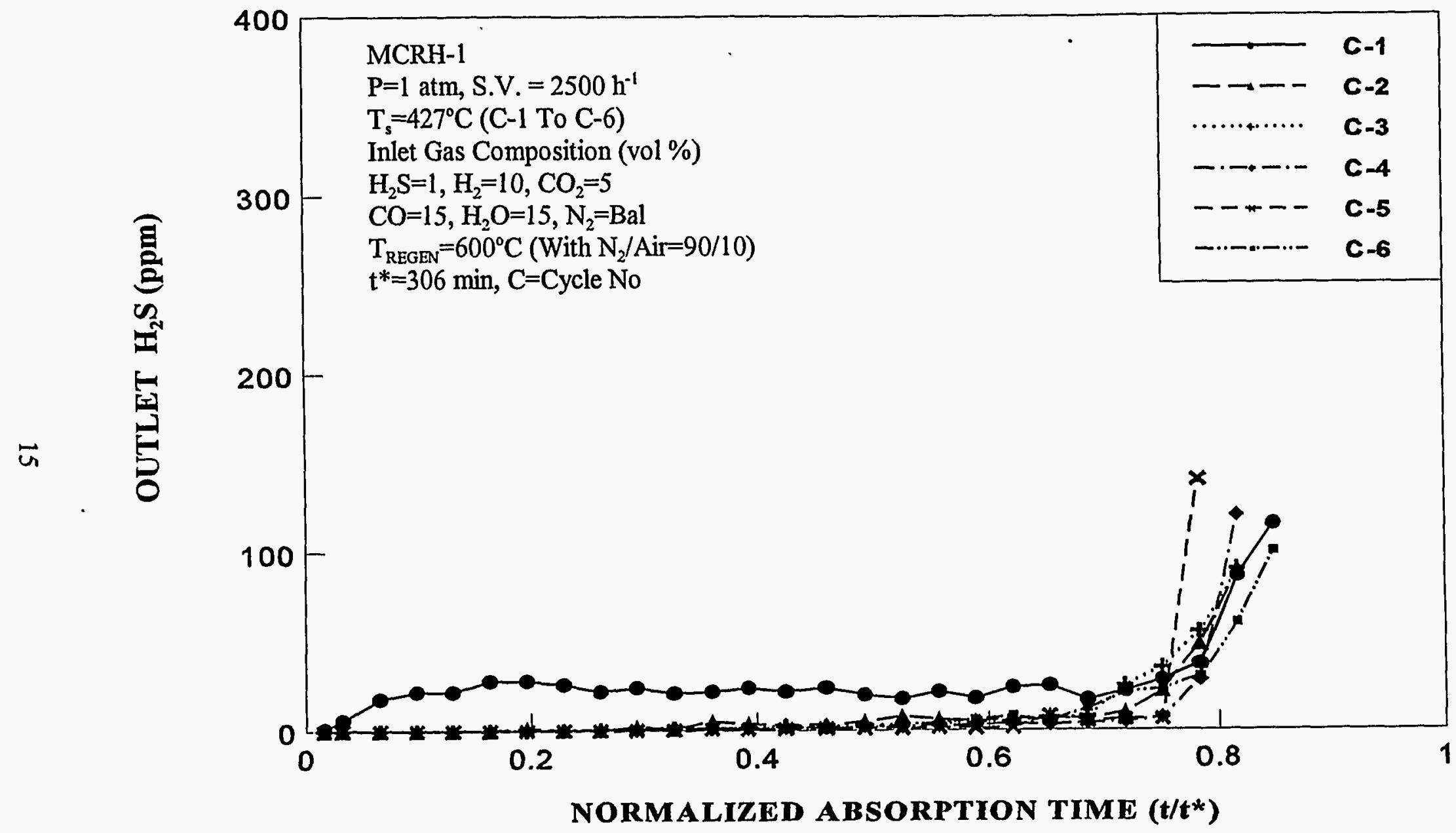

Figure 3. $\mathrm{H}_{2} \mathrm{~S}$ Breakthrough Curves in Successive Sulfidation Cycles of MCRH-1 Sorbent 


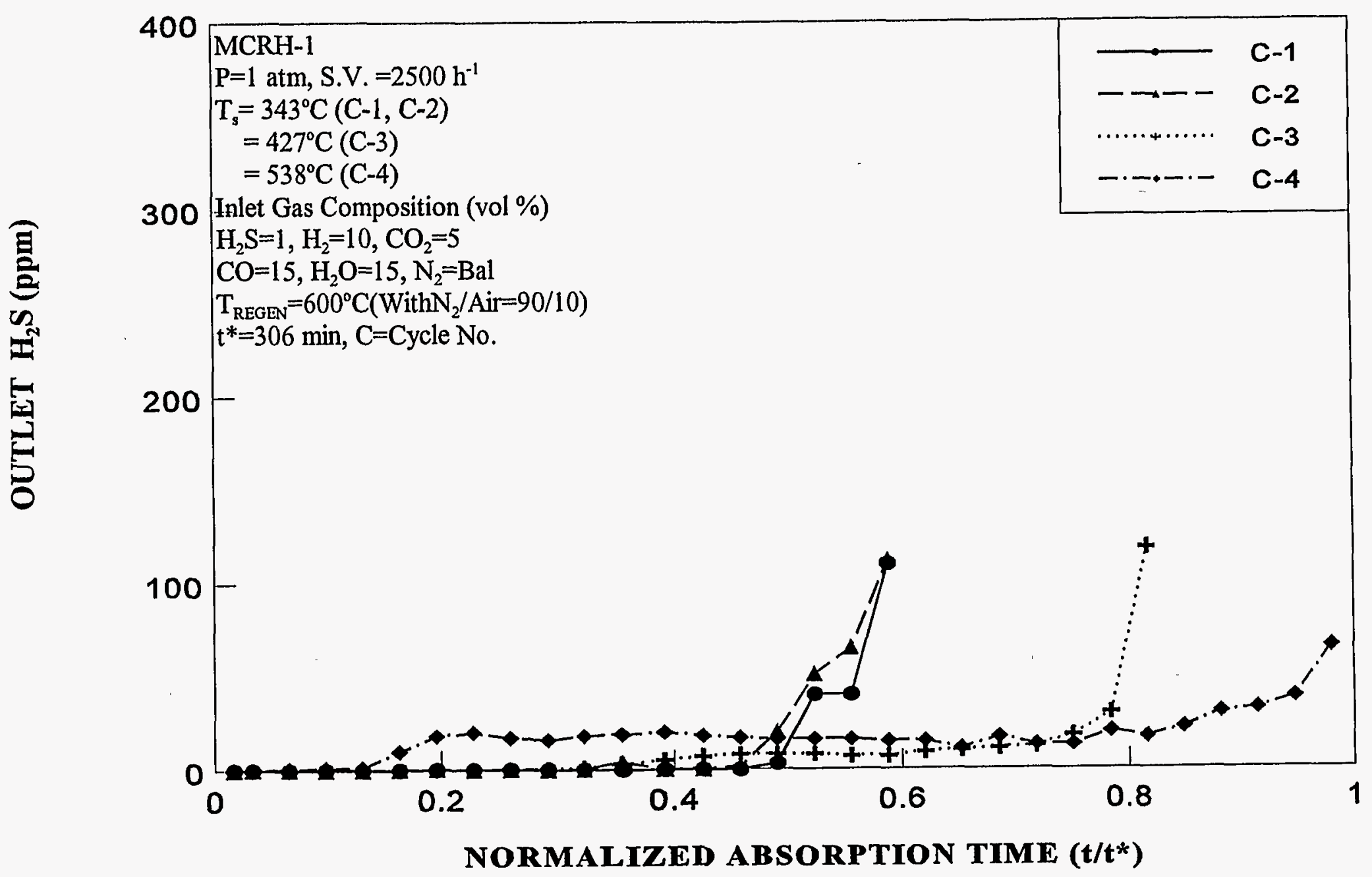

Figure 4. $\mathrm{H}_{2} \mathrm{~S}$ Breakthrough Curves in Successive Sulfidation Cycles of MCRH-1 Sorbent 
feed, breakthrough time and the amount of sorbent used.

As mentioned previously, the sorbent for the desulfurization application must have high chemical reactivity. The chemical reactivity is measured by the total sulfur loading as well as the rate of sulfur absorption. In order to measure the latter, standard 1.5 cycle TGA reactivity tests were carried out for fresh, and 6 cycle used sorbent. The TGA results (Figure 5), indicate that the rate of sulfur pickup (indicated by the slope of the sulfidation curve) remained relatively constant over six cycles of test. In the conventional sorbents, both the rate of sulfur pick-up and capacity progressively decreases with cycling. TGA results indicate that MCRH-1 has high chemical reactivity for sulfur capture even at a relatively low temperature of $427^{\circ} \mathrm{C}$.

MCRH-2 : A mixed oxide sorbent (designated MCRH-2) was prepared by the same procedure as MCRH-1 in page 13. This material was tested for sulfidation in a laboratory scale reactor. Regeneration between cycles was conducted with 10 vol\% air-90 vol\% $\mathrm{N}_{2}$ at $600^{\circ} \mathrm{C}$. The gas . hourly space velocity was about $2500 \mathrm{~h}^{-1}$ (STP) both in sulfidation and in regeneration. In tests with MCRH-2 sorbent conducted at $427^{\circ} \mathrm{C}$, with a sulfidation gas containing (vol \%) $10 \mathrm{H}_{2}, 15$ $\mathrm{CO}, 5 \mathrm{CO}_{2}, 1 \mathrm{H}_{2} \mathrm{~S}, 15 \mathrm{H}_{2} \mathrm{O}$, balance $\mathrm{N}_{2}$, the sorbent conversion at breakthrough was 60 percent or higher. As shown in Figure 6, the $\mathrm{H}_{2} \mathrm{~S}$ level remained at $0 \mathrm{ppm}$ until 13 percent sorbent conversion and then gradually increased to $\sim 20 \mathrm{ppm}$ when conversion reached 60 percent. The sulfur capacities of the MCRH-2 sorbent during cycle 4 was $28.66 \mathrm{gS} / 100 \mathrm{~g}$ of sorbent. Sulfur capacity is calculated using the concentration of $\mathrm{H}_{2} \mathrm{~S}$ in feed, breakthrough time and the amount of sorbent used. 
TGA Reactivities of MCRH-1(Fresh) and

MCRH-(Regenerated) Sorbents

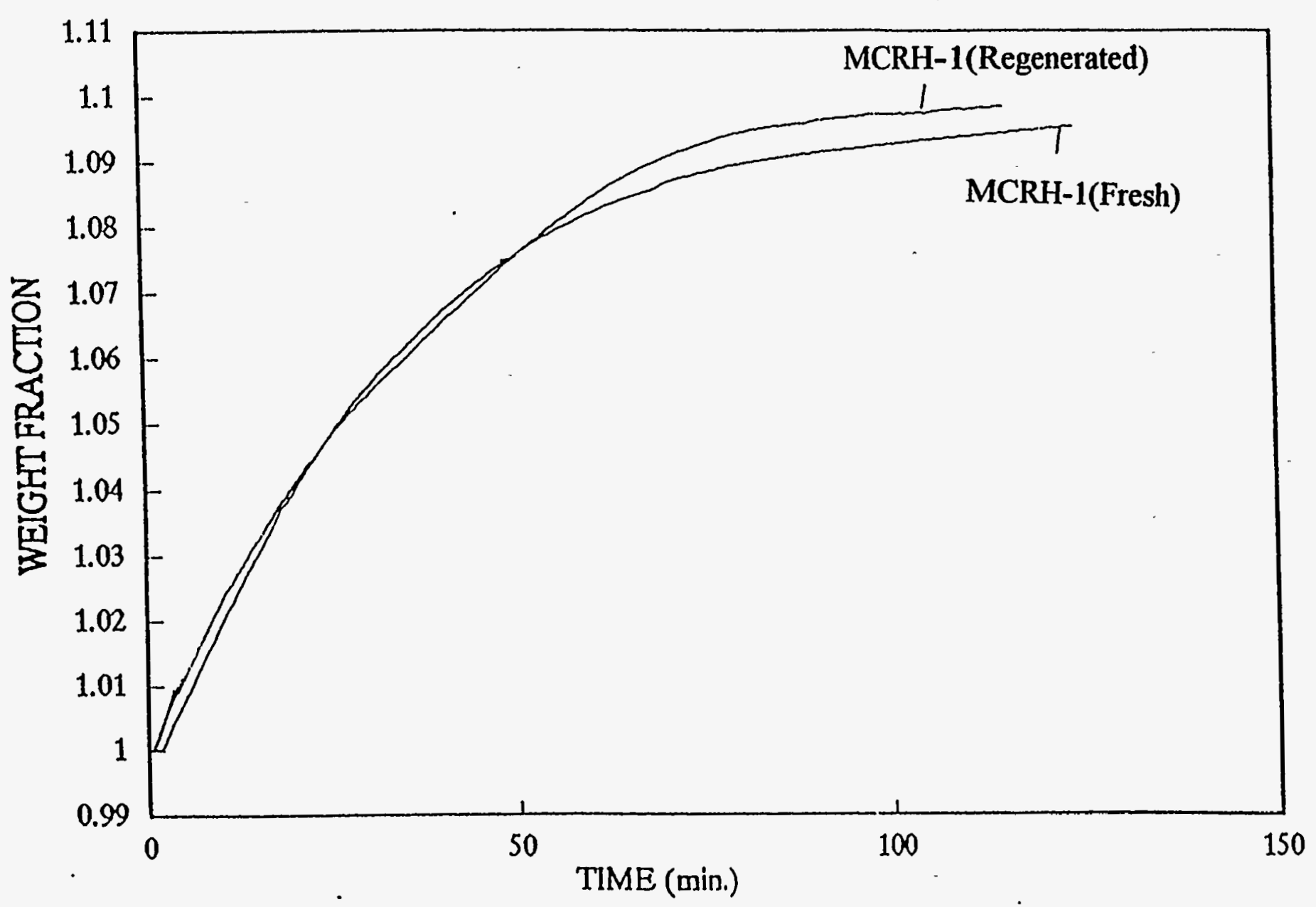

Figure 5. TGA Reactivities of MCRH-1 Sorbents 


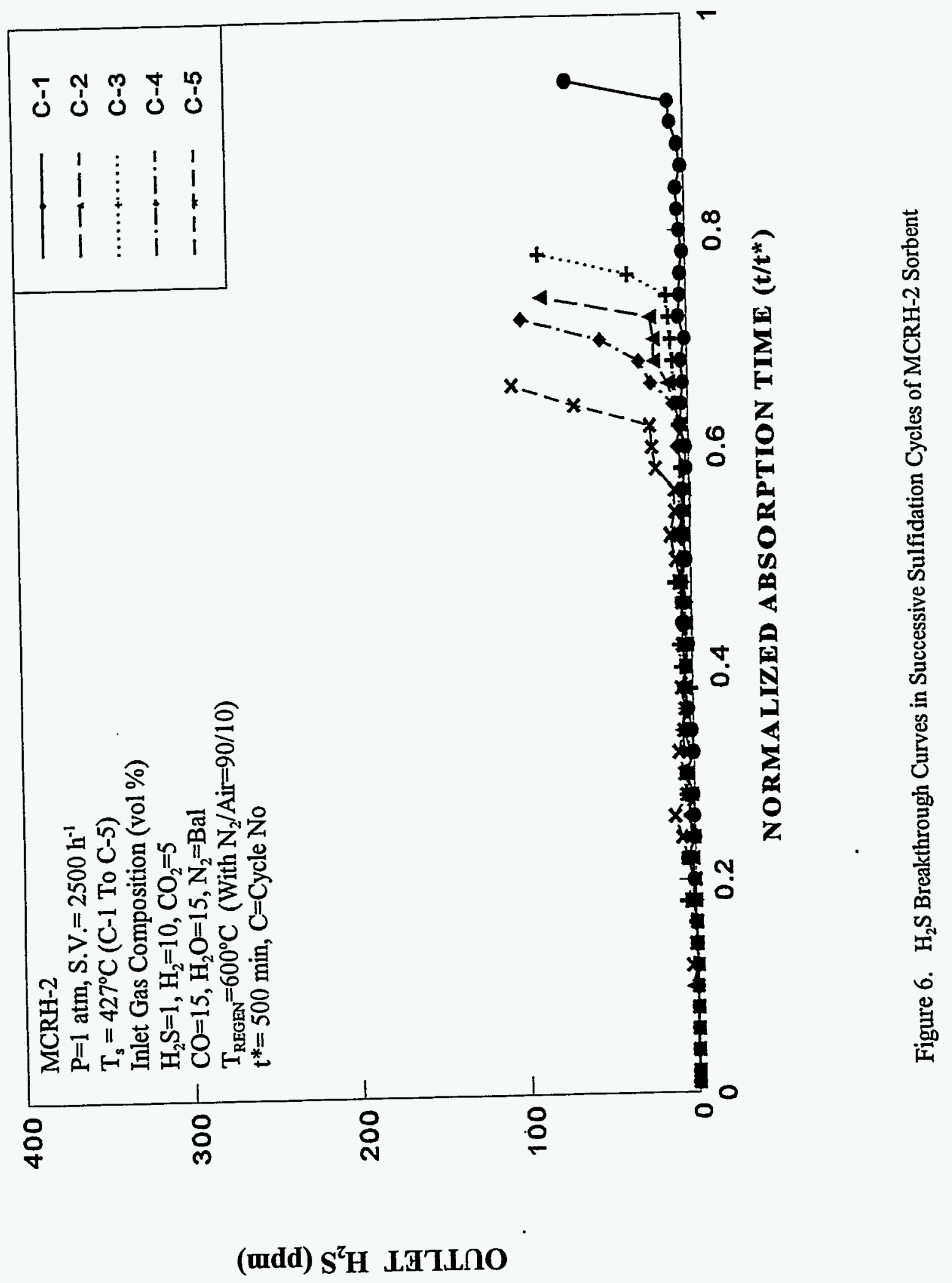


MCRH-4 : A mixed oxide sorbent (designated MCRH-4) was prepared by the same procedure as $\mathrm{MCRH}-1$ in page 13 . In tests with MCRH-4 sorbent conducted at $427^{\circ} \mathrm{C}$, with a sulfidation gas containing (vol \%) $10 \mathrm{H}_{2}, 15 \mathrm{CO}, 5 \mathrm{CO}_{2}, 1 \mathrm{H}_{2} \mathrm{~S}, 15 \mathrm{H}_{2} \mathrm{O}$, balance $\mathrm{N}_{2}$, the sorbent conversion at breakthrough was less than 10 percent. As shown in Figure 7, the $\mathrm{H}_{2} \mathrm{~S}$ level remained at $0 \mathrm{ppm}$ until the breakthrough.

MCRH-7 : A mixed oxide sorbent (designated MCRH-7) was prepared by the same procedure as $\mathrm{MCRH}-1$ in page 13 . In tests with $\mathrm{MCRH}-7$ sorbent conducted at $427^{\circ} \mathrm{C}$, with a sulfidation gas containing (vol \%) $10 \mathrm{H}_{2}, 15 \mathrm{CO}, 5 \mathrm{CO}_{2}, 1 \mathrm{H}_{2} \mathrm{~S}, 15 \mathrm{H}_{2} \mathrm{O}$, balance $\mathrm{N}_{2}$, the sorbent conversion at breakthrough was 100 percent. As shown in Figure 8, the pre-breakthrough $\mathrm{H}_{2} \mathrm{~S}$ level remained below $30 \mathrm{ppm}$

MCRH-8 : A mixed oxide sorbent (designated MCRH-8) was prepared by the same procedure as MCRH-1 in page 13 . In tests with MCRH-8 sorbent conducted at $427^{\circ} \mathrm{C}$, with a sulfidation gas containing (vol \%) $10 \mathrm{H}_{2}, 15 \mathrm{CO}, 5 \mathrm{CO}_{2}, 1 \mathrm{H}_{2} \mathrm{~S}, 15 \mathrm{H}_{2} \mathrm{O}$, balance $\mathrm{N}_{2}$, the sorbent conversion at breakthrough was 70 percent. As shown in Figure 9, the prebreakthrough $\mathrm{H}_{2} \mathrm{~S}$ level remained below $30 \mathrm{ppm}$.

MCRH-10： A mixed oxide sorbent (designated MCRH-10) was prepared by the same procedure as MCRH-1 in page 13. The SEM morphology of the MCRH-10 fresh sorbent is depicted in Figure 10. In tests with MCRH-10 sorbent conducted at $427^{\circ} \mathrm{C}$, with a sulfidation gas containing (vol \%) $10 \mathrm{H}_{2}, 15 \mathrm{CO}, 5 \mathrm{CO}_{2}, 1 \mathrm{H}_{2} \mathrm{~S}, 15 \mathrm{H}_{2} \mathrm{O}$, balance $\mathrm{N}_{2}$, the sorbent conversion at 


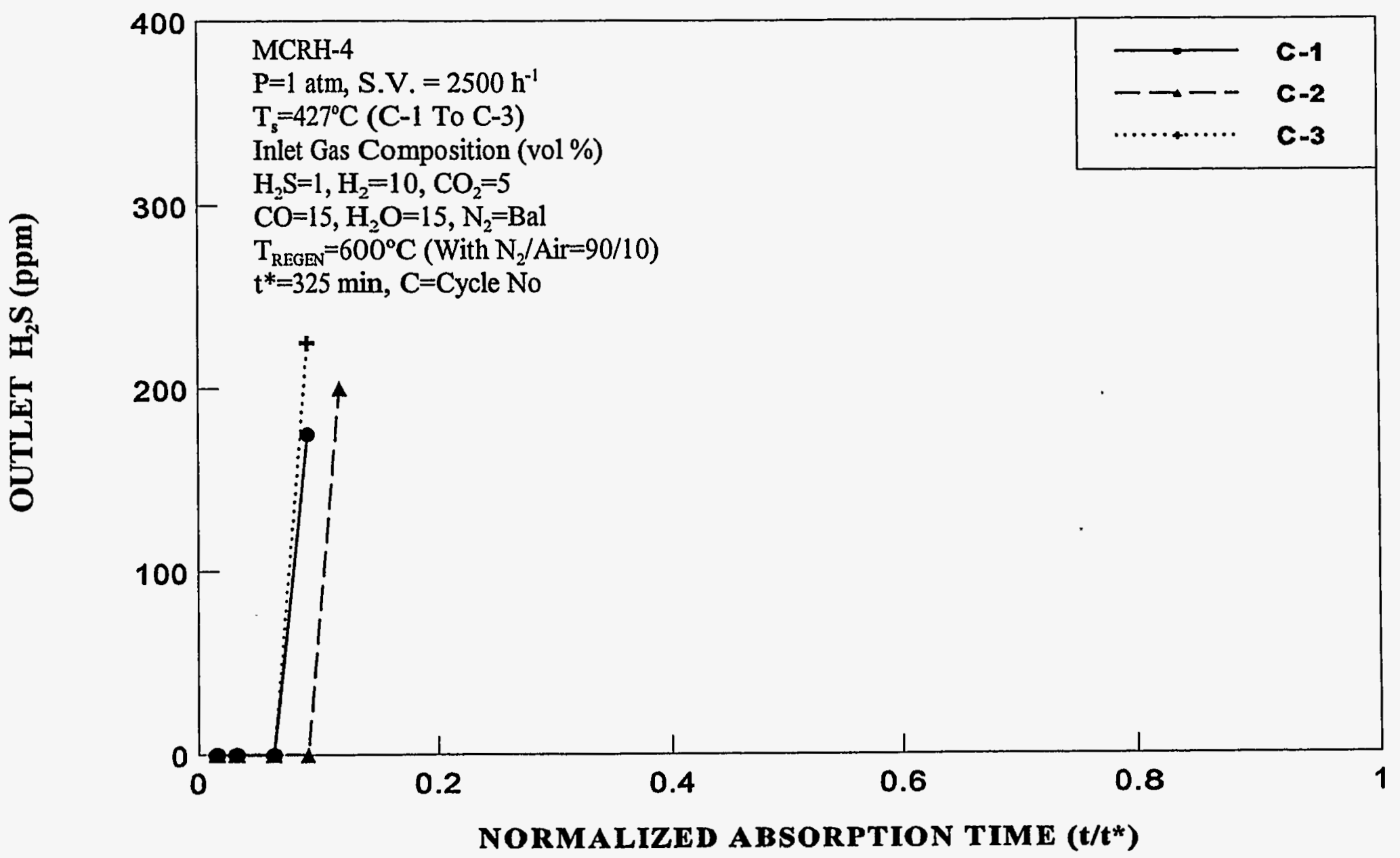

Figure 7. $\mathrm{H}_{2} \mathrm{~S}$ Breakthrough Curves in Successive Sulfidation Cycles of MCRH-4 Sorbent 


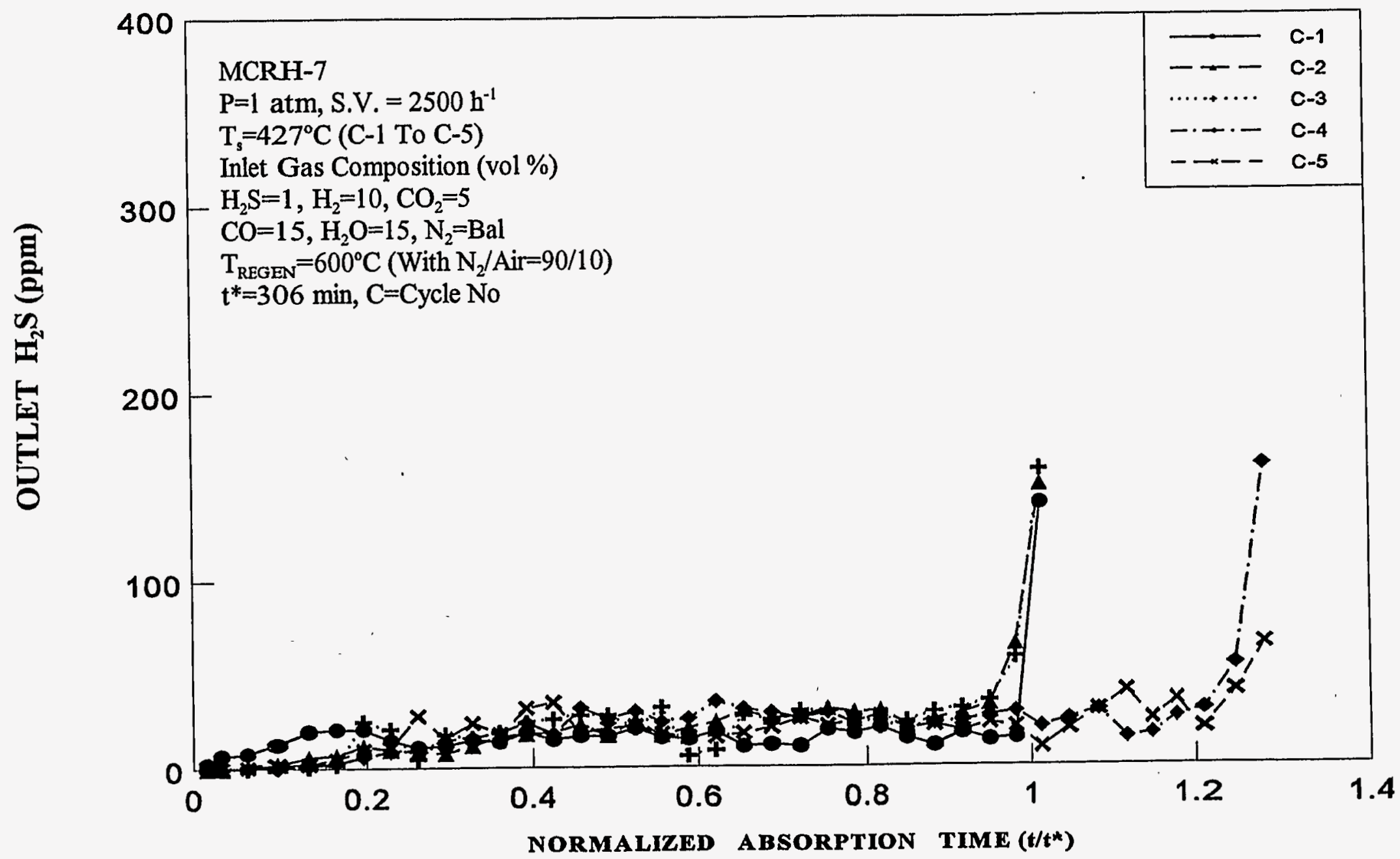

Figure 8. $\mathrm{H}_{2} \mathrm{~S}$ Breakthrough Curves in Successive Sulfidation Cycles of MCRH-7 Sorbent 


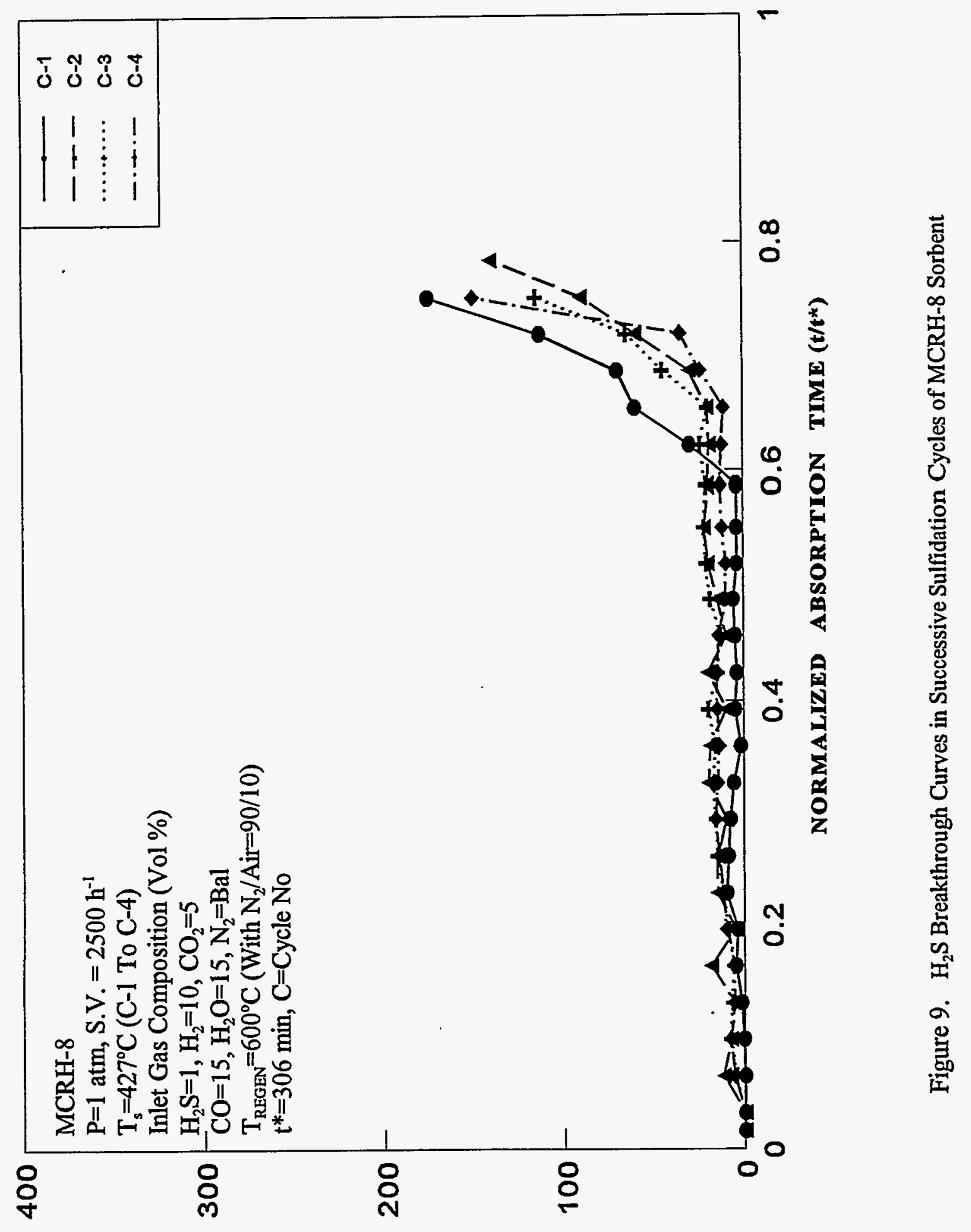

(mdd) $S^{2} H$ LATLCOO 


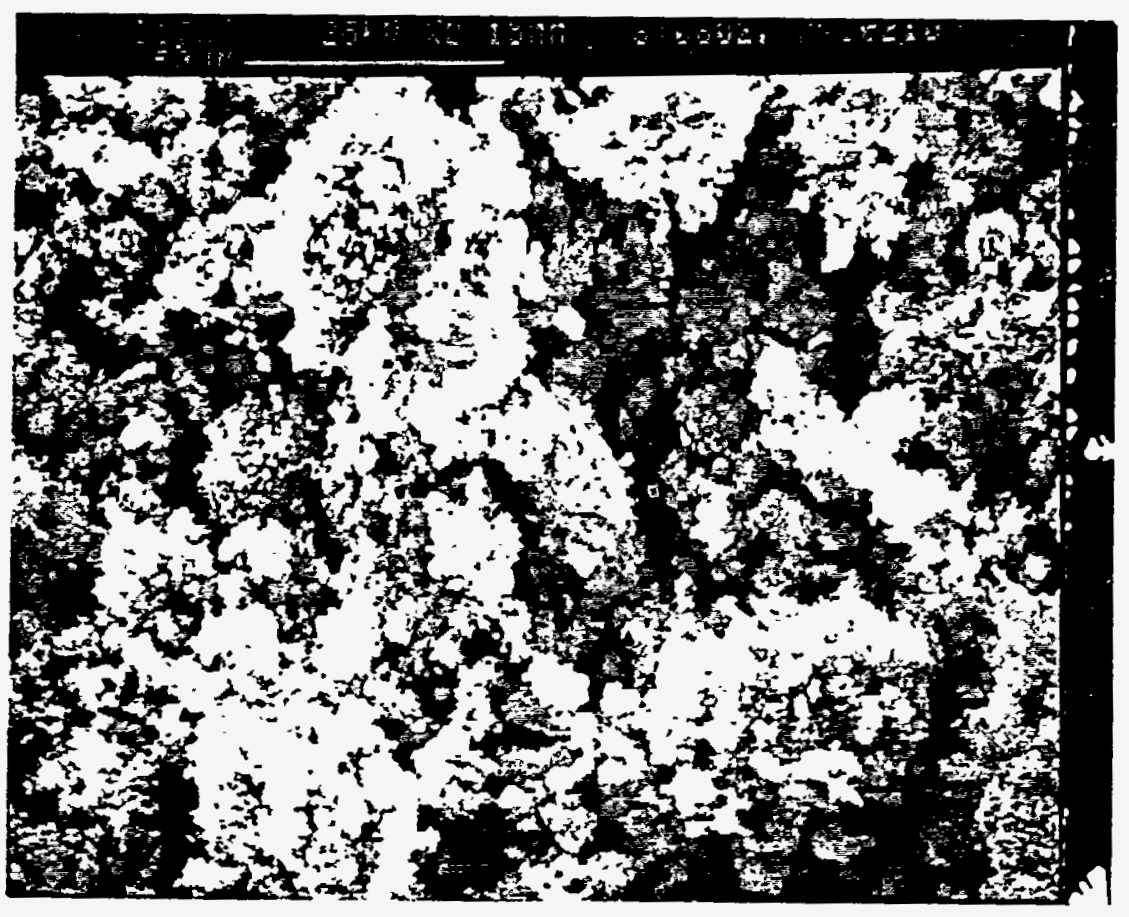

Figure 10. SEM Micrographs of MCRH-10 Fresh Sorbent 
breakthrough was 90 percent. As shown in Figure 11, the prebreakthrough $\mathrm{H}_{2} \mathrm{~S}$ level remained below $60 \mathrm{ppm}$. The sulfur capacities of the MCRH-10 sorbent during cycles 4 was $21.06 \mathrm{gS} / 100$ $\mathrm{g}$ of sorbent. Sulfur capacity is calculated using the concentration of $\mathrm{H}_{2} \mathrm{~S}$ in feed, breakthrough time and the amount of sorbent used.

MCRH-24 : A mixed oxide sorbent (designated MCRH-24) was prepared by the same procedure as MCRH-1 in page 13. This material was tested for sulfidation in a laboratory scale reactor. Regeneration between cycles was conducted with 10 vol\% air- 90 vol\% with $\mathrm{N}_{2}$ at $600^{\circ} \mathrm{C}$. The gas hourly space velocity was about $2500 \mathrm{~h}^{-1}$ (STP) both in sulfidation and in regeneration. As shown in Figure 12, at $427^{\circ} \mathrm{C}$, with a sulfidation gas containing (vol \%) $10 \mathrm{H}_{2}, 15 \mathrm{CO}, 5 \mathrm{CO}_{2}, 1$ $\mathrm{H}_{2} \mathrm{~S}, 15 \mathrm{H}_{2} \mathrm{O}$, balance $\mathrm{N}_{2}$, the sorbent conversion at breakthrough was greater than 95 percent and the pre-breakthrough was about $100 \mathrm{ppm}$. The sulfur capacities of the MCRH-24 sorbent during cycles 4 was $23.77 \mathrm{gS} / 100 \mathrm{~g}$ of sorbent. Sulfur capacity is calculated using the concentration of $\mathrm{H}_{2} \mathrm{~S}$ in feed, breakthrough time and the amount of sorbent used.

MCRH-14: A mixed oxide sorbent (designated MCRH-14) was prepared by the same procedure as MCRH-1 in page 13. The SEM morphology of the MCRH-14 fresh sorbent is depicted in Figure 13 and for the sulfided sample in Figure 14. In tests with MCRH-14 sorbent conducted at $427^{\circ} \mathrm{C}$, with a sulfidation gas containing (vol \%) $10 \mathrm{H}_{2}, 15 \mathrm{CO}, 5 \mathrm{CO}_{2}, 1 \mathrm{H}_{2} \mathrm{~S}, 15$ $\mathrm{H}_{2} \mathrm{O}$, balance $\mathrm{N}_{2}$, the sorbent conversion at breakthrough was 70 percent. As shown in Figure 15 , greater than $70 \%$ sorbent conversion was observed at breakthrough at $427^{\circ} \mathrm{C}$ and the prebreakthrough $\mathrm{H}_{2} \mathrm{~S}$ level was below $80 \mathrm{ppm}$. The sulfur capacities of the MCRH-14 sorbent 


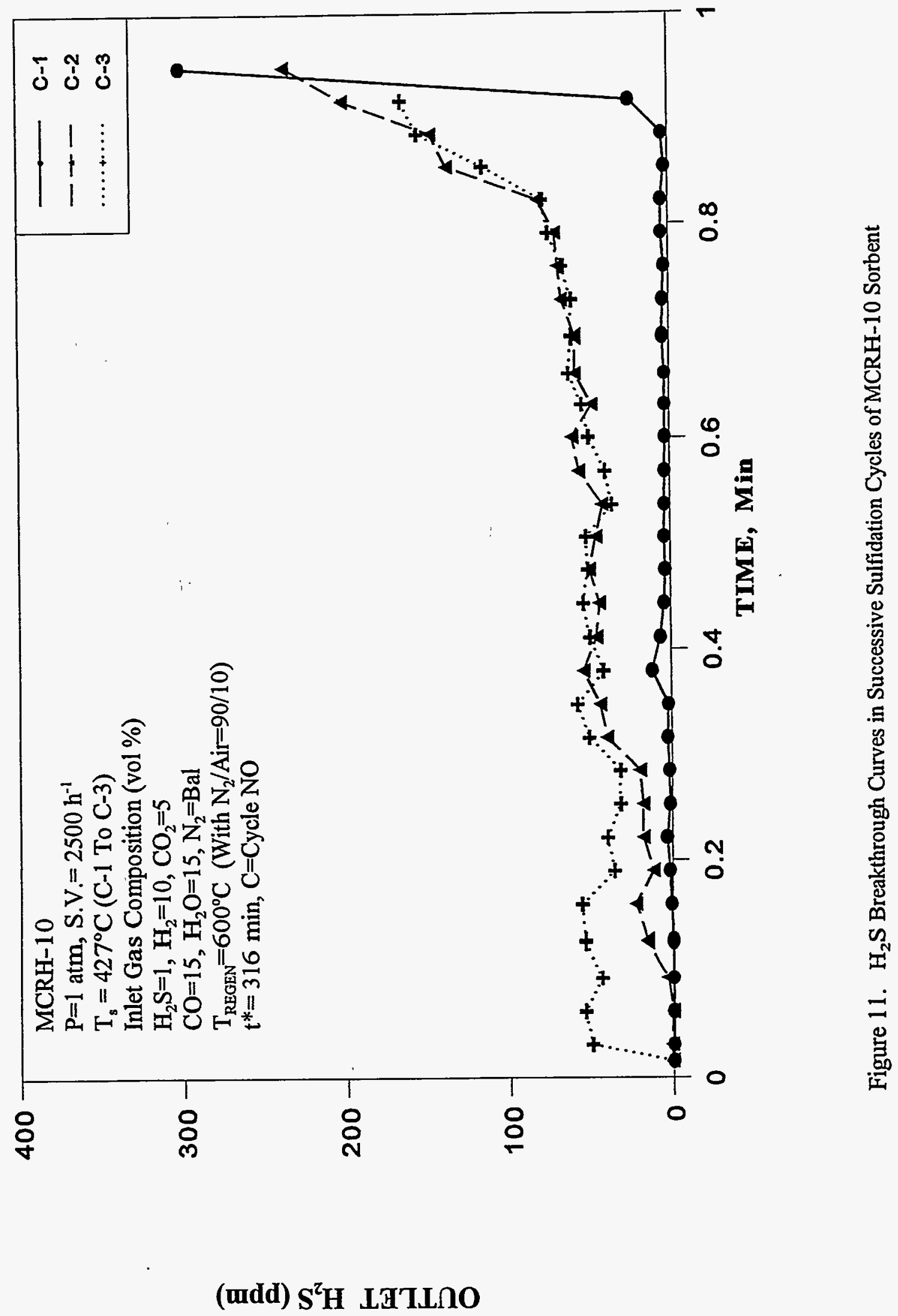




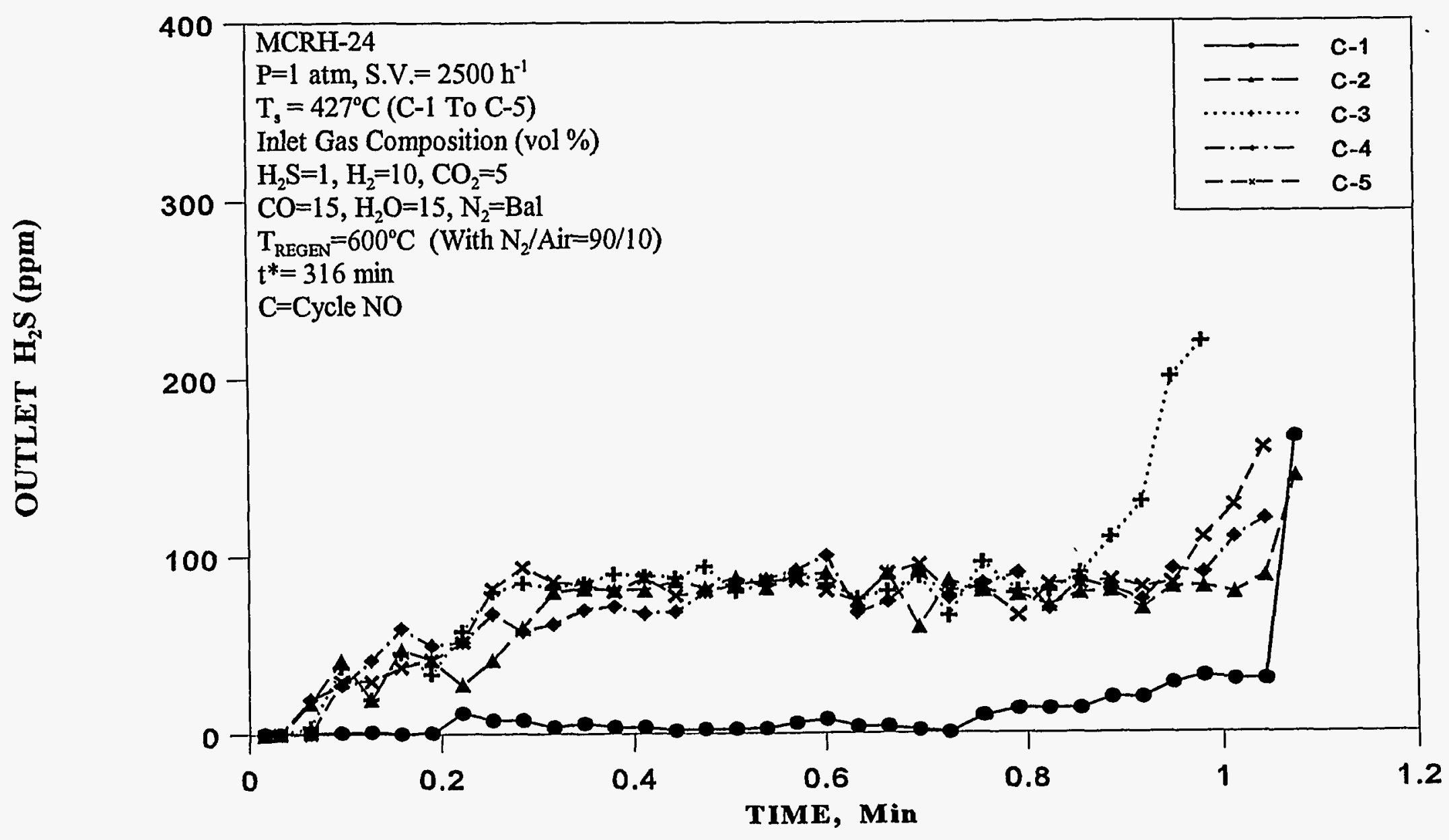

Figure 12. $\mathrm{H}_{2} \mathrm{~S}$ Breakthrough Curves in Successive Sulfidation Cycles of MCRH-24 Sorbent 


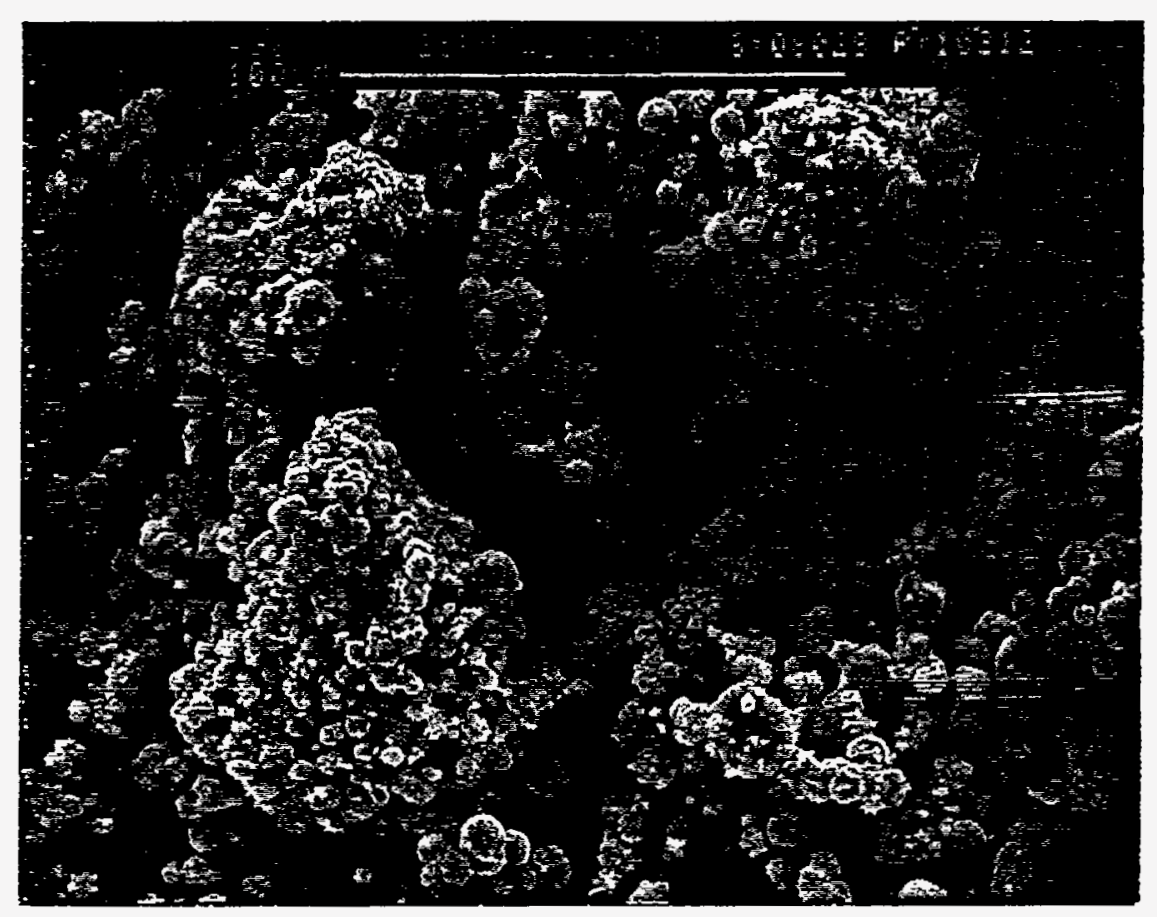

Figure 13. SEM Micrographs of MCRH-14 Fresh Sorbent 


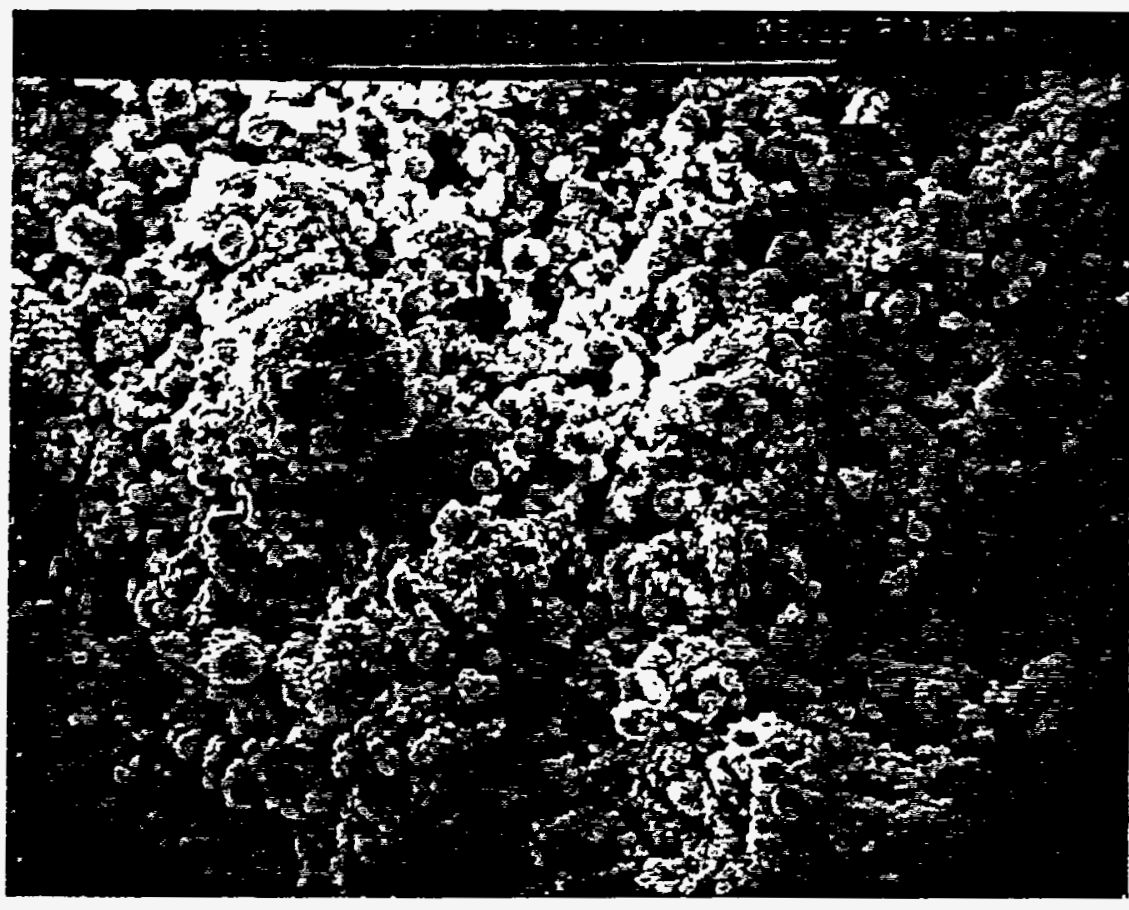

Figure 14. SEM Micrographs of MCRH-14 Sulfided Sorbent 
高

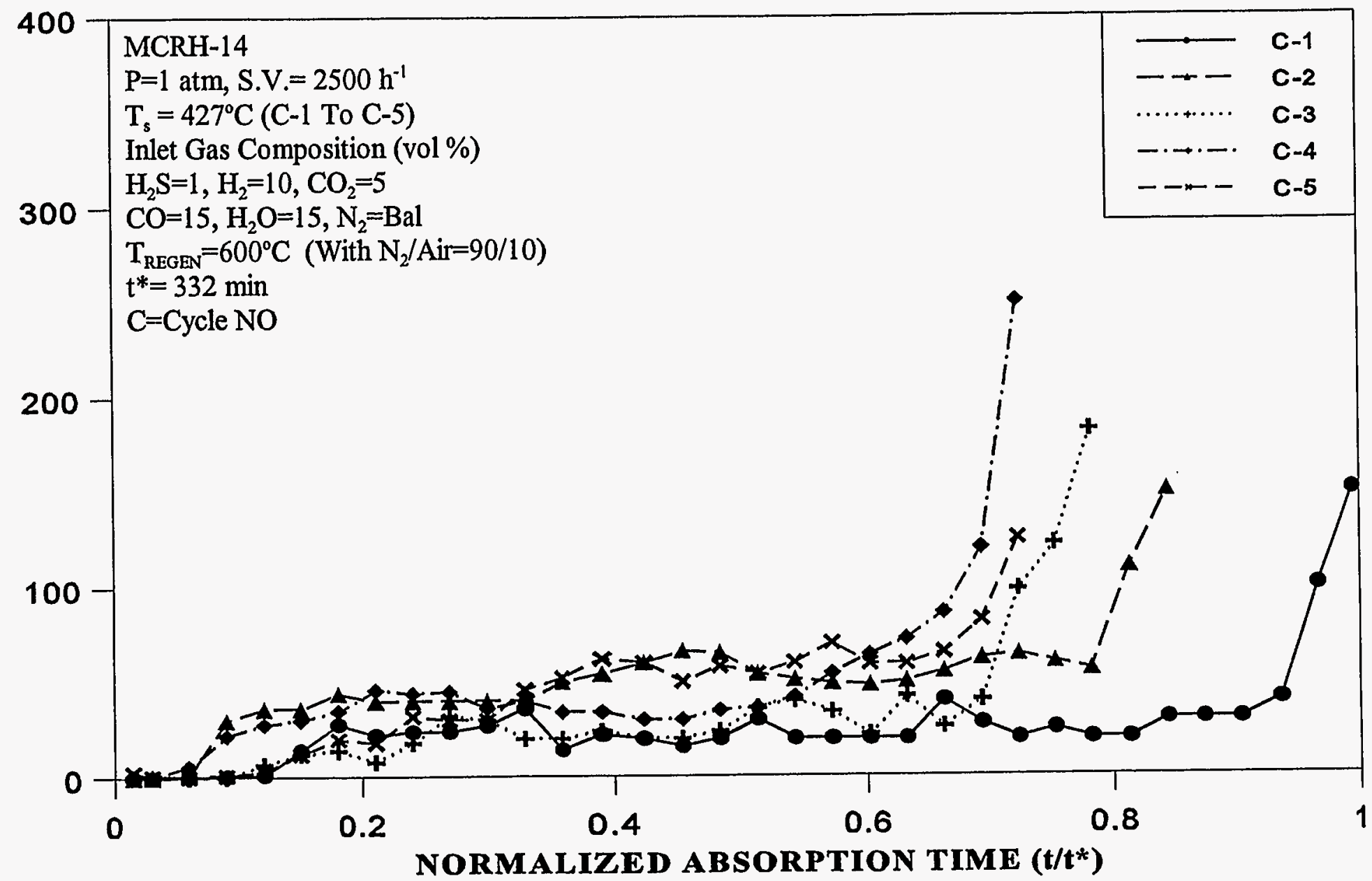

Figure 15. $\mathrm{H}_{2} \mathrm{~S}$ Breakthrough Curves in Successive Sulfidation Cycles of MCRH-14 Sorbent 
during cycles 4 was $17.31 \mathrm{gS} / 100 \mathrm{~g}$ of sorbent. Sulfur capacity is calculated using the concentration of $\mathrm{H}_{2} \mathrm{~S}$ in feed, breakthrough time and the amount of sorbent used.

MCRH-18 : A mixed oxide sorbent (designated MCRH-18) was prepared by the same procedure as MCRH-1 in page 13. The SEM morphology of the MCRH-18 fresh sorbent is depicted in Figure 16 and for the sulfided sample in Figure 17. In tests with MCRH-18 sorbent conducted at $427^{\circ} \mathrm{C}$, with a sulfidation gas containing (vol \%) $10 \mathrm{H}_{2}, 15 \mathrm{CO}, 5 \mathrm{CO}_{2}, 1 \mathrm{H}_{2} \mathrm{~S}, 15$ $\mathrm{H}_{2} \mathrm{O}$, balance $\mathrm{N}_{2}$, the sorbent conversion at breakthrough was less than 10 percent after cycle 1 . As shown in Figure 18, $80 \%$ sorbent conversion was observed at cycle 1 breakthrough at $427^{\circ} \mathrm{C}$ and the pre-breakthrough $\mathrm{H}_{2} \mathrm{~S}$ level was below $5 \mathrm{ppm}$. After the cycle 1, the sorbent deteriorated very fast and the sorbent conversion at cycle 4 was only about $4 \%$. Copper seems to be a very bad catalyst.

MCRH-23: A mixed oxide sorbent (designated MCRH-23) was prepared by the same procedure as MCRH-1 in page 13. The SEM morphology of the MCRH-23 fresh sorbent is depicted in Figure 19. As shown in Figure 20,80\% sorbent conversion was observed at cycle 1 to 3 breakthrough at $427^{\circ} \mathrm{C}$ and the pre-breakthrough $\mathrm{H}_{2} \mathrm{~S}$ level was below $80 \mathrm{ppm}$. After the cycle 3 , the sorbent deteriorated very fast and the sorbent conversion at cycle 4 and was only about 30. The sulfur capacities of the MCRH-23 sorbent during cycle 4 was $7.81 \mathrm{gS} / 100 \mathrm{~g}$ of sorbent. Sulfur capacity is calculated using the concentration of $\mathrm{H}_{2} \mathrm{~S}$ in feed, breakthrough time and the amount of sorbent used. 


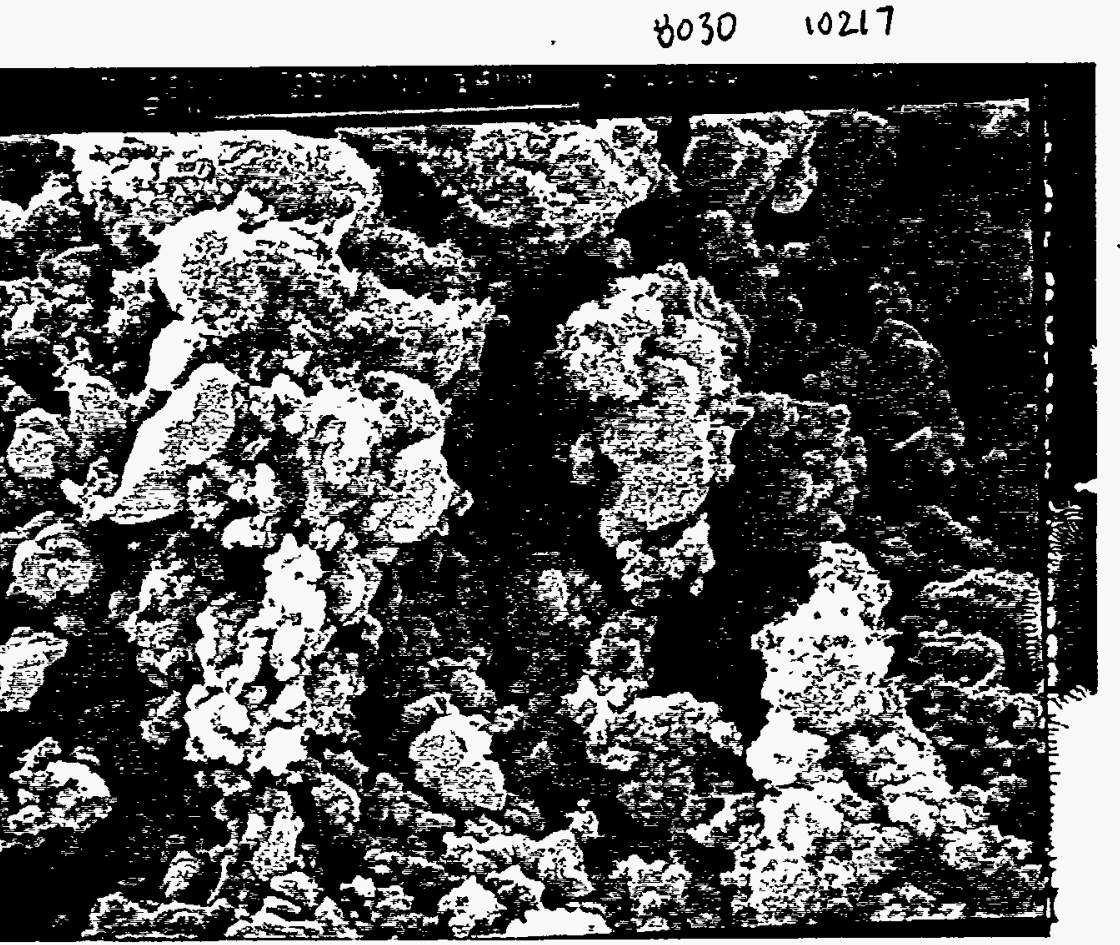

Figure 16. SEM Micrographs of MCRH-18 Fresh Sorbent 


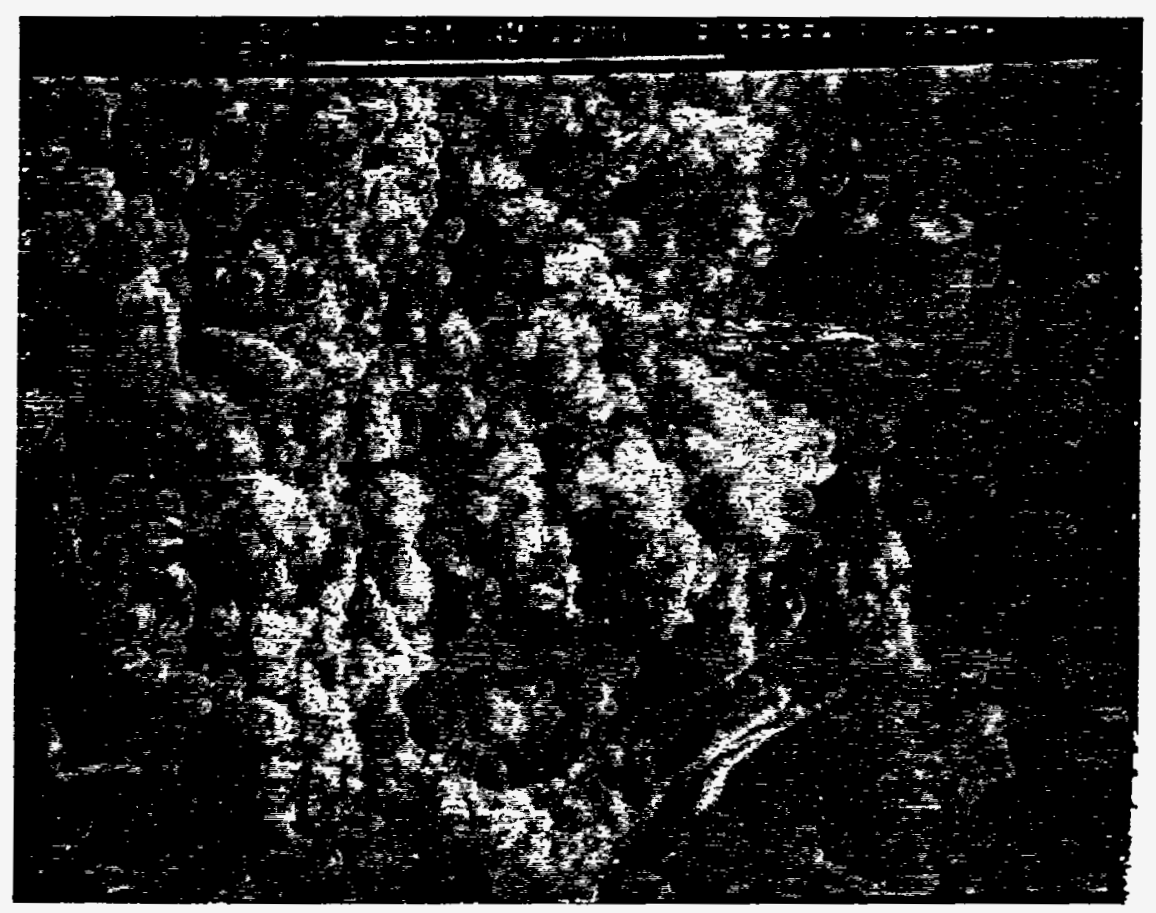

Figure 17. SEM Micrographs of MCRH-18 Sulfided Sorbent 
高

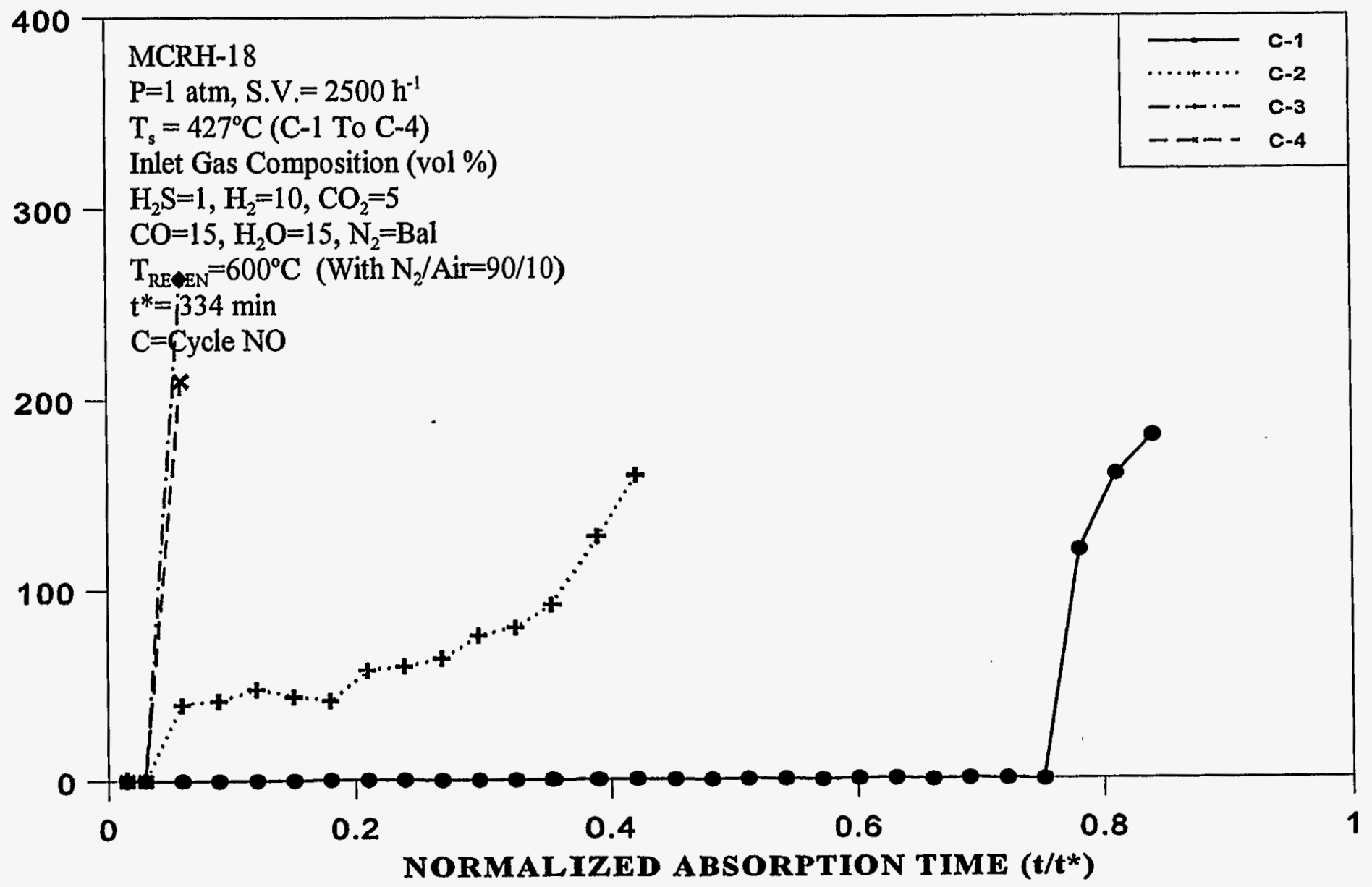

Figure 18. $\mathrm{H}_{2} \mathrm{~S}$ Breakthrough Curves in Successive Sulfidation Cycles of MCRH-18 Sorbent 


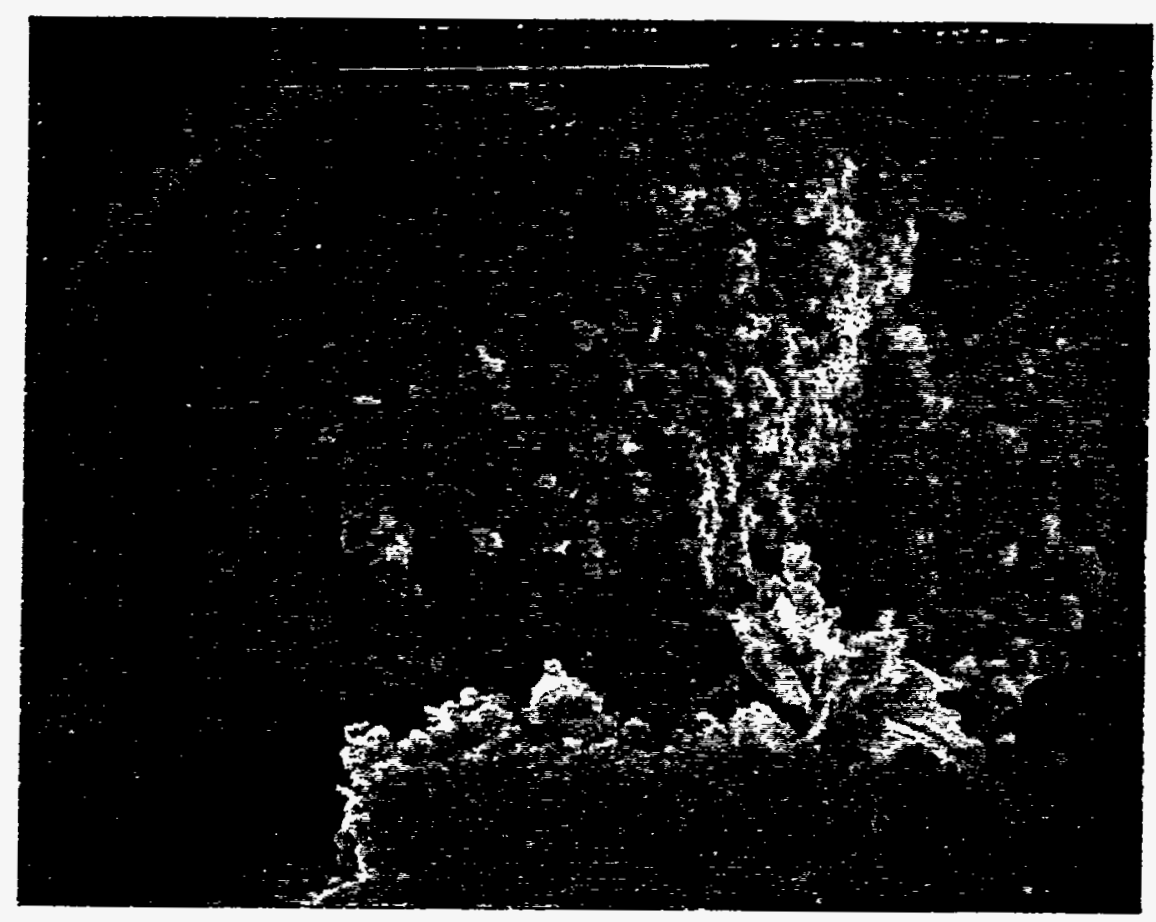

Figure 19. SEM Micrographs of MCRH-23 Fresh Sorbent 
昌

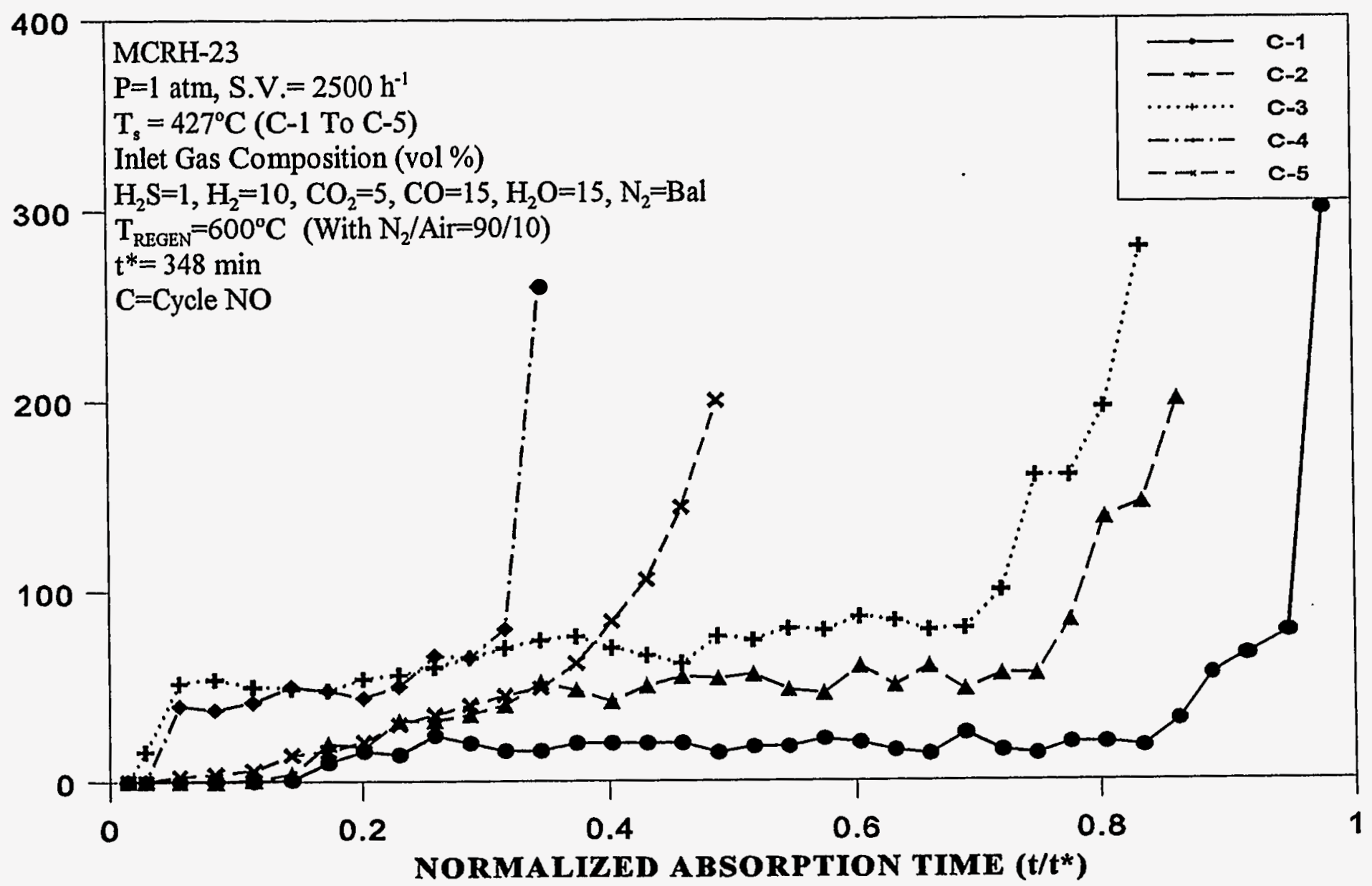

Figure 20. $\mathrm{H}_{2} \mathrm{~S}$ Breakthrough Curves in Successive Sulfidation Cycles of MCRH-23 Sorbent 
MCRH-25: A mixed oxide sorbent, (designated MCRH-25) was prepared by the same procedure as MCRH-1 in page 13. The SEM morphology of the MCRH-25 fresh sorbent is depicted in Figure 21. The experimental results are discussed in multicycle section.

MCRH-26 : A mixed oxide sorbent (designated by MCRH-26) was prepared by the same procedure as MCRH-1 in page 13. The SEM morphology of the MCRH-26 fresh sorbent was depicted in Figure 22. As shown in Figure 23, $40 \%$ sorbent conversion was observed at breakthrough at $427^{\circ} \mathrm{C}$ and the pre-breakthrough $\mathrm{H}_{2} \mathrm{~S}$ level was below $30 \mathrm{ppm}$. The sulfur capacities of the MCRH-26 sorbent during cycles 4 was $11.89 \mathrm{gS} / 100 \mathrm{~g}$ of sorbent. Sulfur capacity is calculated using the concentration of $\mathrm{H}_{2} \mathrm{~S}$ in feed, breakthrough time and the amount of sorbent used.

MCRH-27 : A mixed oxide sorbent (designated MCRH-27) was prepared by the same procedure as MCRH-1 in page 13. The SEM morphology of the MCRH-27 fresh sorbent is depicted in Figure 24. In tests with MCRH-27 sorbent conducted at $427^{\circ} \mathrm{C}$, with a sulfidation gas containing (vol \%) $10 \mathrm{H}_{2}, 15 \mathrm{CO}, 5 \mathrm{CO}_{2}, 1 \mathrm{H}_{2} \mathrm{~S}, 15 \mathrm{H}_{2} \mathrm{O}$, balance $\mathrm{N}_{2}$, the sorbent conversion at breakthrough was 90 percent. As shown in Figure 25, the pre-breakthrough $\mathrm{H}_{2} \mathrm{~S}$ level was below $80 \mathrm{ppm}$. The sulfur capacities of the MCRH-27 sorbent during cycles 4 was $23.73 \mathrm{gS} / 100 \mathrm{~g}$ of sorbent. Sulfur capacity is calculated using the concentration of $\mathrm{H}_{2} \mathrm{~S}$ in feed, breakthrough time and the amount of sorbent used.

MCRH-31: A mixed oxide sorbent (designated MCRH-31) was prepared by the same 


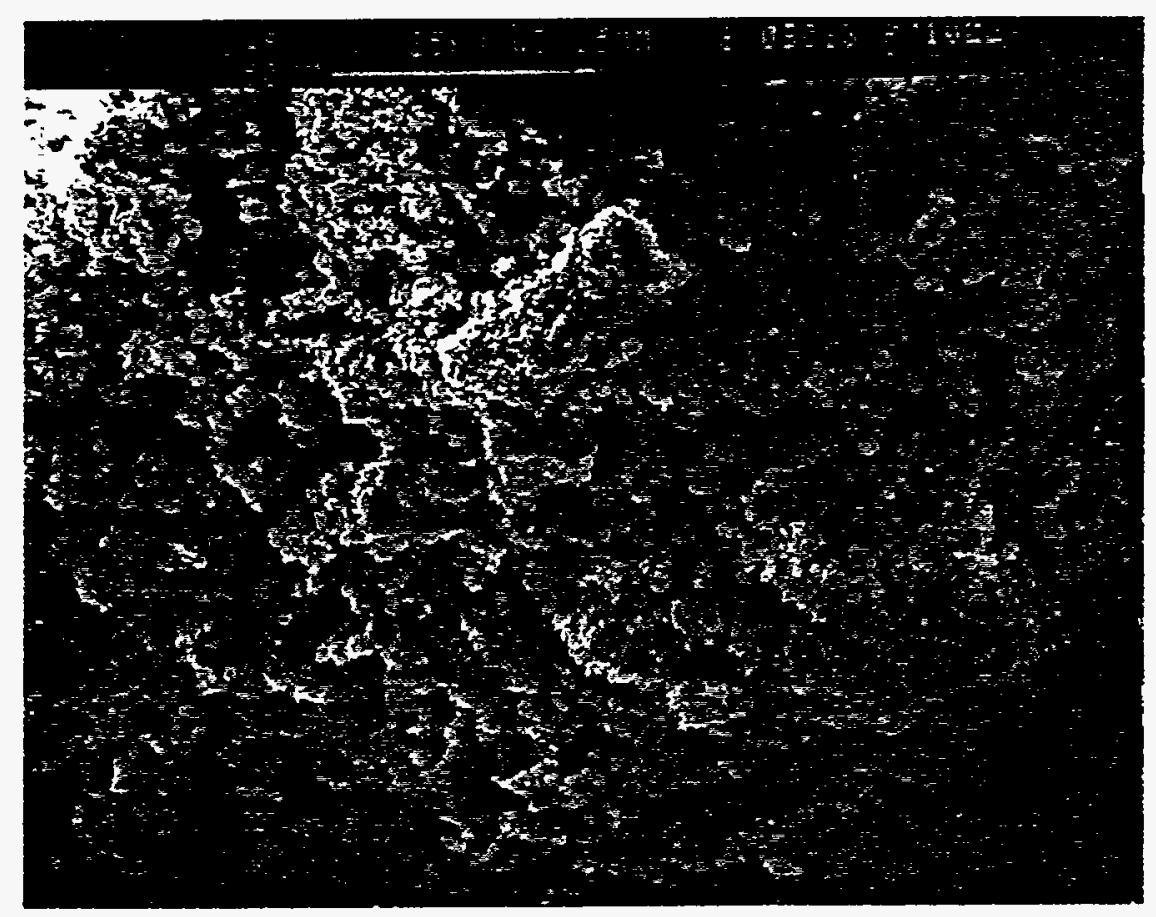

Figure 21. SEM Micrographs of MCRH-25 Fresh Sorbent 


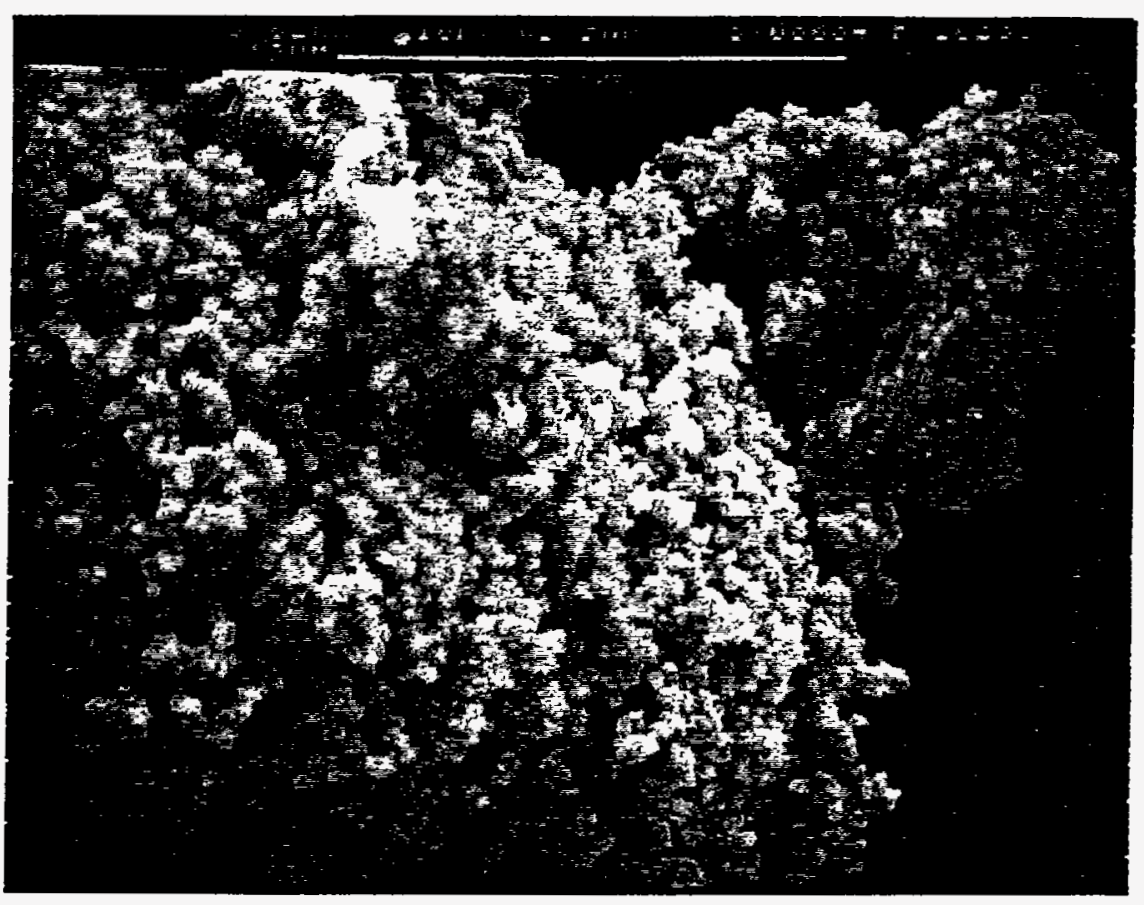

Figure 22. SEM Micrographs of MCRH-26 Fresh Sorbent 


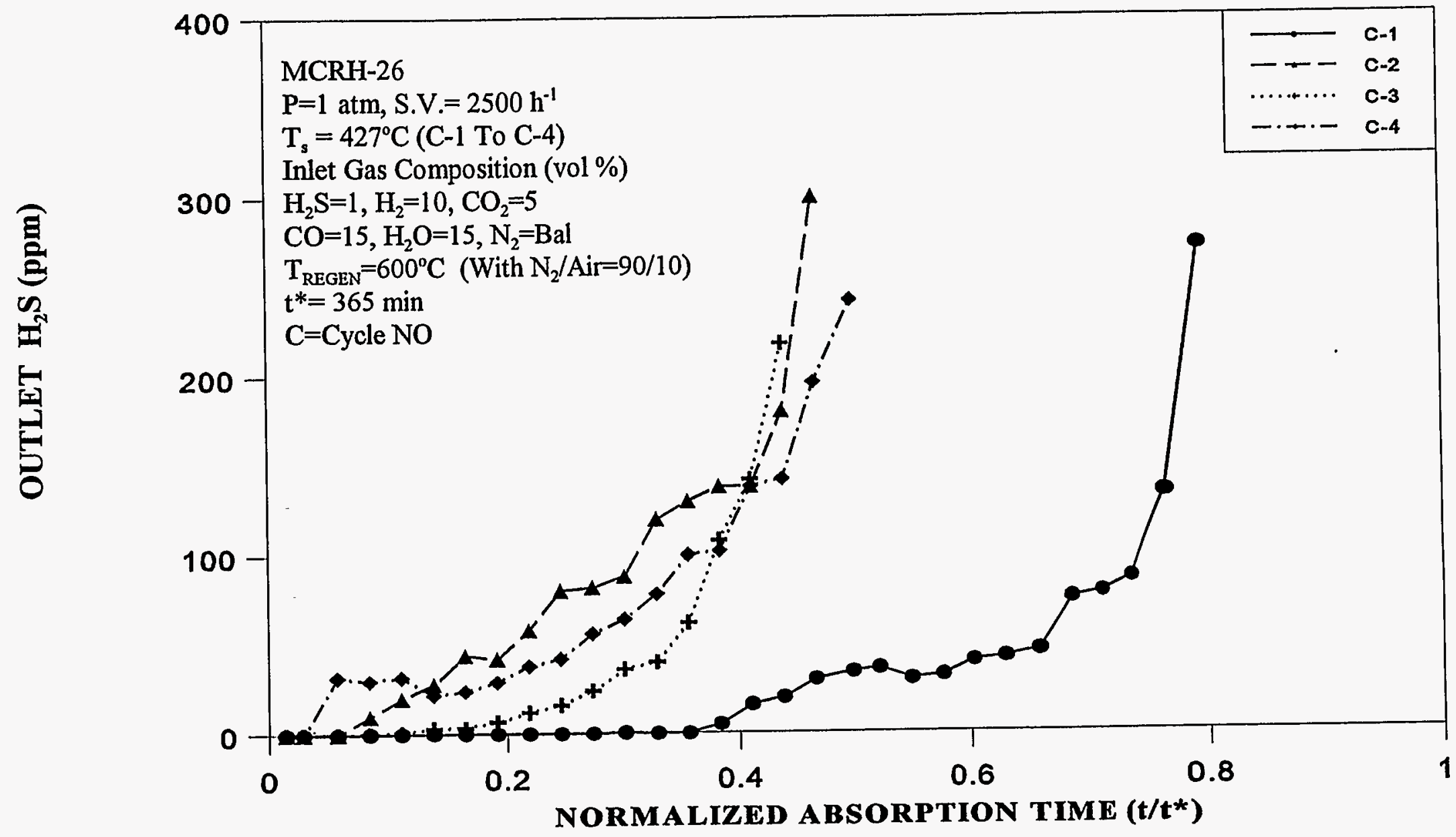

Figure 23. $\mathrm{H}_{2} \mathrm{~S}$ Breakthrough Curves in Successive Sulfidation Cycles of MCRH-26 Sorbent 


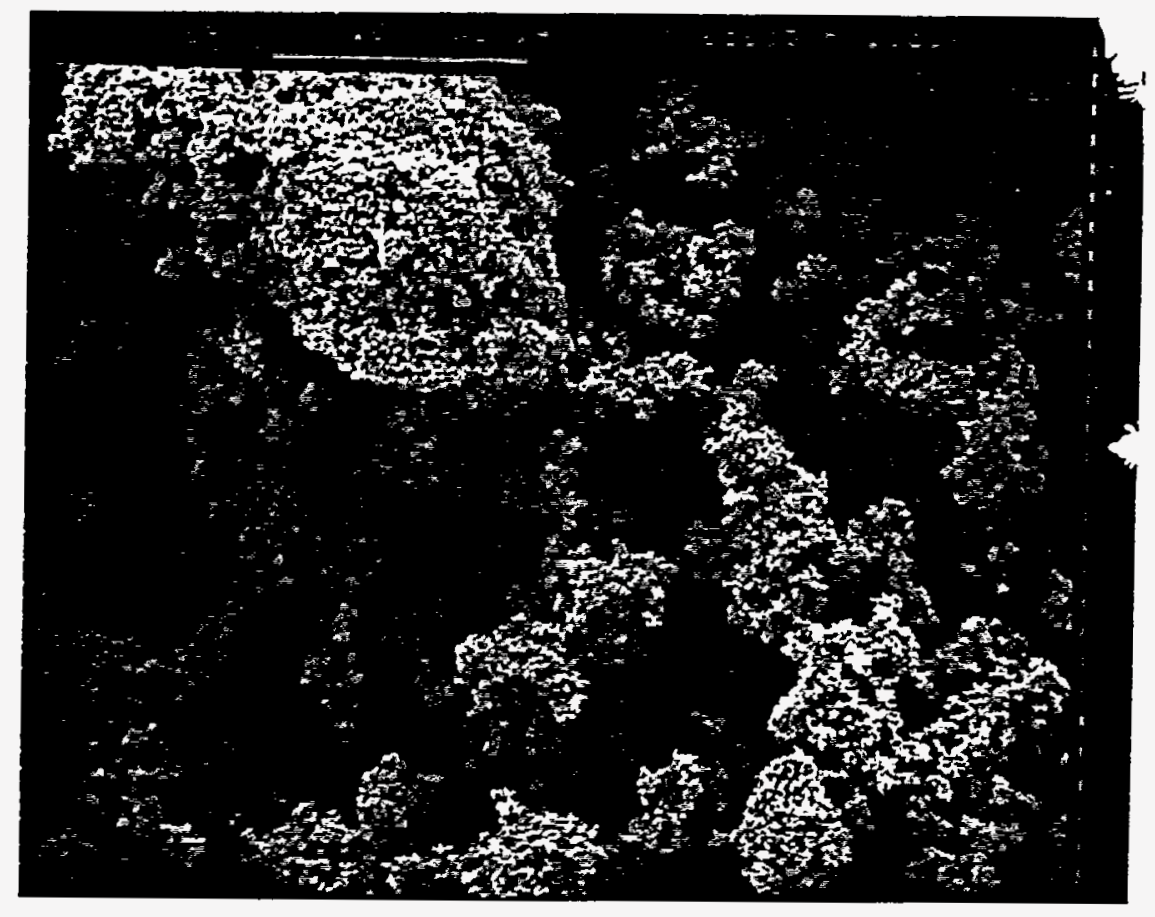

Figure 24. SEM Micrographs of MCRH-27 Fresh Sorbent 


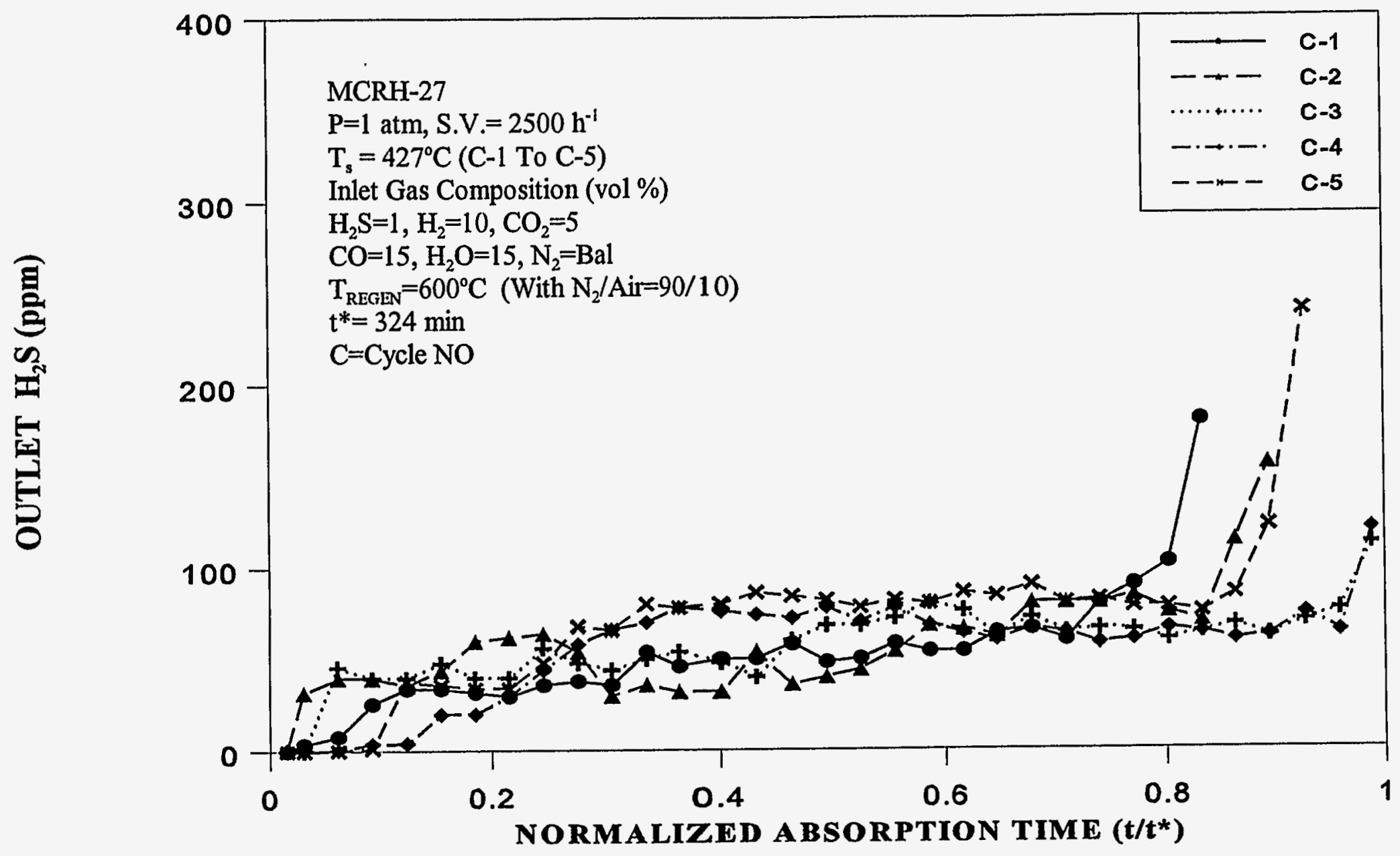

Figure 25. $\mathrm{H}_{2} \mathrm{~S}$ Breakthrough Curves in Successive Sulfidation Cycles of MCRH-27 Sorbent 
procedure as $\mathrm{MCRH}-1$ in page 13 . In tests with $\mathrm{MCRH}-31$ sorbent conducted at $427^{\circ} \mathrm{C}$, with a sulfidation gas containing(vol \%) $10 \mathrm{H}_{2}, 15 \mathrm{CO}, 5 \mathrm{CO}_{2}, 1 \mathrm{H}_{2} \mathrm{~S}, 15 \mathrm{H}_{2} \mathrm{O}$, balance $\mathrm{N}_{2}$, the sorbent conversion at breakthrough was 90 percent. As shown in Figure 26, the pre-breakthrough $\mathrm{H}_{2} \mathrm{~S}$ level was below $50 \mathrm{ppm}$.

\section{LIGHT-OFF}

Regeneration light-off temperatures of the sorbents are considered as one of the important parameters for sorbent performance evaluation because problems of decrepitation and spalling have occurred after sulfidation and regeneration of the sorbents. Measurements of surface area, structure, porosity, and acidity of the sorbents can be related to the sorbent performance. For sorbents, however, one direct measurement of its performance is to determine its light-off temperature, the temperature at which significant regeneration reactions occur. In general, it is true that the lower the light-off temperature, the more effective will be the sorbent performance. In this study research focused towards adding catalyst additives to zinc-based sorbents to reduce the regeneration light-off temperature to prevent sulfate formation. Experiments are carried out to find the regeneration light-off temperature of the zinc-based sorbents using both fixed and fluidized bed reactors.

A range of zinc based samples were prepared by doping with other metal ions during precipitation. These were required for investigation of the catalytic activity of the metal and to reduce the regeneration light-off temperature to prevent sulfate formation. The doped and undoped zinc based sorbents were evaluated by a two-step test procedure. In the first step, the sorbents were sulfided using a simulated gas at $427^{\circ} \mathrm{C}$, until the breakthrough. In the second step, 


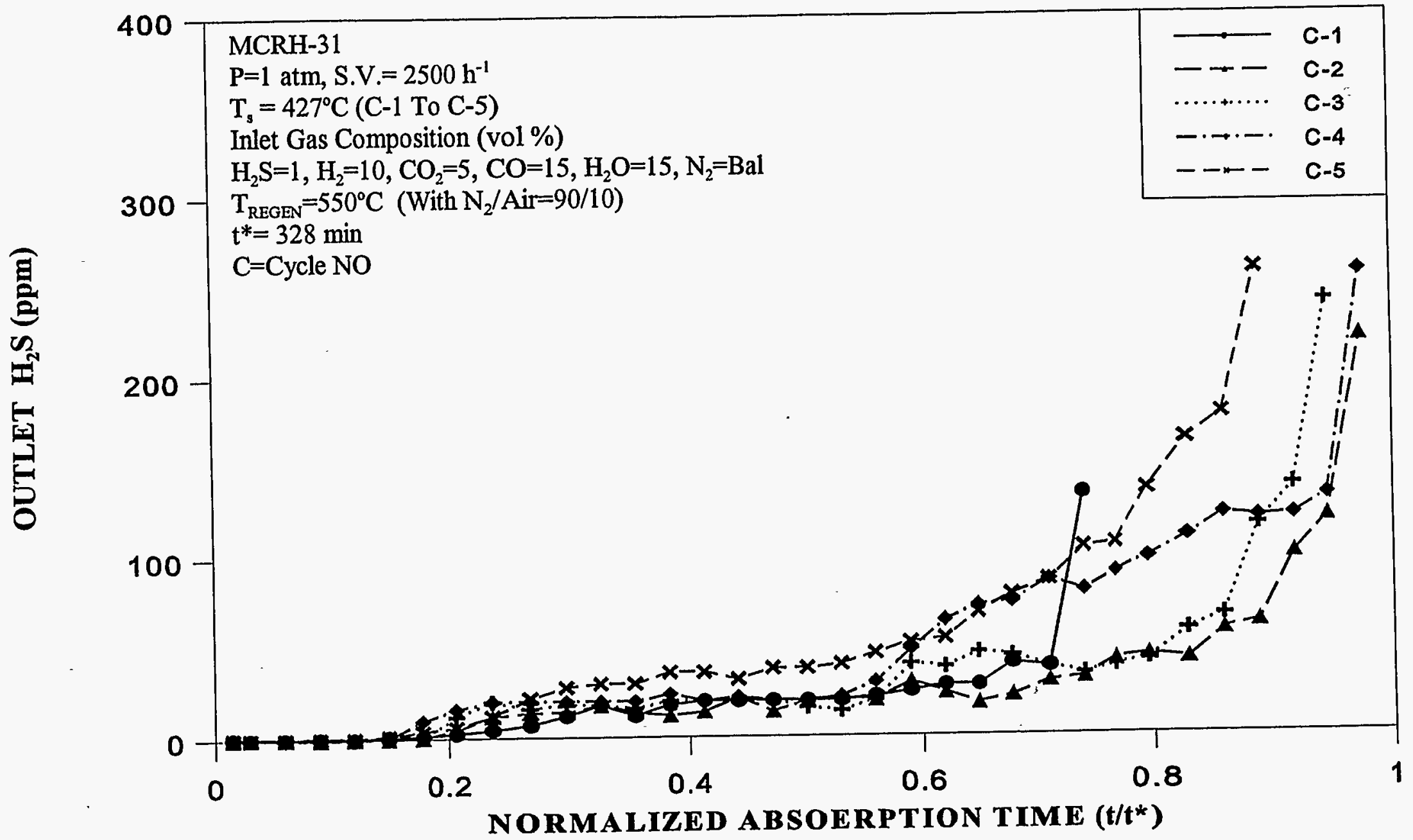

Figure 26. $\mathrm{H}_{2} \mathrm{~S}$ Breakthrough Curves in Successive Sulfidation Cycles of MCRH-31 Sorbent 
the sulfided sorbents were regenerated with $2 \% \mathrm{O}_{2}$ in nitrogen. The reactant gas mixture was introduced into the reactor at about $450^{\circ} \mathrm{C}$ and the reaction temperature was raised in $50^{\circ} \mathrm{C}$ increments after a steady-state condition was reached at each temperature. The regeneration light-off temperature was thus identified at which the reaction occurred with $\mathrm{ZnS}$ conversion to $\mathrm{ZnO}$ exceeding $90 \%$. The light-off temperatures were found to be a strong function of the sorbents that were modified by doping with different metal as shown in Figure 27 and 28 . A light-off temperature of $650^{\circ} \mathrm{C}$ was found for unmodified zinc based sorbents. Thus, addition of metal catalysts significantly lowered the light-off temperature of zinc based sorbents. These results were also confirmed using the TGA. The regeneration light-off temperature for various sorbents tested are shown in Table 2

Table 2. Regeneration Light-off Temperature for MCRH Sorbents

\begin{tabular}{|l|l|}
\hline SORBENT & LIGHT-OFF T ${ }^{\circ}(\mathrm{C})$ \\
\hline MCRH-10 & $650^{\circ} \mathrm{C}$ \\
MCRH-14 & $600^{\circ} \mathrm{C}$ \\
MCRH-18 & $600^{\circ} \mathrm{C}$ \\
MCRH-23 & $600^{\circ} \mathrm{C}$ \\
MCRH-24 & $650^{\circ} \mathrm{C}$ \\
MCRH-25 & $500^{\circ} \mathrm{C}$ \\
MCRH-26 & $600^{\circ} \mathrm{C}$ \\
MCRH-27 & $550^{\circ} \mathrm{C}$ \\
MCRH-29 & $600^{\circ} \mathrm{C}$ \\
MCRH-30 & $550^{\circ} \mathrm{C}$ \\
MCRH-31 & $600^{\circ} \mathrm{C}$ \\
\hline
\end{tabular}

Since the MCRH-25 sorbent showed excellent sulfidation and regeneration behavior in the 100 cycle test (as will be discussed in the multicycle section), it was decided to investigate the feasibility of low temperature regeneration, at about $500^{\circ} \mathrm{C}$. The low temperature regeneration capability of the sorbent is required for Kellogg's transport reactor application. The MCRH-25 sorbent was evaluated in a bubbling fluidized-bed mode. The following paragraphs provide the 


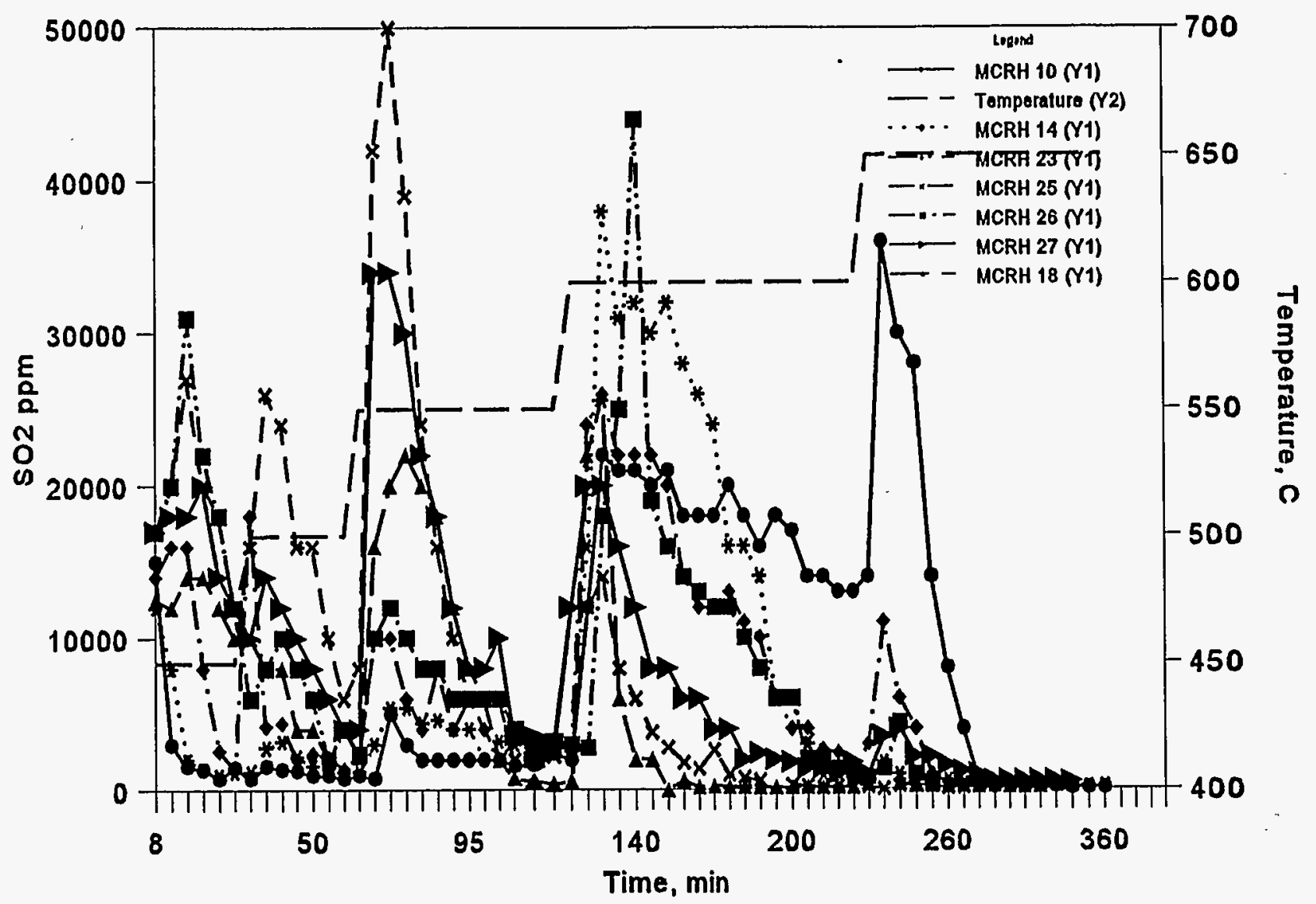

Figure 27. Regeneration Light-Off Temperature for MCRH Sorbents 


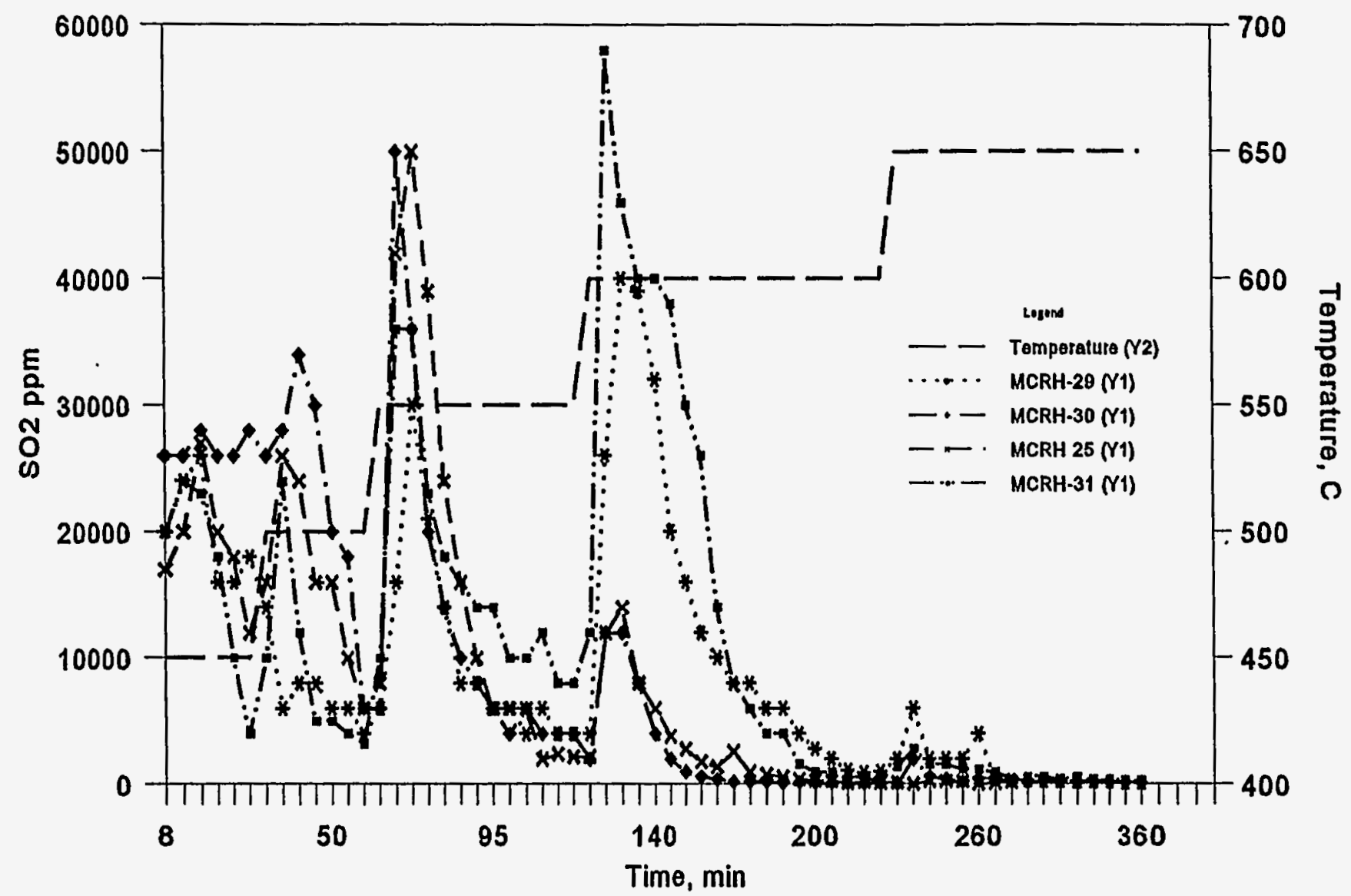

Figure 28. Regeneration Light-Off Temperature for MCRH Sorbents 
detailed description of the experimental system and procedure.

The MCRH-25 sorbent was evaluated in an atmospheric quartz fludized-bed bench-scale unit at RTI (Figure 29). The fludized-bed reactor is a quartz tube (26 mm I.D. and $100 \mathrm{~cm}$ long) separated by a coarse quartz frit located midway in the tube. The sorbent powder is supported on the quartz frit. The section below the frit (lower section of the reactor which is $50 \mathrm{~cm}$ long) is packed with quartz rings (approximately $0.5 \mathrm{~cm}$ diameter and $0.7 \mathrm{~cm}$ long). The reactor is heated by an electric furnace.

During sulfidation, the coal gas source is a tank consisting of premixed gases, namely, $49.8 \% \mathrm{H}_{2}, 23.4 \% \mathrm{CO}_{2}, 13.4 \% \mathrm{CO}, 12 \% \mathrm{~N}_{2}$ and $1.4 \% \mathrm{H}_{2} \mathrm{~S}$. Steam is generated by feeding water through a syringe pump. Desired composition of coal gas $\left(44.3 \% \mathrm{H}_{2}, 20.8 \% \mathrm{CO}_{2}, 11.9 \% \mathrm{CO}\right.$, $11.05 \% \mathrm{H}_{2} \mathrm{O}, 10.7 \% \mathrm{~N}_{2}$, and $1.25 \% \mathrm{H}_{2} \mathrm{~S}$ ) is obtained by feeding metered quantity of dry coal gas and water at the reactor bottom. During regeneration, desired concentration of $\mathrm{O}_{2}$ is obtained by feeding metered quantities of $\mathrm{N}_{2}$ and air.

The effluent gas from the sorbent bed is passed through a condenser, where the steam is condensed and collected in a catch pot. The coolant in the condenser is maintained at $5^{\circ} \mathrm{C}$ using a chiller. During sulfidation, the effluent gas after the condenser catch pot is directly vented to the hood without measuring the reactor outlet $\mathrm{H}_{2} \mathrm{~S}$ concentration. However, during regeneration, the effluent gas after the catch pot is analyzed using a Western Research $\mathrm{SO}_{2}$ Analyzer (Model 721AT) and the $\mathrm{O}_{2}$ concentration by using a Teledyne Trace $\mathrm{O}_{2}$ Analyzer. The dead volume of the catch pot creates a lag time in detecting the $\mathrm{SO}_{2}$ and $\mathrm{O}_{2}$ concentration in the reactor exit gas.

Typical experiment consisted of loading the reactor with $17.5 \mathrm{~g}$ of MCRH-25 sorbent and heating the sorbent bed in $\mathrm{N}_{2}$. After the bed reached $427^{\circ} \mathrm{C}, 900 \mathrm{sccm}$ of coal gas (of 


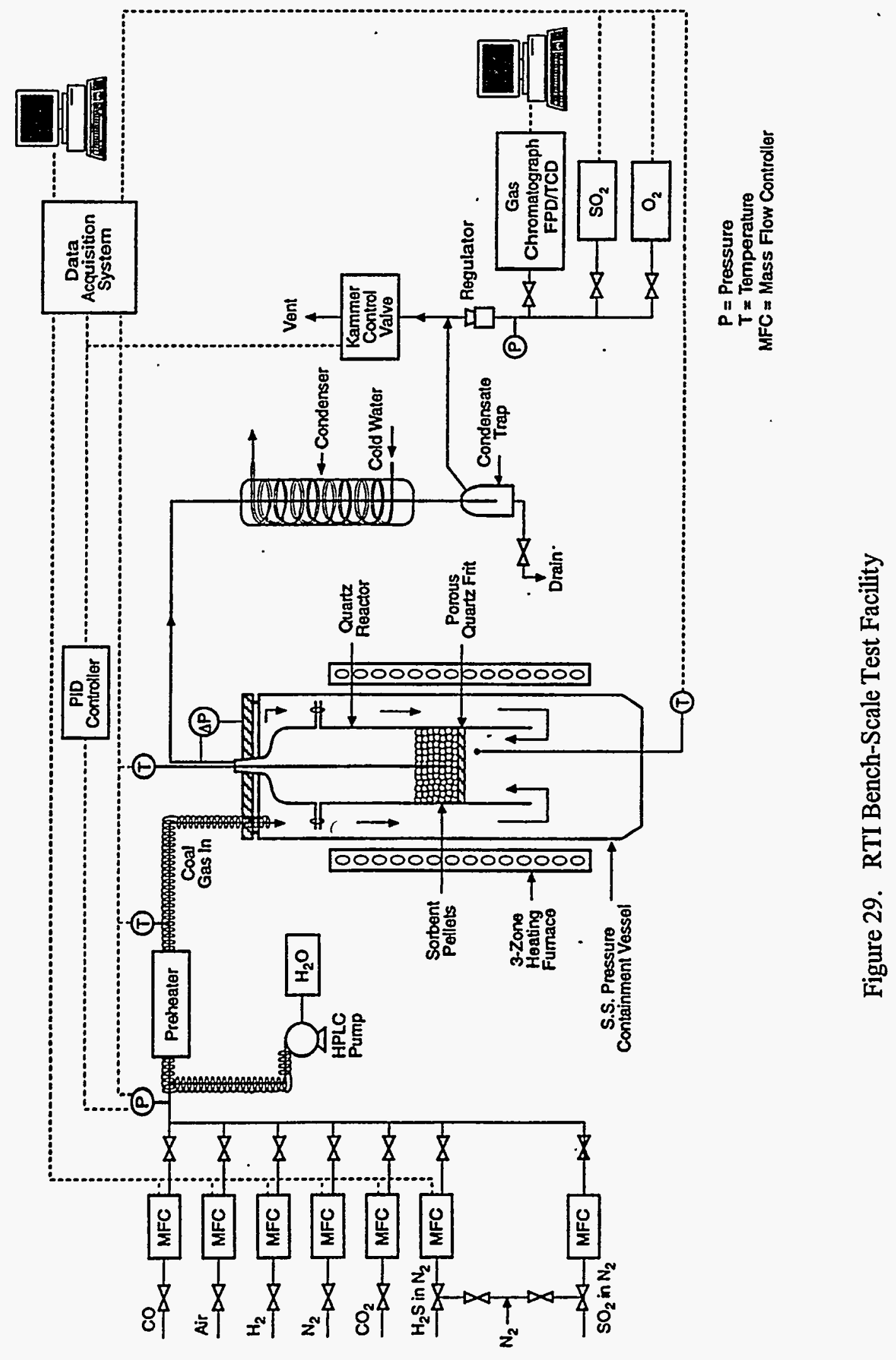


composition as given above) was passed for $4 \mathrm{~h}$. After sulfidation, the reactor was purged with $\mathrm{N}_{2}$ for about 10 minutes before initiating sorbent regeneration.

During regeneration, $500 \mathrm{sccm}$ of approximately 3 vol. $\% \mathrm{O}_{2}$ gas was fed to the reactor, but the bed temperature was varied based on the $\mathrm{SO}_{2} / \mathrm{O}_{2}$ concentration in the exit gas. The regeneration was started at an initial low temperature of $475-525^{\circ} \mathrm{C}$. However, at the onset of decrease in $\mathrm{SO}_{2}$ concentration in the exit gas (or at the onset of $\mathrm{O}_{2}$ breakthrough), the bed temperature was increased by about $25^{\circ} \mathrm{C}$. The bed temperature was increased to sustain the regeneration and/or to decompose the sulfates formed. This increase in bed temperature by $25^{\circ} \mathrm{C}$ at the onset of decrease in $\mathrm{SO}_{2}$ concentration was continued till the bed temperature reached $625^{\circ} \mathrm{C}$. At $625^{\circ} \mathrm{C}$, the regeneration was continued until $\mathrm{O}_{2}$ breakthrough occurred, following which the bed was cooled under $\mathrm{N}_{2}$ flow.

The sorbent was subjected to sulfidation and regeneration cycle testing. The regeneration was started at $475^{\circ} \mathrm{C}$ (Figure 30). As seen in Figure 30, the results clearly show that the sulfided sorbent can be ignited at temperatures as low as $475^{\circ} \mathrm{C}$. Also, any sulfate that forms at these low temperatures is the basic, easy to decompose sulfate. These results confirms our TGA results.

\section{Attrition-Resistant Sorbents}

This section describes the efforts directed towards the development of sorbents for fluidized-bed reactors. The Sierra-Pacific plant employs the M.W.Kellogg (Kellogg) circulating fluidized-bed (transport) HGD process whereas the TECO plant employs the General Electric (GE) moving-bed HGD process. The key barrier issues facing the successful development of a fluidized-bed HGD process are chemical degradation, physical attrition, high regeneration light- 
D. asnฺesadual

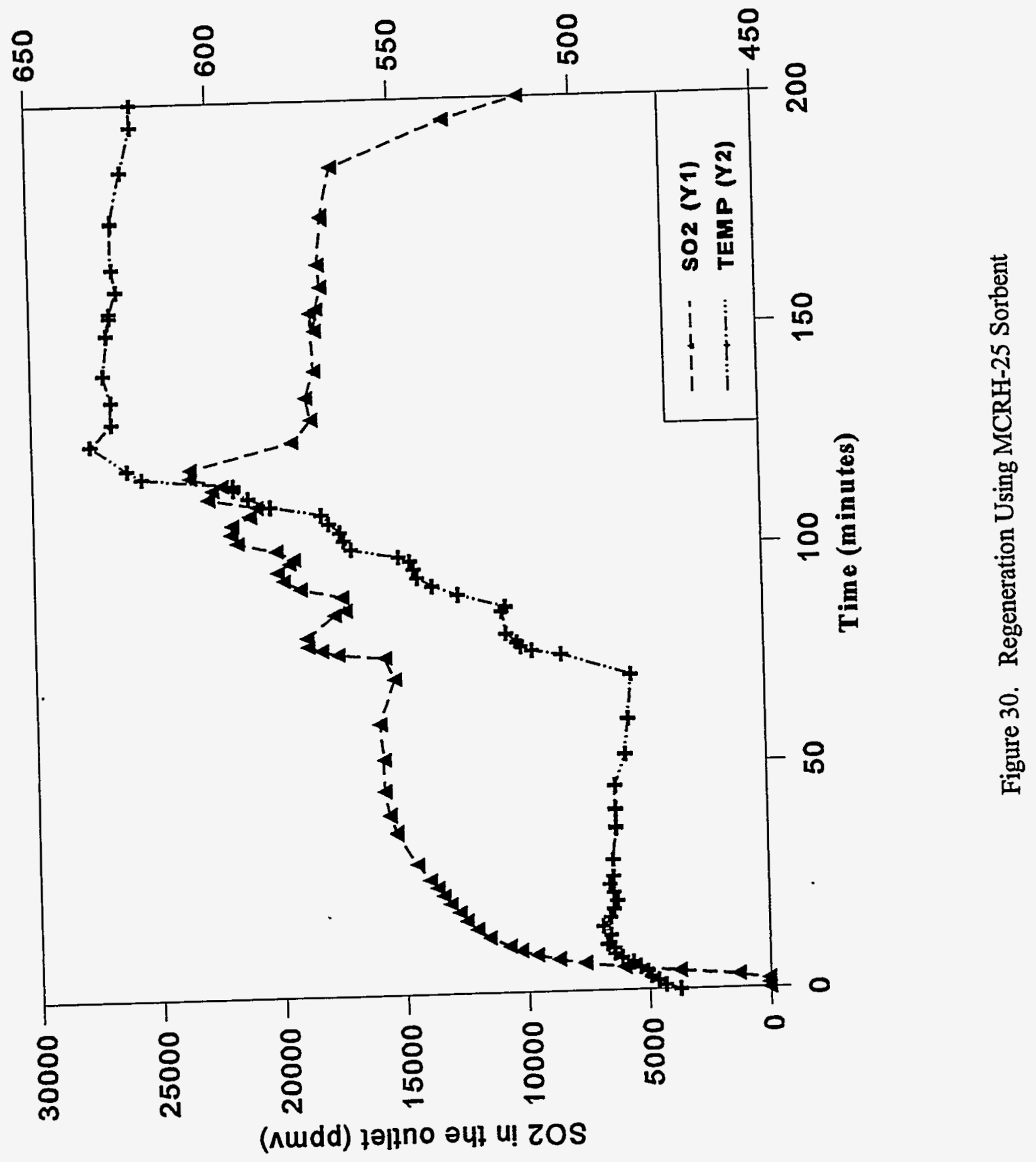


off (initiation) temperature compared to sulfidation temperature, and high cost of the sorbent. Current leading first generation sorbents such as zinc titanate (ZT-4) typically prepared with an average particle size (aps) of $170 \mu \mathrm{m}$ using a granulator and Phillips Petroleum's Z-Sorb III (175 $\mu \mathrm{m}$ aps) undergo significant chemical degradation, losing their reactivity and capacity by as much as $50 \%$ in just 50 cycles and they cost as much as $\$ 8-10$ per $\mathrm{lb}$. These sorbents also have very low attrition resistance compared to bench-mark fluid catalytic cracking (FCC) catalysts (70-80 $\mu \mathrm{m}$ aps) prepared by spray drying and employed in a petroleum refinery. The larger aps of 170 $\mu \mathrm{m}$ results in reduced entrainment and allows greater throughput and flexibility in the choice of reactor type, but has not to date been successfully made using a spray drier. Also, the regeneration light-off temperature of first generation zinc titanate sorbents is around $630-650^{\circ} \mathrm{C}$, which is unacceptably higher than the $480-550^{\circ} \mathrm{C}$ sulfidation temperature being employed at Sierra. To allow efficient heat integration, the sulfidation and regeneration light-off temperatures need to be the same or quite close to each other.

Fluidized-bed HGD systems are also receiving a lot of emphasis due to several potential advantages over fixed- and moving-bed reactors, including excellent gas solid contact, fast kinetics, pneumatic transport, ability to handle particles in the gas, and ability to control the highly exothermic regeneration process. However, an attrition-resistant sorbent that can withstand stresses induced by fluidization, transport, chemical transformation, and rapid temperature swings must be developed.

MCRH-39 : A zinc oxide-based fluidizable sorbent was prepared, using a proprietary technique with proprietary binders. The sorbent was dried at $120^{\circ} \mathrm{C}$ and then calcined in an oxygen- 
containing atmosphere at $600^{\circ} \mathrm{C}$ for 2 hours.

As shown in Figure 31, two cycles of sulfidation and regeneration were carried out in a bench-scale reactor over the resultant sorbent. The sulfidation was carried out with $85 \%$ of coal gas (containing $0.6 \% \mathrm{H}_{2} \mathrm{~S}, 12 \% \mathrm{H}_{2}, 18 \% \mathrm{CO}, 6 \% \mathrm{CO}_{2}$, and balance $\mathrm{N}_{2}$ ) and $15 \%$ steam with 180 sccm total flow at $450^{\circ} \mathrm{C}$. Regeneration of the sorbent to convert $\mathrm{ZnS}$ to $\mathrm{ZnO}$ was carried out with $3 \% \mathrm{O}_{2}$ and balance $\mathrm{N}_{2}$ at $600{ }^{\circ} \mathrm{C} .18$ grams of sorbent was used for these tests. The surface area of the fresh and sulfided samples were 104.9 and $95.8 \mathrm{~m}^{2} / \mathrm{g}$, respectively as shown in Table 3 .

The following results were found during the above tests. During the first cycle, the sulfidation was carried out for $31 \frac{1}{2}$ hours and no $\mathrm{H}_{2} \mathrm{~S}$ breakthrough was observed by gas chromatograph-flame photometric detector (GC-FPD). The sulfided sorbents were then purged with $\mathrm{N}_{2}$ for 30 minutes followed by regeneration at $600^{\circ} \mathrm{C}$. The regeneration was stopped after 75 minutes when the flue gas contained $\sim 2600 \mathrm{ppm}$ of $\mathrm{SO}_{2}$. The sorbents were then kept in $\mathrm{N}_{2}$ and cooled to $450^{\circ} \mathrm{C}$ overnight. The second cycle was started the following morning. The $\mathrm{H}_{2} \mathrm{~S}$ breakthrough was undetectable for the first 2 hours and 45 minutes. Then, the $\mathrm{H}_{2} \mathrm{~S}$ concentration increased fast and reached $350 \mathrm{ppm}$ after 3 hours and 30 minutes on stream.

These results demonstrate that very high sulfur removal efficiency can be achieved with this $\mathrm{ZnO}$ based sorbent prepared in this project. It is particularly noteworthy that $\mathrm{H}_{2} \mathrm{~S}$ remained undetectable prior to initial breakthrough, which indicates that the sorbent has a high reactivity and retains a high reactivity following regeneration.

Table 3. BET Surface Area of the Attrition-Resistant MCRH Sorbents

\begin{tabular}{|l|l|}
\hline Sorbent & $\begin{array}{l}\text { BET Surface } \\
\text { Area, } \mathrm{m}^{2} / \mathrm{g}\end{array}$ \\
\hline MCRH-39 (F) & 104.9 \\
\hline
\end{tabular}




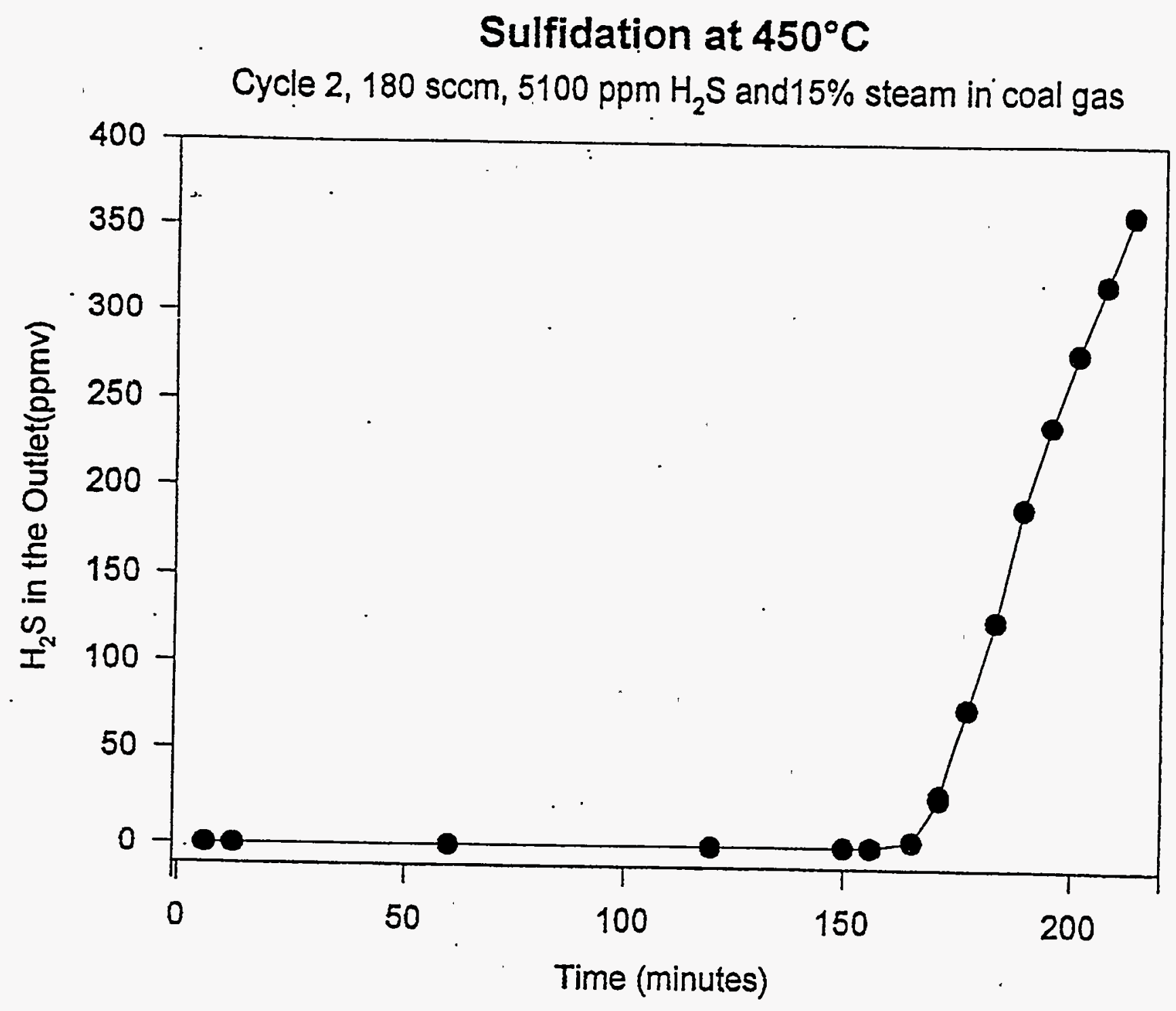

Figure 31. $\mathrm{H}_{2} \mathrm{~S}$ Breakthrough Curves in Successive Sulfidation Cycles of MCRH-39 Sorbent 


\begin{tabular}{|l|l|}
\hline MCRH-39 (S) & 95.8 \\
\hline MCRH-51 (F) & 79.4 \\
\hline MCRH-51 (S) & 63.1 \\
\hline MCRH-53 (F) & 78.6 \\
\hline MCRH-53 (S) & 71.9 \\
\hline MCRH-54 (F) & 82.1 \\
\hline MCRH-54 (S) & 71.5 \\
\hline MCRH-55 (F) & 99.8 \\
\hline MCRH-55 (R) & 90.8 \\
\hline MCRH-56 (F) & 100.9 \\
\hline MCRH-60 (F) & 101.2 \\
\hline MCRH-61 (F) & 102.9 \\
\hline
\end{tabular}

MCRH-51 : A fluidizable zinc oxide-based sorbent was prepared, using the proprietary technique. The sorbent was dried at $120^{\circ} \mathrm{C}$ and then calcined in an oxygen-containing atmosphere at $600^{\circ} \mathrm{C}$ for 2 hours.

A sulfidation test was then carried out on this sorbent with a sulfidation gas containing $10 \% \mathrm{H}_{2}, 15 \% \mathrm{CO}, 5 \% \mathrm{CO}_{2}, 0.4 \% \mathrm{H}_{2} \mathrm{~S}, 15 \% \mathrm{H}_{2} \mathrm{O}$, balance $\mathrm{N}_{2}$ (volume \%). As shown in Figure 32 , at $482^{\circ} \mathrm{C}$ sulfidation temperature, the stable conversion achieved by this sorbent was found to be $100 \%$, and the pre-breakthrough $\mathrm{H}_{2} \mathrm{~S}$ level in the desulfurized gas was found to be less than 100 ppm. Regeneration of this sorbent was conducted with 2 volume percent $\mathrm{O}_{2}$ in $\mathrm{N}_{2}$ at 550 ${ }^{\circ} \mathrm{C}$. Sulfidation and regeneration of the sorbent was repeated for a total of five cycles. The sorbent capacity and activity was stable for the 5 cycles it was tested for. The sulfur capacity of the sorbent was measured during cycle 4 and found to be $9.12 \mathrm{~g}$ (sulfur)/100 $\mathrm{g}$ of sorbent. The surface area of the fresh and sulfided samples were measured and found to be 79.4 and $63.1 \mathrm{~m}^{2} / \mathrm{g}$. 


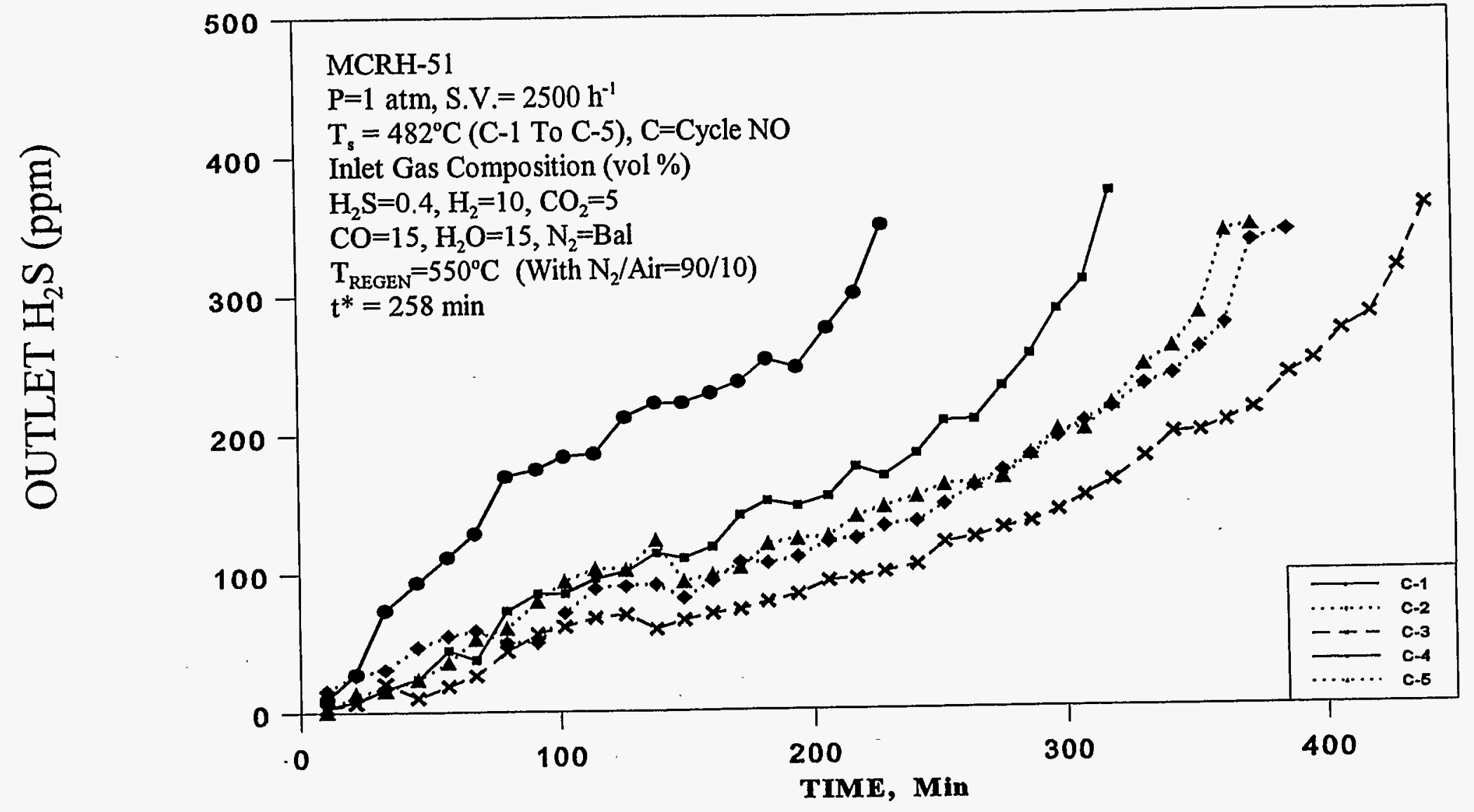

Figure 32. $\mathrm{H}_{2} \mathrm{~S}$ Breakthrough Curves in Successive Sulfidation Cycles of MCRH-51 Sorbent 
The 5 hour and 20 hour attrition loss of the fresh sorbent were tested and found to be 0.0 and $0.62 \mathrm{wt} . \%$, respectively in a standard 3-hole tester as shown in Table 4. The high stable conversion achieved by the sorbent of this example indicates rapid kinetics and little or no loss of surface area in successive cycles.

Table 4. Attrition Test of MCRH Sorbents

\begin{tabular}{|l|l|l|}
\hline \multirow{2}{*}{ Sorbent } & \multicolumn{2}{|l|}{ 3-hole attrition loss (wt \%) } \\
\cline { 2 - 3 } & 5 hour & 20 hour \\
\hline MCRH-51 & 0.00 & 0.62 \\
\hline MCRH-53 & 0.28 & 0.56 \\
\hline MCRH-54 & 0.36 & 0.36 \\
\hline MCRH-55 & 0.56 & 1.41 \\
\hline MCRH-56 & $\mathbf{0 . 0 0}$ & $\mathbf{1 . 0 6}$ \\
\hline ZT-4 & 40.00 & 89.00 \\
\hline Z-sorb III & 16.00 & 32.40 \\
\hline
\end{tabular}

MCRH-53 : $\quad$ A fluidizable zinc oxide-based sorbent was prepared, using the proprietary technique. The sorbent was dried at $120^{\circ} \mathrm{C}$ and then calcined in an oxygen-containing atmosphere at $600^{\circ} \mathrm{C}$ for 2 hours.

A sulfidation test was carried out on the resultant sorbent with a sulfidation gas containing $10 \% \mathrm{H}_{2}, 15 \% \mathrm{CO}, 5 \% \mathrm{CO}_{2}, 0.4 \% \mathrm{H}_{2} \mathrm{~S}, 15 \% \mathrm{H}_{2} \mathrm{O}$, balance $\mathrm{N}_{2}$ (volume \%). Regeneration of this sorbent was conducted with 2 volume percent $\mathrm{O}_{2}$ in $\mathrm{N}_{2}$ at $550^{\circ} \mathrm{C}$. Sulfidation and regeneration were repeated for a total of five cycles.

As shown in Figure 33, it was found that at $482^{\circ} \mathrm{C}$ sulfidation temperature, the stable conversion, i.e., sulfur removal, achieved by the sorbent was $100 \%$ and the pre-breakthrough $\mathrm{H}_{2} \mathrm{~S}$ 


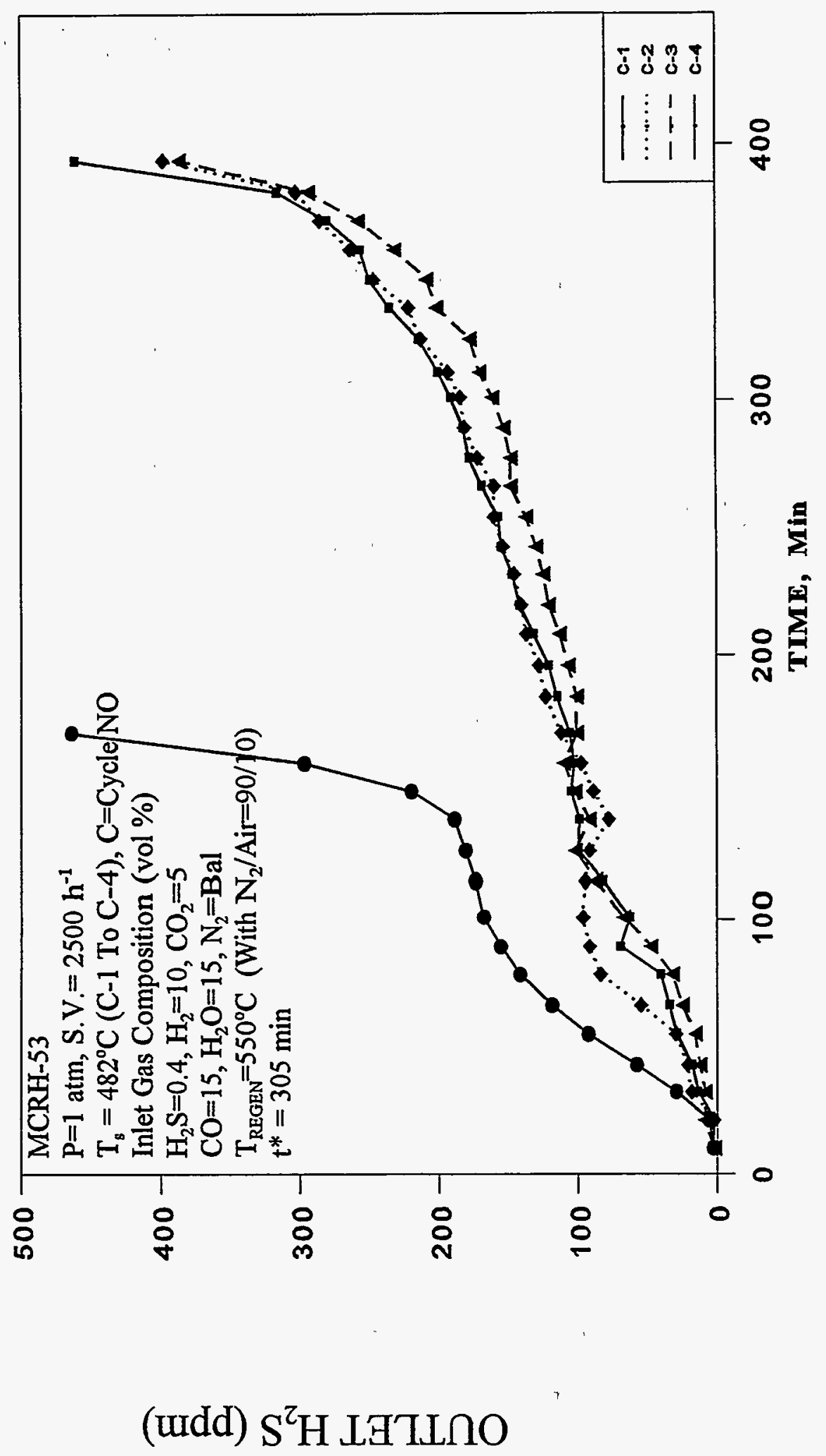

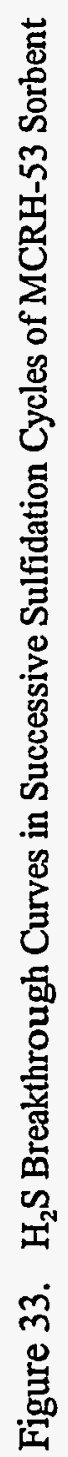


level was less than 100 ppmv. The high stable conversion indicates rapid kinetics and little or no loss of surface area in successive cycles. The sulfur capacities of the sorbent of this example was measured during cycle 4 and was found to be $10.43 \mathrm{~g}(\mathrm{~S}) / 100 \mathrm{~g}$ of sorbent. The activity and capacity of the sorbent were stable for all 5 cycles of the test. The surface area of the fresh and sulfided samples were found to be 78.6 and $71.9 \mathrm{~m}^{2} / \mathrm{g}$. The 5 hour and 20 hour attrition loss of the fresh sorbent were found to be 0.28 and $0.56 \mathrm{wt} . \%$, respectively, in a standard 3-hole tester as shown in Table 4.

MCRH-54: A zinc oxide-based fluidizable sorbent was prepared, using the proprietary technique. The sorbent was dried at $120^{\circ} \mathrm{C}$ and then calcined in an oxygen-containing atmosphere at $600^{\circ} \mathrm{C}$ for 2 hours.

A sulfidation test was carried out with a sulfidation gas containing $10 \% \mathrm{H}_{2}, 15 \% \mathrm{CO}, 5 \%$ $\mathrm{CO}_{2}, 0.4 \% \mathrm{H}_{2} \mathrm{~S}, 15 \% \mathrm{H}_{2} \mathrm{O}$, balance $\mathrm{N}_{2}$ (volume \%). Regeneration of this sorbent was conducted with 2 volume percent $\mathrm{O}_{2}$ in $\mathrm{N}_{2}$ at $550^{\circ} \mathrm{C}$. Sulfidation and regeneration were repeated to achieve a total of five cycles. As shown in Figure 34 , at $482^{\circ} \mathrm{C}$ sulfidation temperature, the stable conversion achieved by this sorbent was found to be $100 \%$ and the pre-breakthrough $\mathrm{H}_{2} \mathrm{~S}$ level was less than 100 ppmv. The high stable conversion indicates rapid kinetics and little or no loss of surface area in successive cycles. The sulfur capacities of this sorbent was measured during cycle 4 and was found to be $11.98 \mathrm{~g}(\mathrm{~S}) / 100 \mathrm{~g}$ of sorbent. The sorbent activity and capacity was stable for the 5 cycles of the test. The surface area of the fresh and sulfided samples were 82.1 and $71.5 \mathrm{~m}^{2} / \mathrm{g}$. The 5 hour and 20 hour attrition loss were 0.36 and $0.36 \mathrm{wt} . \%$, respectively, in a standard 3-hole tester as shown in Table 4. 


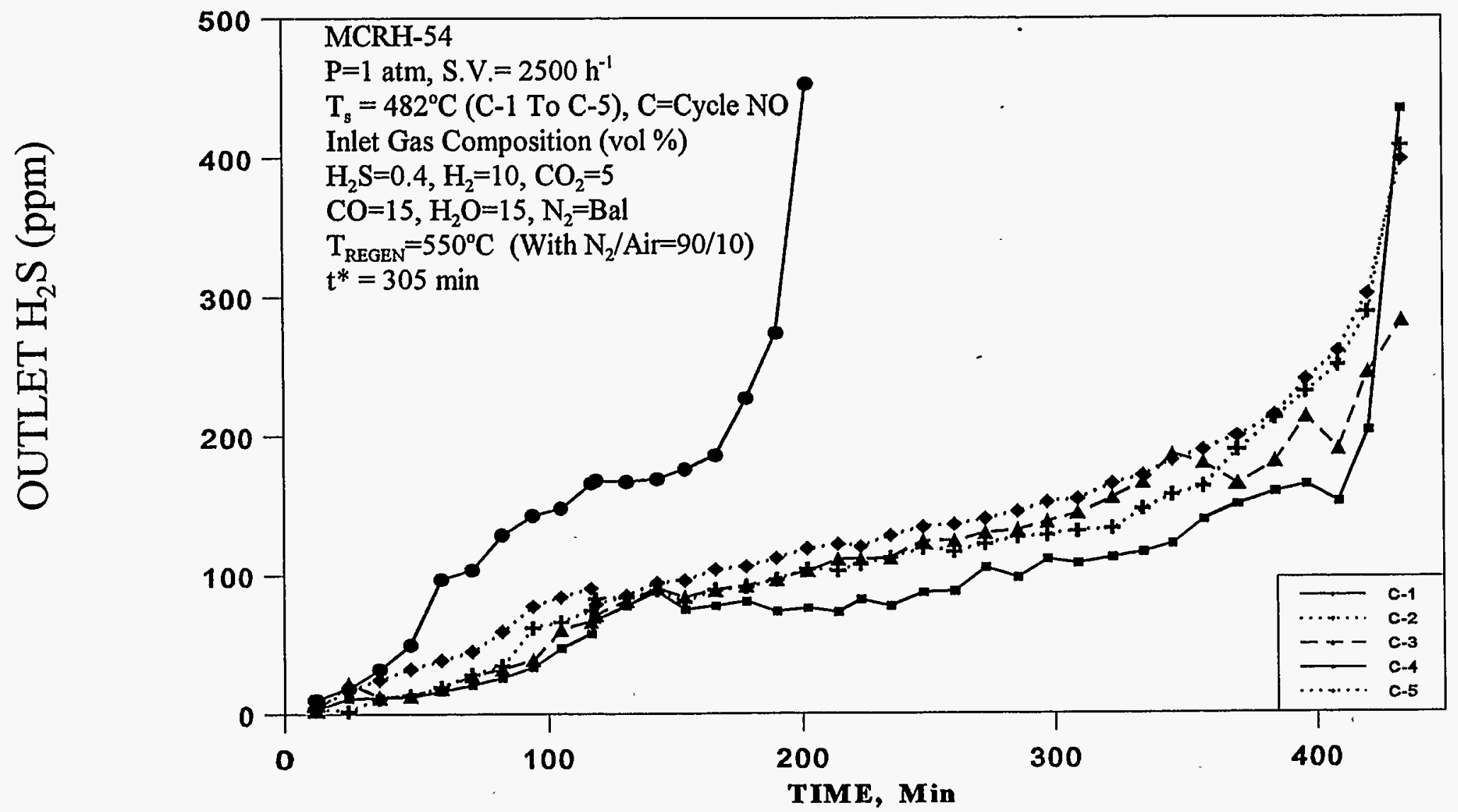

Figure 34. $\mathrm{H}_{2} \mathrm{~S}$ Breakthrough Curves in Successive Sulfidation Cycles of MCRH-54 Sorbent 
MCRH-55: A fluidizable zinc oxide-based sorbent was prepared, using the proprietary technique. The sorbent was dried at $120^{\circ} \mathrm{C}$ and then calcined in an oxygen-containing atmosphere at $600^{\circ} \mathrm{C}$ for 2 hours.

A sulfidation test was carried out with a sulfidation gas containing $10 \% \mathrm{H}_{2}, 15 \% \mathrm{CO}, 5 \%$ $\mathrm{CO}_{2}, 0.4 \% \mathrm{H}_{2} \mathrm{~S}, 15 \% \mathrm{H}_{2} \mathrm{O}$, balance $\mathrm{N}_{2}$ (volume \%). Regeneration of this sorbent was conducted with 2 volume percent $\mathrm{O}_{2}$ in $\mathrm{N}_{2}$ at $550^{\circ} \mathrm{C}$. Sulfidation and regeneration were repeated to achieve a total of five cycles.

As shown in Figure 35 , it was found that at $482^{\circ} \mathrm{C}$ sulfidation temperature, the stable conversion achieved by this sorbent was $100 \%$ and the pre-breakthrough $\mathrm{H}_{2} \mathrm{~S}$ level was less than 100 ppmv. The high stable conversion indicates rapid kinetics and little or no loss of surface area in successive cycles. The sulfur capacities of this sorbent was measured during cycle 4 and was $11.98 \mathrm{gS} / 100 \mathrm{~g}$ of sorbent. The sorbent activity and capacity was stable for the 5 cycles of the test. The surface area of the fresh and sulfided samples were 99.8 and $90.8 \mathrm{~m}^{2} / \mathrm{g}$. The 5 hour and 20 hour attrition loss were 0.56 and $1.41 \mathrm{wt} . \%$, respectively, in a standard 3-hole tester as shown in Table 4.

MCRH-56: A fluidizable zinc oxide-based sorbent was prepared, using the proprietary technique. The sorbent was dried at $120^{\circ} \mathrm{C}$ and then calcined in an oxygen-containing atmosphere at $600^{\circ} \mathrm{C}$ for 2 hours.

A sulfidation test was carried out with a sulfidation gas containing $10 \% \mathrm{H}_{2}, 15 \% \mathrm{CO}, 5 \%$ $\mathrm{CO}_{2}, 0.4 \% \mathrm{H}_{2} \mathrm{~S}, 15 \% \mathrm{H}_{2} \mathrm{O}$, balance $\mathrm{N}_{2}$ (volume \%). Regeneration of this sorbent was conducted with 2 volume percent $\mathrm{O}_{2}$ in $\mathrm{N}_{2}$ at $550^{\circ} \mathrm{C}$. Sulfidation and regeneration were repeated to achieve 


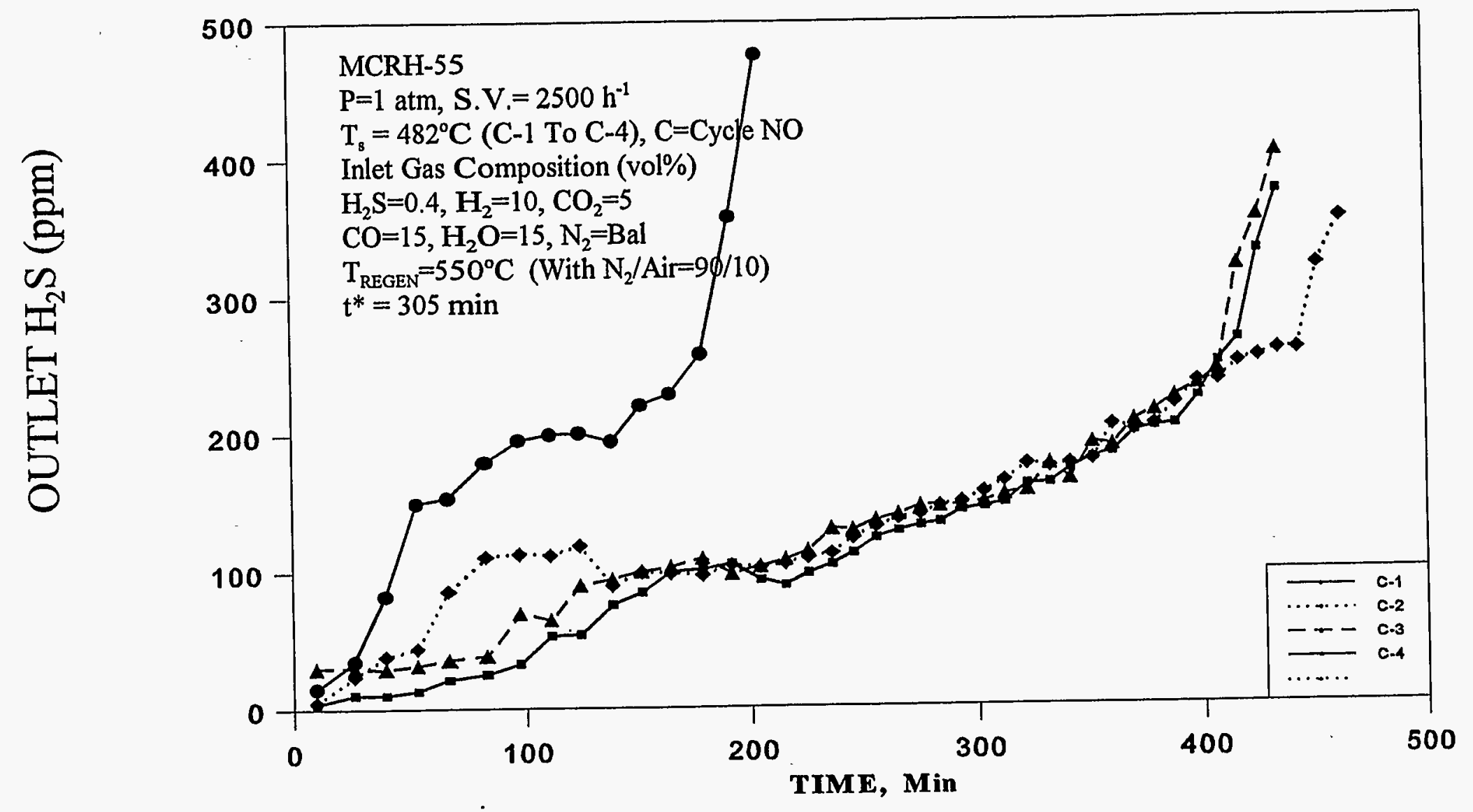

Figure 35. $\mathrm{H}_{2} \mathrm{~S}$ Breakthrough Curves in Successive Sulfidation Cycles of MCRH-55 Sorbent 
a total of five cycles.

As shown in Figure 36 , at $482^{\circ} \mathrm{C}$ sulfidation temperature, the stable conversion achieved by the sorbent was found to be $100 \%$ and the pre-breakthrough $\mathrm{H}_{2} \mathrm{~S}$ level was less than $100 \mathrm{ppm}$. The high stable conversion indicates rapid kinetics and little or no loss of surface area in successive cycles. The sulfur capacities of this sorbent was measured during cycle 4 and was found to be $10.52 \mathrm{~g}(\mathrm{~S}) / 100 \mathrm{~g}$ of sorbent. The sorbent capacity and activity was stable for the 5 cycles of the test. The surface area of the fresh sample was $100.9 \mathrm{~m}^{2} / \mathrm{g}$. The 5 hour and 20 hour attrition loss of the fresh sorbent were 0.0 and $1.1 \mathrm{wt} . \%$, respectively, in a standard 3-hole tester as shown in Table 4.

The extensive data base and analysis presented in sections 3.0 and 4.0 were used to guide the selection of the most promising $\mathrm{H}_{2} \mathrm{~S}$ sorbents for further studies under Task 3 . The criteria used for selection of the sorbents were, namely high $\mathrm{H}_{2} \mathrm{~S}$ removal efficiency and sulfur loading as low as at $343^{\circ} \mathrm{C}$ with a simulated coal gas, good performance regenerability with a lower light-off temperature, high attrition resistant and stable reactivity in cyclic operation.

\section{TASK 3. CYCLIC TESTING}

The ability of a sorbent to maintain its reactivity through a number of sulfidation/ regeneration is of paramount importance. The objective of the cyclic test was to determine how well the sulfidation performance of the sorbent was retained in many cycles of sulfidation/ regeneration experiments.

MCRH-25 sorbent was tested for 100 cycles of sulfidation in a laboratory scale reactor. Regeneration between cycles was conducted with 10 vol\% air-90 vol\% with $\mathrm{N}_{2}$ at $580^{\circ} \mathrm{C}$. The gas 


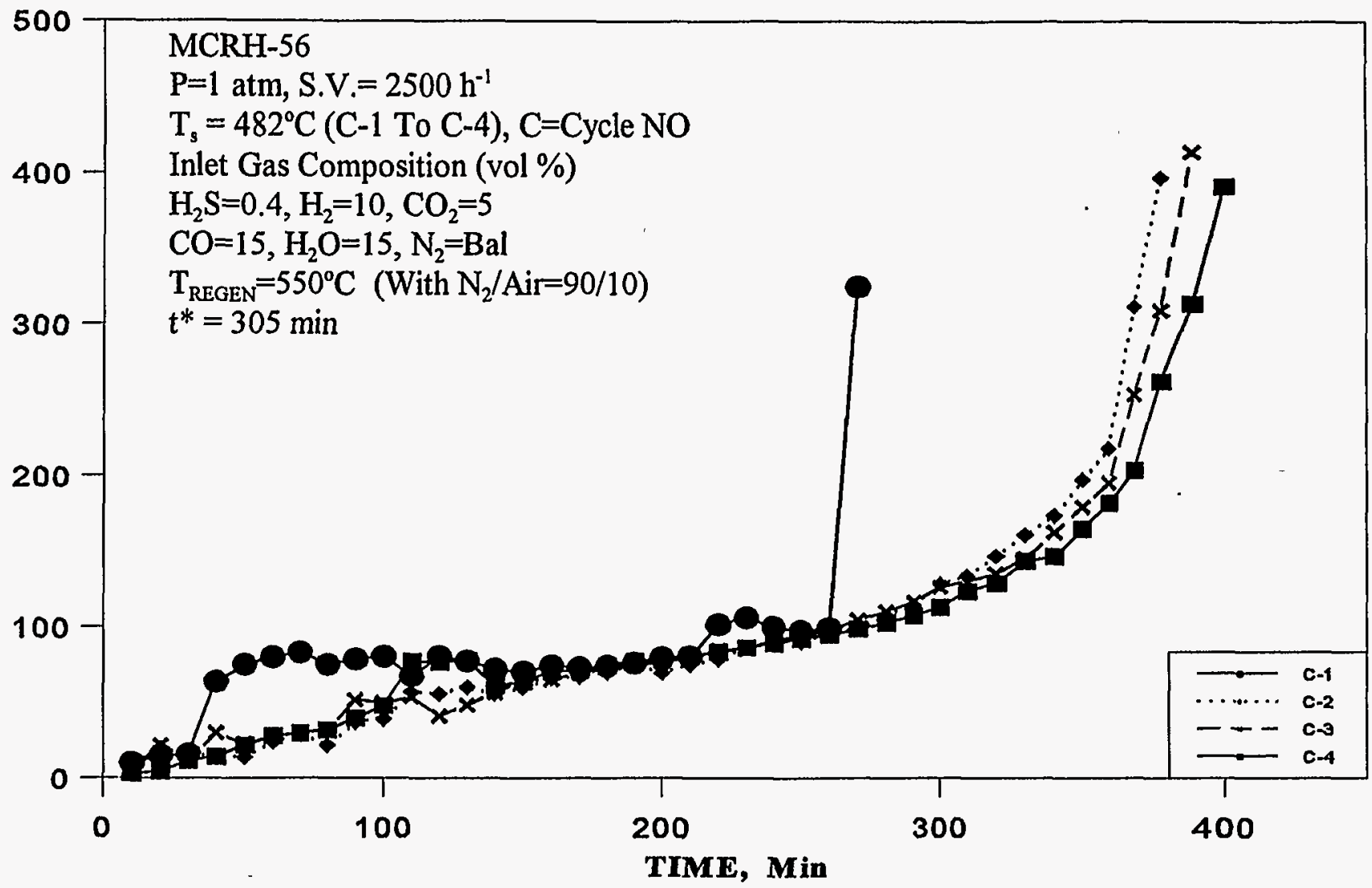

Figure 36. $\mathrm{H}_{2} \mathrm{~S}$ Breakthrough Curves in Successive Sulfidation Cycles of MCRH-56 Sorbent 
hourly space velocity was about $2500 \mathrm{~h}^{-1}$ (STP) both in sulfidation and in regeneration. Sulfidation tests were carried out with a sulfidation gas containing $10 \mathrm{~mol}_{\%} \mathrm{H}_{2}, 15 \mathrm{~mol} \% \mathrm{CO}, 5 \mathrm{~mol} \% \mathrm{CO}_{2}$, $1 \mathrm{~mol} \% \mathrm{H}_{2} \mathrm{~S}, 15 \mathrm{~mol} \% \mathrm{H}_{2} \mathrm{O}$ and balance $\mathrm{N}_{2}$. As shown in Figure 37, at $427^{\circ} \mathrm{C}$ sulfidation, for cycles 1 to 20 the pre-breakthrough conversion was between $80-90 \%$ and for cycles $21-30$ the conversion increased from 90 to $100 \%$ and remained constant at 100\% conversion up to the 100 cycles. There was no deactivation in $\mathbf{1 0 0}$ cycles in this fixed-bed study. The sulfur capacities of the MCRH-25 sorbent during cycles 1, 25, 50, 75 and 100 were 22.5, 27.7, 27.7, 27.7 and $27.7 \mathrm{gS} / 100 \mathrm{~g}$ of sorbent, respectively, again indicating a 100 percent capacity utilization even after 100 cycles. Sulfur capacity was calculated using the concentration of hydrogen sulfide in the feed, breakthrough time and the amount of sorbent used. The chemical reactivity is measured by using TGA for fresh, and 100 cycle regenerated sorbent. As shown in Figure 38, the TGA results indicated that the rate of sulfur pickup for the fresh and the 100 cycle used sorbent remained relatively constant. The interesting thing is that the reactivity of the 100 cycle used sorbent is higher in TGA results. This clearly explains the increase in breakthrough in the 100 cycle fixedbed study.

MCRH-60: A fluidizable zinc oxide-based sorbent was prepared, using the proprietary technique. The sorbent was dried at $120^{\circ} \mathrm{C}$ and then calcined in an oxygen-containing atmosphere at $600^{\circ} \mathrm{C}$ for 2 hours.

Figure 39 shows the breakthrough profiles for MCRH-60. This sorbent was modified to regenerate at temperatures as low as 475 to $525^{\circ} \mathrm{C}$. It was tested for 30 cycles of sulfidation in the laboratory-scale reactor. Regeneration between cycles was conducted with 2 volume percent 


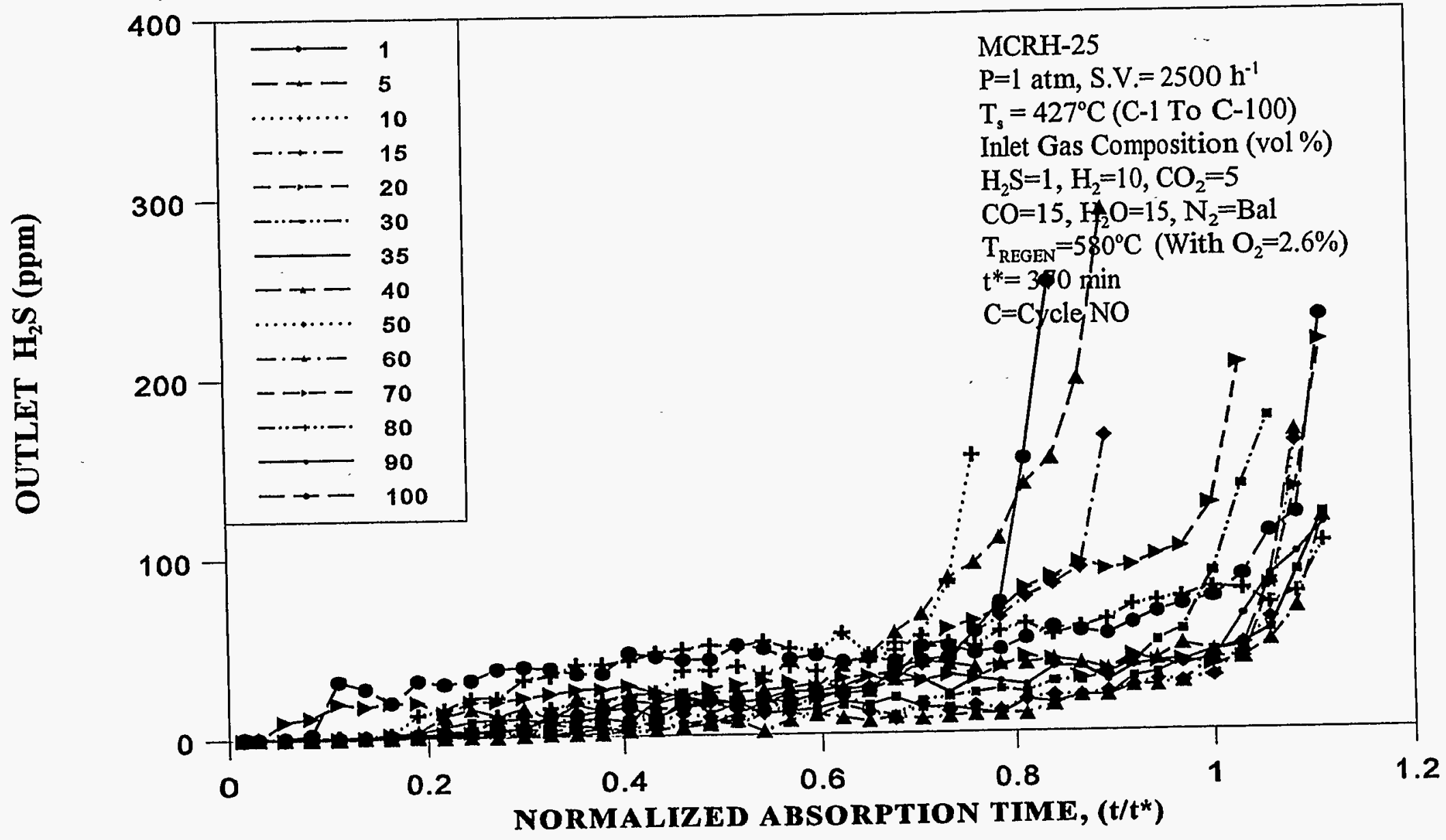

Figure 37. $\mathrm{H}_{2} \mathrm{~S}$ Breakthrough Curves in Successive Sulfidation Cycles of MCRH-25 Sorbent 


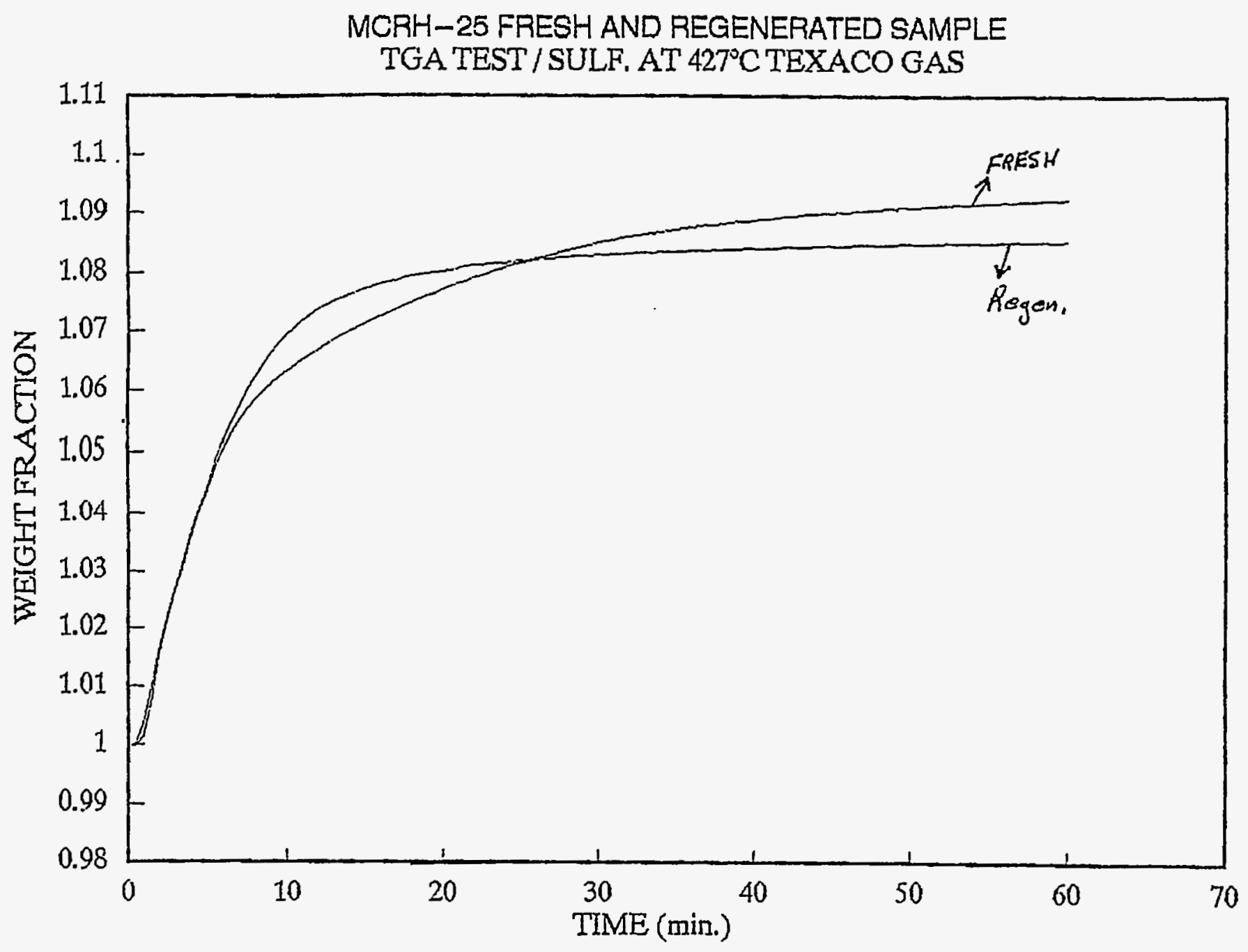

Figure 38. TGA Reactivities of MCRH-25 Sorbents 


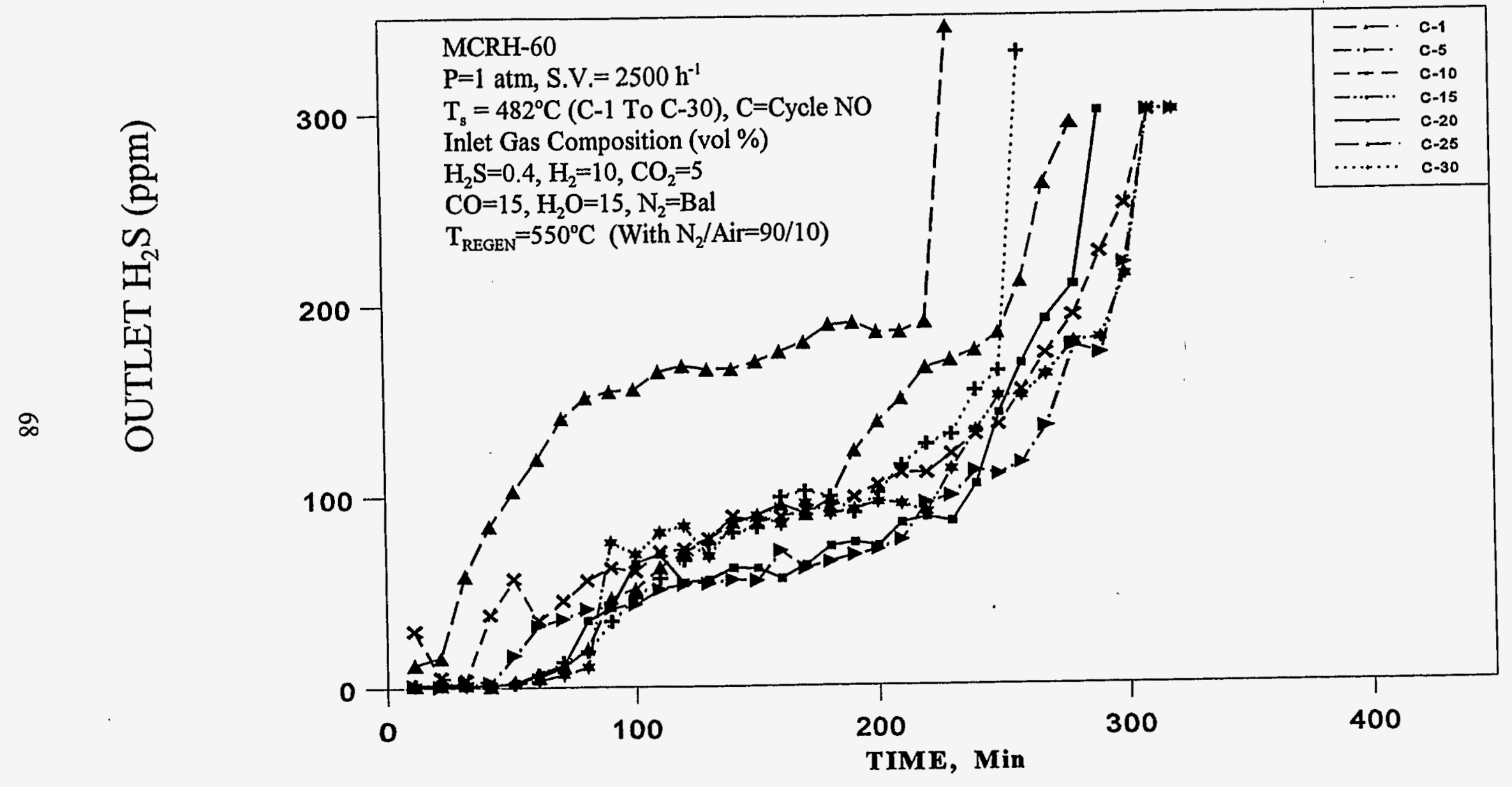

Figure 39. $\mathrm{H}_{2} \mathrm{~S}$ Breakthrough Curves in Successive Sulfidation Cycles of MCRH-60 Sorbent 
$\mathrm{O}_{2}$ in $\mathrm{N}_{2}$ at $550^{\circ} \mathrm{C}$. The gas hourly space velocity for the 30 -cycle test was about $2500 \mathrm{~h}^{-1}$ both in sulfidation and in regeneration. Sulfidation tests were carried out with a sulfidation gas containing (vol $\%$ ): $\mathrm{H}_{2}=10 \%, \mathrm{CO}=15 \%, \mathrm{CO}_{2}=5 \%, \mathrm{H}_{2} \mathrm{~S}=0.4 \%, \mathrm{H}_{2} \mathrm{O}=15 \%$ and bal $\mathrm{N}_{2} . \mathrm{MCRH}-60$ sorbent showed excellent sulfidation behavior. The pre-breakthrough $\mathrm{H}_{2} \mathrm{~S}$ level was less than 100 ppm and the breakthrough conversion was $100 \%$. There was no deactivation in 30 cycles in this fixed bed study.

MCRH-61: A fluidizable zinc oxide-based sorbent was prepared, using the proprietary technique. The sorbent was dried at $120^{\circ} \mathrm{C}$ and then calcined in an oxygen-containing atmosphere at $600^{\circ} \mathrm{C}$ for 2 hours.

Figure 40 shows the breakthrough profiles for MCRH-61. This sorbent was modified to regenerate at temperatures as low as 475 to $525^{\circ} \mathrm{C}$. It was tested for 50 cycles of sulfidation in the laboratory-scale reactor at $482^{\circ} \mathrm{C}$. Regeneration between cycles was conducted with 2 volume percent $\mathrm{O}_{2}$ in $\mathrm{N}_{2}$ at $550^{\circ} \mathrm{C}$. The gas hourly space velocity for the 50 -cycle test was about $2500 \mathrm{~h}^{-1}$ both in sulfidation and in regeneration. Sulfidation tests were carried out with a sulfidation gas containing (vol\%): $\mathrm{H}_{2}=10 \%, \mathrm{CO}=15 \%, \mathrm{CO}_{2}=5 \%, \mathrm{H}_{2} \mathrm{~S}=0.4 \%, \mathrm{H}_{2} \mathrm{O}=15 \%$ and bal $\mathrm{N}_{2}$. MCRH-61 sorbent showed excellent sulfidation behavior. The pre-breakthrough $\mathrm{H}_{2} \mathrm{~S}$ level was less than $100 \mathrm{ppm}$ and the breakthrough conversion was $100 \%$. There was no deactivation in $\mathbf{5 0}$ cycles in this fixed bed study. 


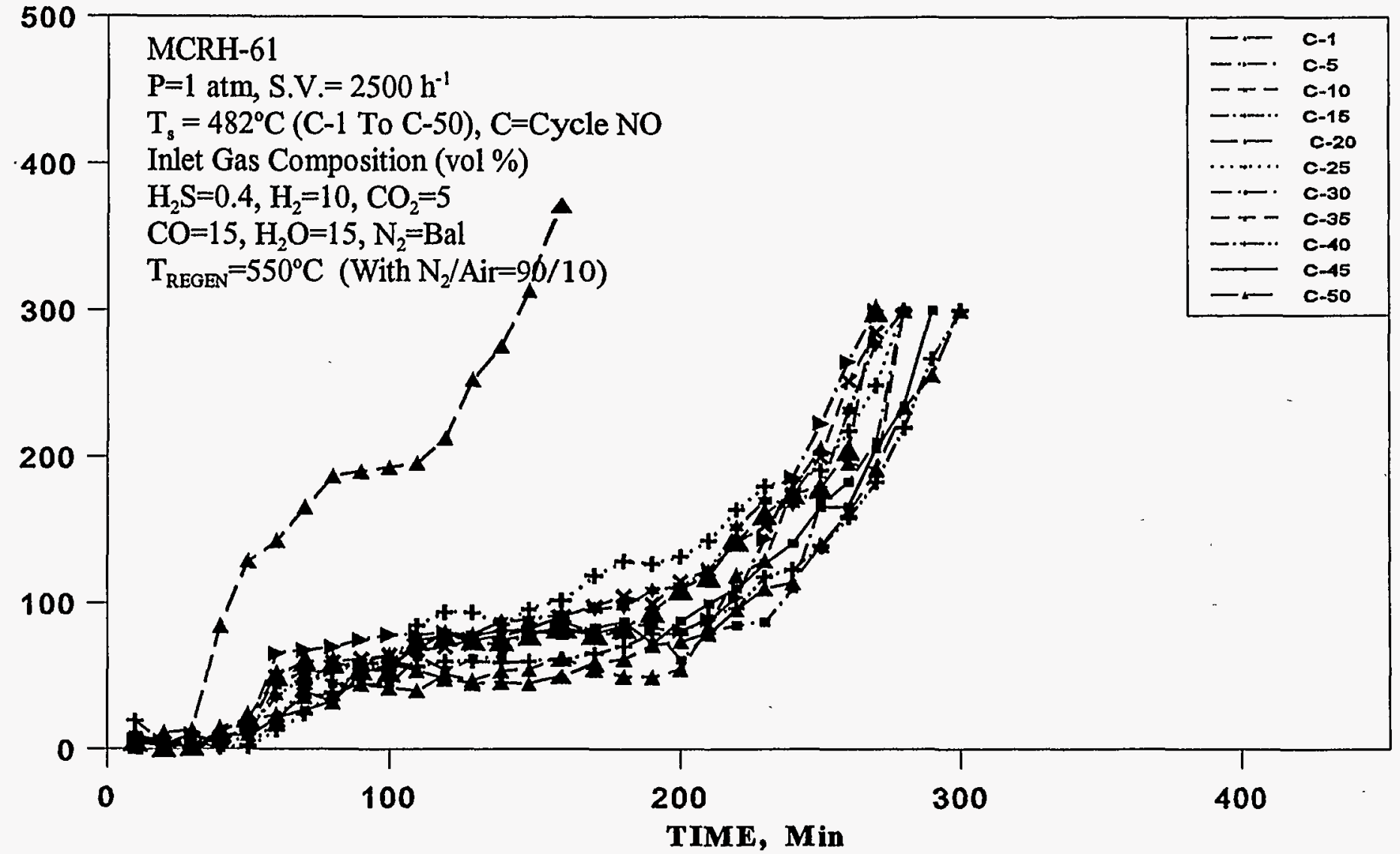

Figure 40. $\mathrm{H}_{2} \mathrm{~S}$ Breakthrough Curves in Successive Sulfidation Cycles of MCRH-61 Sorbent 


\subsection{CONCLUSIONS}

Preparation of mixed metal oxide sorbents with high surface area is crucial for good sorbent performance. The sorbent preparation techniques employed in this project have successfully demonstrated the feasibility of preparing stable sorbents that achieve greater than $99 \% \mathrm{H}_{2} \mathrm{~S}$ removal at temperatures as low as $343^{\circ} \mathrm{C}$ and retain their activity over 50 to 100 cycles.

Doped and undoped zinc-based sorbents were compared in this work in terms of their regeneration light-off temperature. Over all, in this work we have shown that (i) a fixed bed reactor is an excellent tool to quickly evaluate reactivity (ii) effect of selected catalyst additives during regeneration is dramatic (iii) promising catalyst additives can be incorporated in the sorbent to reduce regeneration light-off temperature to $500^{\circ} \mathrm{C}$ or less from the current $>650^{\circ} \mathrm{C}$ (iv) the sulfided sorbent can be lighted-off at a temperature as low as $475^{\circ} \mathrm{C}$.

Fundamental understanding of phenomena leading to chemical deactivation and high regeneration light-off temperature has enabled us to successfully prepare a MCRH-25 sorbent. A 100-cycle test clearly demonstrated that the MCRH-25 sorbent does not chemically deactivate. In fact, the capacity at breakthrough increased between cycles 1 to 25 from 22.5 to $27.7 \mathrm{gS} / 100 \mathrm{~g}$ sorbent and remained stable thereafter. TGA and physical property data confirmed the breakthrough data. This is in contrast to existing leading sorbents that deactivated significantly, as much as $50 \%$ in 50 to 100 cycles. Furthermore, the MCRH-25 sorbent regenerated at temperatures as low as $475^{\circ} \mathrm{C}$, in contrast to current zinc-based sorbents that require $650^{\circ} \mathrm{C}$ or higher.

The problem of physical attrition is being addressed by incorporating binders into the MCRH-25 recipe. This effort to date has led to the preparation of MCRH-61 (70 $\mu \mathrm{m}$ aps) 
sorbent with high attrition resistance suitable for a transport reactor. This sorbent removed $\mathrm{H}_{2} \mathrm{~S}$ to below 20 ppmv and lighted-off nicely at $480^{\circ} \mathrm{C}$ during regeneration. There was no deactivation in 50 cycles in this fixed bed study. This sorbent needs to be scaled up and tested in a bench-scale fluidized-bed reactor. The scale-up of this sorbent and further required modifications to improve its performance is being addressed in another grant (DE-FG22-95MT95011) to Hampton University by DOE. 


\subsection{RECOMMENDATIONS}

Future work should address the following issues:

- Because the complex nature of coal gas cannot be duplicated completely in the laboratory, additional parametric and long term tests on the MCRH-61 sorbent and improved sorbents based there on should be performed at high pressure typical of IGCC and temperatures as low as $343^{\circ} \mathrm{C}$.

- Further studies should be aimed toward determining the effect of trace contaminants such as chloride, alkali, and particulates on the sorbent kinetics and performance

- Testing of MCRH-61 or improved sorbents based there on should be carried out in benchscale fluidized-bed reactors and M.W. Kellogg's transport reactor test unit. Arrangements for this testing is being made in a companion grant (Grant No.DE-FG22-95MT95011) to Hampton University by DOE. 


\subsection{REFERENCES}

Ayala, R.E., A.S. Feitelberg, and A.H. Furman. 1995. "Development of a High-Temperature Moving-Bed Coal Gas Desulfurization System." In Proceedings of 12th Ann. Int. Pittsburgh Coal Conf. p. 1053, September 11-15, Pittsburgh.

Cook, C.S., et al. 1992. "Integrated Operation of a Pressurized Fixed Bed Gasifier and Hot Gas Desulfurization System." In Proceedings of 12 th Annual Gasif. Gas Stream Cleanup Systems Contractor's Review Meeting, Volume 1, DE93000228, p. 84.

Curran, P., et al. 1977. "High Temperature Desulfurization of Low Btu Gas." NTIS No. PB-27108, April.

Flytzani-Stephanopoulos, M., and Jothimurugesan, K., "Preparation of Extrusions of Bulk Mixed Oxide Compounds with High Macroporosity and Mechanical Strength, U. S. Patent, 4,9.77,123, 1990.

Gangwal, S.K, et al. 1988. "Bench-Scale Testing of Novel High-Temperature Desulfurization Sorbents." Report No. DOE/MC/23126-2662 (DE89000935).

Gangwal, S.K., R. Gupta, and W.J. McMichael. 1995. "Hot-Gas Cleanup-Sulfur RecoveryTechnical, Environmental, and Economic Issues," Heat Recovery Systems and CHP. Vol. 15, No. 2, p. 205-214, Elsevier Science Limited.

Gangwal, S.K., J.W. Portzer, R. Gupta, and B.S. Turk. 1996. “Advanced Sulfur Control Processing." In Proceedings of Advanced Coal-Fired Power Systems '96 Review Meeting, Morgantown Energy Technology Center, Morgantown, WV, July.

Grindley, T., and G. Steinfeld, 1981. "Development and Testing of Regenerable Hot Coal-Gas Desulfurization Sorbents." DOE/MC/16545-1125.

Gupta, R., and S.K. Gangwal. 1992. "Enhanced Durability of Desulfurization Sorbents for Fluidized Bed Applications-Development and Testing of Zinc Titanate Sorbents." $\mathrm{DOE} / \mathrm{MC} / 25006-3271$.

Gupta, R., B.S. Turk, and S.K. Gangwal. 1996. "Bench-Scale Development of Fluid-Bed Spray Dried Sorbents." In Proceedings of Advanced Coal-Fired Power Systems '96 Review Meeting, Morgantown Energy Technology Center, Morgantown, WV, July.

Harrison, D.P., F.R. Groves, J.D. White, W. Huang, and A. Lopez-Ortiz. 1996. "Advanced Sulfur Control Processing." In Proceedings of Advanced Coal-Fired Power Systems '96 Review Meeting, Morgantown Energy Technology Center, Morgantown, WV, July.

Heesink, A.B.M., and W.P.M. van Swaaij. 1996. "The Desulfurization of Simulated Coal Gas 
with Calcareous Sorbents in a Small Bubbling Fluidized-Bed Reactor." Presented at the 3rd International Symposium on Gas Clearling at High Temperature, University of Karlsruhi, Germany, September.

Jothimurugesan, $\mathrm{K}$. and Harrison, D. P., "reaction Between $\mathrm{H}_{2} \mathrm{~S}$ and Zinc Oxide -Titanium Oxide Sorbents. 2. Single-Pellet Sulfidation Modeling."Ind.Eng.Chem.Res, 29, 1167(1990).

Khare, G.P., G.A. Delzer, G.J. Greenwood, and D.H. Kubicek. 1996. "Phillips Sorbent Development for Tampa Electric and Sierra Pacific." In Proceedings of Advanced CoalFired Power Systems '96 Review Meeting, Morgantown Energy Technology Center, Morgantown, WV, July.

Michel, M., H. Shirai, and K.K. Schwedtfeger. 1996. "Hot Desulfurization of Coal Gas with Lime Based Absorbers Investigation with Single Pellets and with a Laboratory Fixed-Bed Reactor." Presented at the 3rd International Symposium on Gas Cleaning at High Temperature. University of Karlsruhe, Germany, September.

NOVEM. 1991. "System Study High Temperature Gas Cleaning at IGCC Systems." Netherlands Agency for Energy and the Environment.

Portzer, J.W., S.K. Gangwal, and B.S. Turk. 1996. "Durability Testing of the Direct Sulfur Recovery Process." In Proceedings of Advanced Coal-Fired Power Systems '96 Review Meeting, Morgantown Energy Technology Center, Morgantown, WV, July.

Woods, M. C., Gangwal., S. K. Harrison, D. P. and Jothimurugesan, K." "Kinetics of the Reactions of a Zinc Ferrite Sorbent in High-Temperature Coal Gas Desulfurization" Ind.Eng.Chem.Res., 30, 100(1991).

Woods, M. C. Gangwal, S. K., Jothimurugesan, K. and Harrison, D. P. "Reaction Between $\mathrm{H}_{2} \mathrm{~S}$ and Zinc Oxide-Titanium Oxide sorbents. 1. Single-Pellet Kinetic Studies" Ind.Eng.Chem.Res 29, 1160(1990). 